Florida International University FIU Digital Commons

\title{
The perceptions of best mentoring practices in an early literacy intervention project : a case study of nine coaches
}

Magdalena Castañeda

Florida International University

DOI: $10.25148 /$ etd.FI14060103

Follow this and additional works at: https://digitalcommons.fiu.edu/etd

Part of the Educational Administration and Supervision Commons

\section{Recommended Citation}

Castañeda, Magdalena, "The perceptions of best mentoring practices in an early literacy intervention project : a case study of nine coaches" (2007). FIU Electronic Theses and Dissertations. 2071.

https://digitalcommons.fiu.edu/etd/2071 
Miami, Florida

THE PERCEPTIONS OF BEST MENTORING PRACTICES IN AN EARLY

LITERACY INTERVENTION PROJECT: A CASE STUDY OF NINE COACHES

A dissertation submitted in partial fulfillment of the

requirements for the degree of

DOCTOR OF EDUCATION

in

EDUCATIONAL ADMINISTRATION AND SUPERVISION

by

Magdalena Castañeda

2007 
To: Dean Luis Mirón

College of Education

This dissertation, written by Magdalena Castañeda, and entitled The Perceptions of Best Mentoring Practices in an Early Literacy Intervention Project: A Case Study of Nine Coaches, having been approved in respect to style and intellectual content, is referred to you for judgment.

We have read this dissertation and recommend that it be approved.

Charles Bleiker

Delia Garcia

Anthony Normore

Gaetane Jean-Marie, Major Professor

Date of Defense: July 20, 2007

The dissertation of Magdalena Castañeda is approved.

Dean Luis Mirón

College of Education

Dean George Walker University Graduate School

Florida International University, 2007 
(C) Copyright 2007 by Magdalena Castañeda

All rights reserved. 


\section{DEDICATION}

I dedicate this dissertation to my sister Maggie, who I unexpectedly lost during this journey. Maggie gave me the emotional and spiritual support to persevere in attaining my goals. She made it possible for me, as a single mom, to further my education. I know she continues to help me from heaven above. I will always be grateful for the gift of having her as a sister for 34 years. 


\section{ACKNOWLEDGMENTS}

First, I want to express my appreciation to the participants of my study, the LIX literacy coaches. I am indebted to them for giving me their time and honest feedback. I learned so much from them and their experience.

I wish to express my sincere gratitude to the members of my committee, Dr. Charles Bleiker, Dr. Anthony Normore, and Dr. Delia Garcia for their strong support. My heartfelt appreciation goes to my major professor, Dr. Gaetane Jean-Marie, whose unwavering commitment and guidance provided me with the support I needed to get this done. I believe things happen for a reason, her short time at F.I.U. was no coincidence. I would also like to thank Dr. Sally Pell, who encouraged me to begin this journey, years ago.

I am especially grateful to my colleagues at the University of Florida and the Early Childhood Initiative Foundation, especially Dr. Don Pemberton, Dr. Alyson Adams, Mr. David Lawrence, Jr., and Mrs. Ana Sejeck. May the Lord bless them for their assistance, patience, and support, without them this would not be possible.

I have to thank my family, my parents, my siblings, and especially, my son Eric Daniel. Their love and support have made me who I am. Most of all they have reminded me to have faith that in God all things are possible. I must also thank my nieces and nephews and all in their generation of my extended family, especially my cousins Albert and Laura, may this endeavor inspire you to fulfill your dreams. I hope that that I have demonstrated the many doors that education can open for you. 
Finally, I thank all my friends that have loved me and have shared in all my struggles and accomplishments. I especially have to thank, my dear friend and fellow educator, Mia DiRocco, she has given me the strength and belief in myself to persevere. 
ABSTRACT OF THE DISSERTATION

THE PERCEPTIONS OF BEST MENTORING PRACTICES IN AN EARLY

LITERACY INTERVENTION PROJECT: A CASE STUDY OF NINE COACHES

by

Magdalena Castañeda

Florida International University, 2007

Miami, Florida

Professor Gaetane Jean-Marie, Major Professor

There is significant national evidence the language development of four year-olds is a critical area for later school success (Brooks-Gunn, Fuligni, \& Berlin, 2003;

Cunningham, \& Stanovich, 1998). This study originated as part of Literacy Intervention X (LIX), a larger national study conducted to examine the effectiveness of early literacy curricula implemented in subsidized childcare centers. The professional development of childcare center providers is key to improving the quality of subsidized care. In exploring the mentoring practices of nine LIX literacy coaches, the researcher investigated the perceptions of what best mentoring practices facilitated the implementation of literacy curricula by childcare providers. A qualitative case study was conducted using a combination of participant observer notes, document analysis, and focus group semi-structured interviews. The researcher is a participant observer, one of the nine Literacy Coaches.

The best mentoring practices from the perspective of the literacy coaches are related to building relationships including trust, mutual respect, support, empathy, and encouragement with the childcare providers, the center directors, and with fellow literacy 
coaches. Clear, constant, and consistent communication with the childcare providers was a vital mentoring practice in building a relationship between the literacy coach and childcare provider. Another best mentoring practice in building a relationship with the childcare provider was the perceptions of the literacy coaches as co-learners in the mentoring process.

The best mentoring practices highlighted in this study exemplified the kind of effective professional development that builds on the strengths of the childcare providers and does not disrupt the childcare centers or the services provided by the subsidized childcare programs that meet the needs of children and families. The experience of these nine literacy coaches, including their perceptions of effective mentoring practices, along with lesson learned about relationships, mentoring team structures, and general project design sheds light on the challenge of mentoring subsidized childcare providers in future literacy intervention projects. 


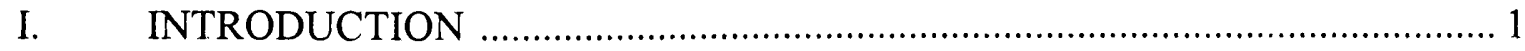

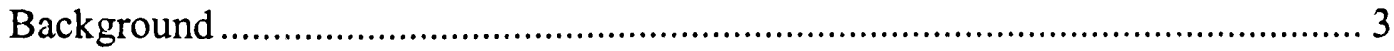

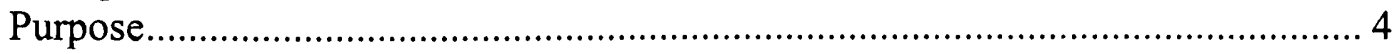

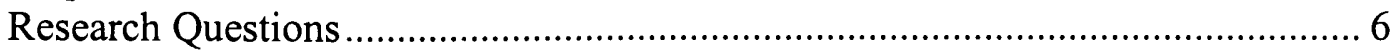

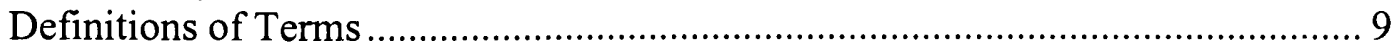

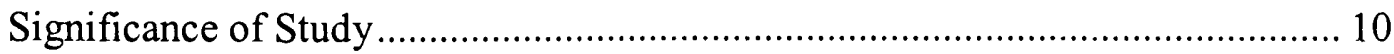

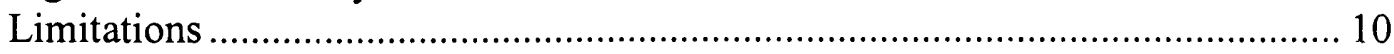

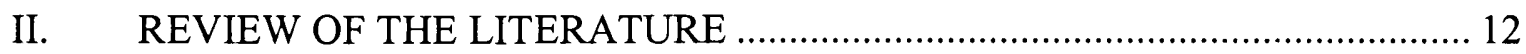

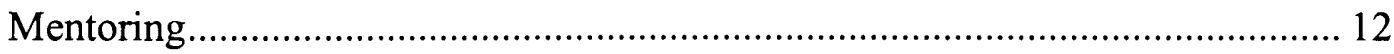

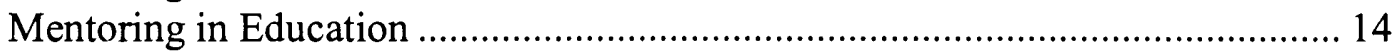

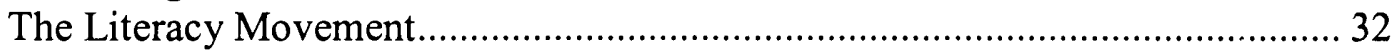

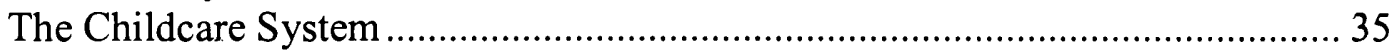

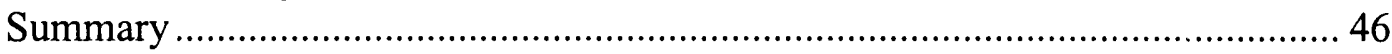

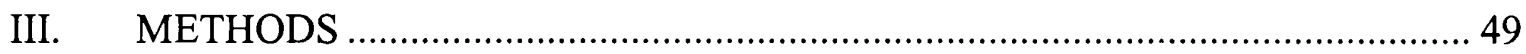

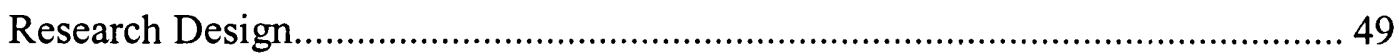

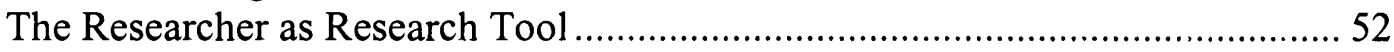

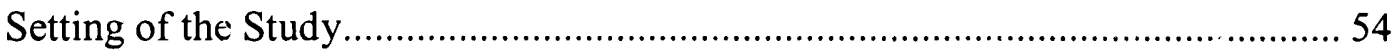

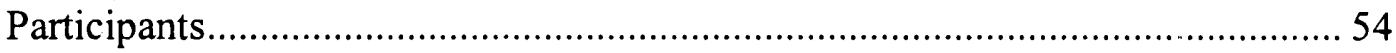

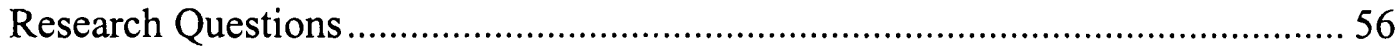

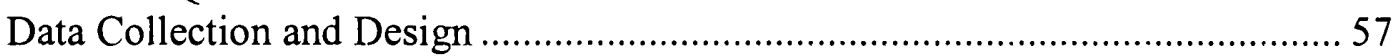

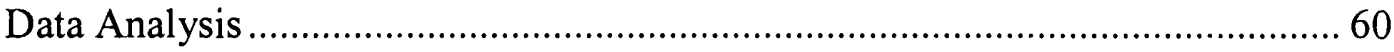

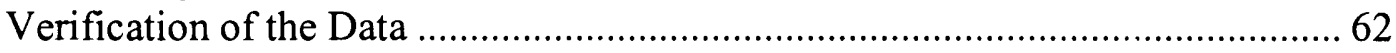

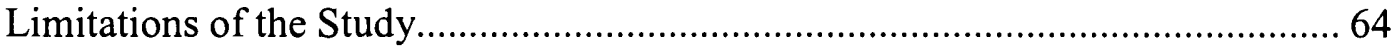

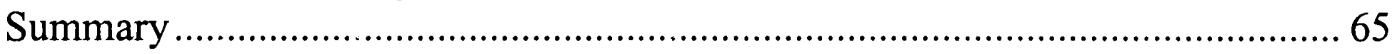

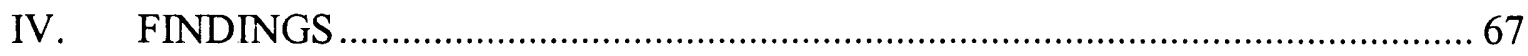

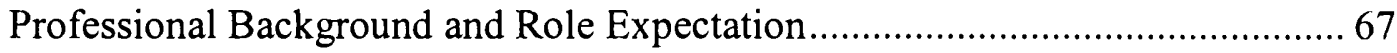

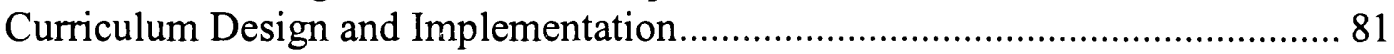

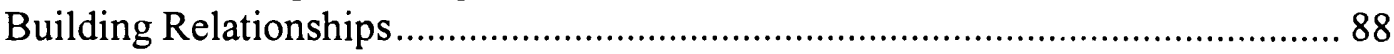

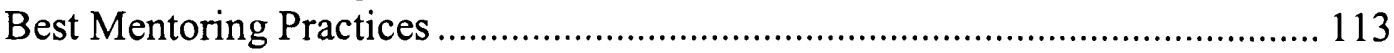

V. DISCUSSION, CONCLUSION AND IMPLICATIONS .............................. 122

Responses to Subsidiary Research Questions.................................................. 123

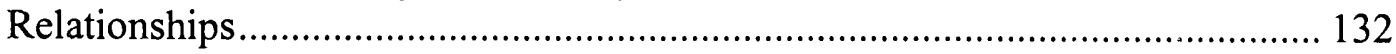

Response to Primary Research Question ..................................................... 136

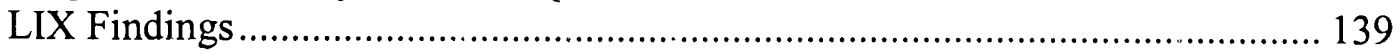

The Childcare Centers Post-LIX ................................................................... 139

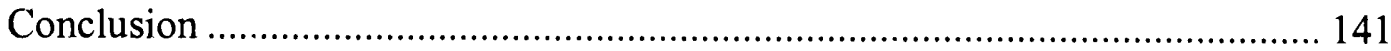

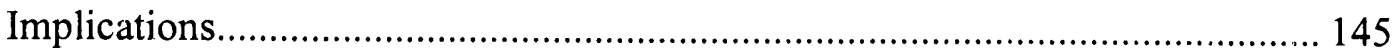


Recommendations for Future Study ............................................................. 147

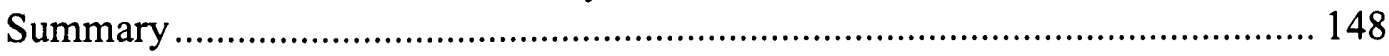

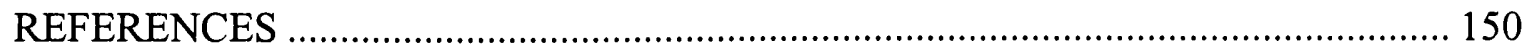

APPENDIX

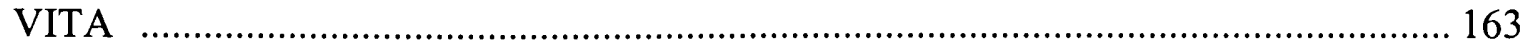




\section{LIST OF TABLES}

TABLE

PAGE

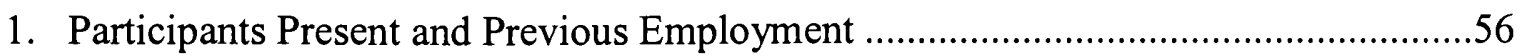

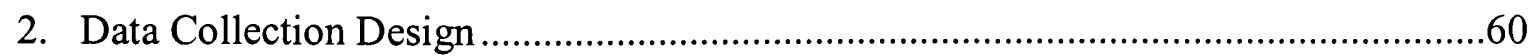

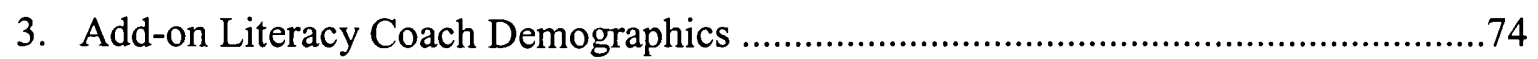

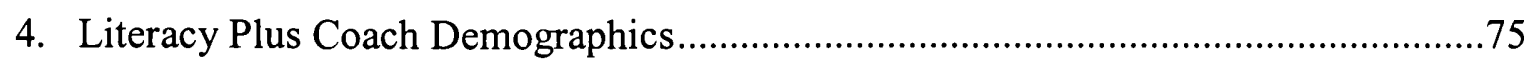

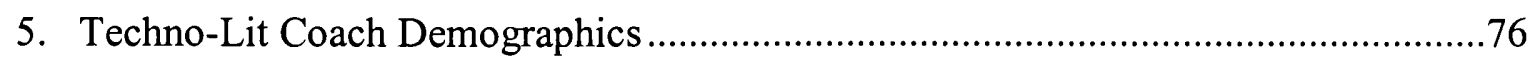

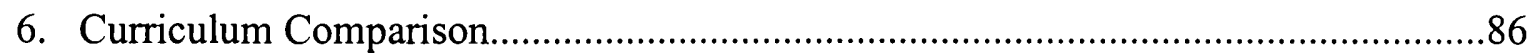




\section{CHAPTER I \\ INTRODUCTION}

Many childcare providers today have a tremendous amount of experience and considerable expertise in caring for children but little knowledge of how to formally teach them. They have not had the benefit of formal university training in child development education. As the push from systems of care moves to systems of education, childcare providers will need to improve their teaching skills or risk losing their jobs. Furthermore, the childcare system needs to raise its standards in early childhood curriculum and improve the development of professional knowledge of childcare providers.

Recently, significant national evidence from major research projects involving assessments of 4-year-olds reports language development is critical for later school success (Brooks-Gunn, Fuligni, \& Berlin, 2003; Cunningham \& Stanovich, 1998). One such project was Literacy Intervention X (LIX), a federally funded project that introduced three high quality language and literacy curricula for 4-year-old children in subsidized care. The LIX study assigned nine literacy coaches to three teams to mentor childcare center providers to implement one of three literacy curricula. I was one of the nine LIX literacy coaches and the researcher in this study. Unlike their counterparts (prekindergarten teachers in the public school system using similar curricula), none of the childcare center providers in Literacy Intervention X had earned a college degree in the area of education.

As a literacy coach and a degreed public school teacher, I suffered from culture shock when I first visited a childcare center. I was amazed at the long work hours and 
the work the childcare provider was required to do in addition to teaching 4-year-olds without an adequate level of educational preparation in early childhood development, pedagogy and literacy training. From what I witnessed and discussions held in the LIX project meetings with my fellow literacy coaches, I began to appreciate the importance of the literacy coaches' mentoring practices in facilitating the introduction of quality early literacy to non-degreed teachers in subsidized care. It occurred to me the mentoring process was an essential ingredient to the success of the program. The LIX study measured student achievement in literacy skills and focused on differences in the curricula as the variable, not differences in mentoring practices. This was an ignored, yet crucial variable in the larger study. Therefore, understanding the complexity and effectiveness of the mentoring practices is essential in transforming many of the existing early childhood settings from custodial to educational. One approach, the focus of this study was to examine how mentoring facilitated the professional development of childcare providers.

Mentoring has become the selected preparation and training for childcare providers in the county where LIX takes place. Like the literacy coaches in LIX, mentors from other childcare intervention projects are only trained in the curriculum implemented in the childcare centers. They do not undergo any type of training specific to the mentoring itself. Furthermore, the mentors do not have teaching experience, teacher certification, or a degree specifically in education from a United States institution (e.g., a U.S. university bachelor's degree in Education). In order to ensure the success of mentoring in future intervention projects, a closer look at the LIX Coaches' best mentoring practices and how these practices emerged requires further investigation. 


\section{Background}

The system of subsidized childcare serving children from the lowest

socioeconomic families is the least funded of all government programs (General Accounting Office, Health, Education and Human Services Division [GAOHSD], 1998; Lyter, Sills, \& Oh, 2002). These families depend on public assistance and face a variety of obstacles in changing the condition of their lives apart from the lack of education (Behrman, 2002; Fuller, Kagan, \& Loeb, 2002; Lyter et al., 2002). Due to these barriers in many instances, subsidized childcare centers may be the sole source for a foundation in early literacy skills children from these families receive.

Improvement in the quality of early childhood care is related to the development of literacy skills essential for school readiness (Brooks-Gunn, Fuligni, \& Berlin, 2003; Cunningham \& Stanovich, 1998). Legislators address measures of skills believed to be critical in improving quality in childcare. One of these measures is professional development that leads to more stringent credentials for childcare providers (BrooksGunn et al., 2003; DeBord \& Boling, 2002; Hyun, 2003). Currently, in order to work as a childcare provider, one has to obtain a Child Development Associate (CDA) certificate. The duration of the certificate program amounts to 40 hours of childcare training. This is a stark difference from the bachelor's degree required of a pre-kindergarten public school teacher with similar responsibilities.

In the world of childcare, the site of this investigation, childcare providers are being paid little more than minimum wage with few benefits (Behrman, 2002; Gable \& Halliburton, 2003; Walker, 2002). Owners and directors are reluctant to invest time and money on professional development to improve a workforce often seen as transient and 
unreliable (Behrman; Gable \& Halliburton; Todd \& Deery-Schmitt, 1996; Walker). In addition, childcare providers have little incentive to remain at a center or invest their unpaid time in improving their skills (Behrman; Gable \& Halliburton; Todd \& DeerySchmitt; Walker). The childcare system is not designed to reward teachers for higher skills or level of education. If childcare providers become too educated, they can price themselves out of the market. Childcare providers who do pursue degrees can leave the childcare system for more lucrative public education system. Directors and agencies understand this and may believe supporting professional development actually encourages their investments, their best childcare providers, to leave.

What develops is an uneasy stalemate between childcare providers and owners/directors. Owners may give small raises or send their staff to workshops or trainings not associated with any degrees. Childcare providers who stay, often feel exploited by their centers, trapped in a job both physically (i.e., responsible for cleaning the center, feeding the children and teaching) and psychologically taxing (Walker, 2002). Without the proper training to cope with a difficult job and a living wage to support themselves and their families, many leave for less demanding or better paying positions in a service industry that operates in competition with childcare for low skilled workers.

\section{Purpose}

This study focused on the mentoring practices of the nine Literacy Intervention X coaches. The nature of mentoring by the literacy coaches in delivering the curricula to non-degreed childcare providers was not examined by the larger LIX study. In exploring the mentoring practices of the nine LIX literacy coaches, as the researcher, I investigated 
their perceptions of what best mentoring practices facilitated the implementation of literacy curricula by childcare providers.

The study follows the attempts of nine literacy coaches to mentor 108 low-skilled childcare providers as they implemented an early literacy curriculum during the 2-year LIX study. It originated as part of LIX, a larger national study of the effectiveness of early literacy curricula implemented in pre-kindergarten. The literacy coaches were hired specifically because they had experience either as classroom teachers or technical assistants who monitored subsidized childcare centers.

As one of the nine literacy coaches in LIX, I realized the mentoring relationships in the curriculum interventions were essential to the successful study of these curricula. If the literacy coaches could not encourage the childcare providers to implement the materials as the curriculum developers intended, the three curricula could not be implemented effectively. That childcare providers would be able and willing to learn to use the materials was a huge assumption given their relative lack of education and training. Childcare providers working in subsidized care in the LIX community typically have less than an Associate in Arts (A.A.) degree (Barnett, 2003).

There was no detailed mentoring model to use as a guide; therefore, each curriculum team's coordinator guided the mentoring practice. Not only were differences apparent in mentoring practices among curriculum teams but within each team as well. In our discussions at the LIX project meetings, my fellow literacy coaches and I shared our experiences. Although we confronted the same obstacles, how we dealt with those issues sometimes differed. Realizing these differences in the mentoring practices existed 
sparked my interest for further investigation. Investigating the differences in mentoring practices led to highlighting the best of those mentoring practices.

The study considers the literacy coach participants' perceptions as an assessment

of the effectiveness of the mentoring practices. According to Bandura (1986), people are not objective in defined contexts; contrarily, they label and interpret situations based on perceptions. Perception allows humans to construct their feelings, understanding, and experience based on their unique insight to form distinctive and individual knowledge, a fundamental condition of human behavior and learning (Bandura, 1986). In short, as the literacy coaches were learning how to mentor and developing mentoring practices, they labeled and interpreted situations based on their perceptions. This study examined the perceptions of the nine LIX literacy coaches concerning the caliber of the mentoring practices.

\section{Research Questions}

The study sought to identify the best mentoring practices in LIX from the perspectives of nine literacy coaches. It was designed to especially elicit their perspectives concerning those mentoring practices in which their particular curriculum team engaged and perceived as successful.

\section{Primary Research Question}

What are the mentoring practices used by literacy coaches to prepare subsidized childcare providers to implement curriculum in Literacy Intervention $\mathrm{X}$ ?

\section{Subsidiary Questions}

1. What preparation and training impact the mentoring practices of the literacy coaches? 
2. What mentoring practices do the literacy coaches perceive as producing the best results in preparing subsidized childcare providers to implement literacy curriculum?

3. Do differences in the three curricula influence the mentoring practices provided by the literacy coaches?

A qualitative case study was conducted that used a combination of field notes, small focus groups, and a large focus group follow-up session. The case is the group of nine Literacy Intervention X coaches. The researcher was a participant-observer, one of the nine literacy coaches, specifically the certified teacher (i.e., CT Coach) in the Add-on Literacy Team. A case study is a type of qualitative study that denotes a "bounded system...bounded by time and place" (Creswell, 1998, p. 61). In this study, it was bounded by a time frame, the 2-year LIX project, and a place, 108 subsidized childcare centers in a large urban community in a southeastern state. The metropolitan area in the southeastern state in which the project was situated has a large minority population known for its diverse culture and ethnicities (i.e., 58\% Hispanic, 21\% non-Hispanic White, $21 \%$ African American, with more than half of its residents born in another country). This county has a significantly higher number of under-skilled, undereducated, and impoverished residents compared to the national average.

There are three separate curricula implemented in LIX. All three curricula, although structured by the same basic literacy components, differ in their use of technology and the amount of time in the school day dedicated to implementing them. Each curriculum team has a certified teacher subcontracted from the local public school system for LIX, a technical assistant subcontracted from a social service agency, and a coordinator coach. Each of the teachers and technical assistants was randomly selected 
and assigned to one of the three curricula. The coordinator coaches were selected and hired by each of the curriculum developers. It is important to note all of the literacy coaches in this case study were participants. The participants were the nine female LIX Coaches, all between 30 and 52 years of age.

Seven focus groups with the three mentor teams were the principal way of collecting data. Each literacy mentor team was interviewed in the small focus groups two times (i.e., two rounds), a total of 6 small focus groups. Each of the first two rounds of focus group sessions was conducted with each individual curriculum team separately (i.e., small group), one while the implementation was occurring and the other when the project had just ended. The final focus group was a follow-up session that brought all three literacy curriculum teams (i.e., large group) together almost a year after the completion of the implementation phase of the project. This approach was chosen to build upon and explore my experience as a literacy coach with the rest of the participants' experience as literacy coaches in the context of LIX.

As a participant-observer, I was part of the case. As a benefit of the participantobserver format, I could analyze what the other literacy coaches shared with me in the context of my own "insider" experience. However, I remained aware that while a participant-observer becomes immersed in the setting, its people, and the research questions, I must be able to suspend personal judgment and concerns in attempts to understand issues from the other participants' perspectives (Glesne \& Peshkin, 1992). The other LIX literacy coaches and I worked with the same population distribution, had similar educational backgrounds, and operated within the same curriculum team framework. As a researcher, throughout the study, my relationship with the other literacy 
coaches was that of a learner. During project meetings, personal conversations, and formal focus group sessions, I learned from them about their experiences and insights.

Definitions of Terms

\section{Mentoring}

The establishment of a personal relationship for the purpose of professional instruction and guidance (Patton et al., 2005), in an authentic teaching situation, where knowledge of teaching is situated in the activity of teaching and grows out of practices in "real-life" situations (Grove, et al. 2004, p.87).

\section{Mentoring Practices}

The exchange of ideas through modeling, observation, dialogue, and experience that foster professional growth, not only for the protégé, but also for the mentor (Fairbanks, Freedman, \& Kahn, 2000, p. 109).

\section{Literacy Curricula}

Three different types of curricula (e.g., Add-on Literacy, Literacy Plus, and Techno-Lit) implemented in the LIX childcare centers.

\section{Add-on Literacy}

A literacy curriculum used as a supplement to the full day pre-kindergarten curriculum developed by three university professors.

\section{Literacy Plus}

A full day pre-kindergarten literacy curriculum that includes math, science, dance, cooking gross motor development and fine motor development activities developed by an entrepreneur couple. 


\section{Techno-Lit}

A full day pre-kindergarten literacy curriculum that includes math, science, and other subject areas developed by a large toy corporation.

\section{Significance of Study}

As the need for the improvement of knowledge and skills of early childhood educators increases, increased efforts are necessary to explore the retention and development of childcare center providers in subsidized care systems (Hyun, 2003; Todd \& Deery-Schmitt, 1996: Walker, 2002). The professional development of childcare center providers is key to raising the quality of subsidized care. Therefore, the need to attain a deeper level of understanding of early literacy mentoring in literacy intervention projects is a critical step toward improving the quality of early childhood education.

\section{Limitations}

As do all research designs, case study research has limitations. Researchers are so immersed in anecdotes and stories they may unconsciously adopt the participants' perspectives (Denzin \& Lincoln, 2003). This is why field notes written as a participant before focus group sessions were necessary. This made me aware of my own perspective before listening to my fellow literacy coaches.

Another limitation considered in this study focused on mentoring in an Early Literacy Intervention Project in one southeastern state with a unique mix of cultures. Although these groups can be similar to other cities in the United States, they do not necessarily reflect similar conditions, situations, cultural elements or issues involved in a mentor/ childcare center provider relationship. It is important to bear in mind the purpose of qualitative research is to obtain descriptions of the real world and to obtain 
interpretations of meaning, not to provide general opinion (Kvale, 1996). Although the purpose of qualitative research is not to generalize research findings, what is learned from one context may be useful in other settings and conditions with similar populations (Charles, 1995). Since many literacy intervention projects that involve mentoring have surged in the LIX setting it is important to identify the best mentoring practices in this literacy intervention project. 


\section{CHAPTER II}

\section{REVIEW OF THE LITERATURE}

The aim of this literature review is to examine the best mentoring practices in education and through that lens, search for their possible relevance to literacy intervention projects in subsidized childcare. The first section provides an overview of mentoring in general and then specifically in education. In discussing mentoring in education, the following areas are addressed: teacher preparation programs, professional development, mentoring practices, the mentoring relationship, social learning theories, benefits of mentoring, and successful mentoring models. The next section describes the literacy movement in the United States: the crises that initiated it, the government's response, and the importance of early literacy intervention programs. The chapter concludes with a discussion of the childcare system: its history of challenges, subsidized childcare funding, childcare and professional development, and mentoring childcare providers.

\section{Mentoring}

Mentoring has many interpretations and these interpretations have changed over the years. It has become such a global phenomenon in a number of social spheres that it needs careful scrutiny (Cullingford, 2006, p. xiii). Recently, the concept of mentoring has been highly charged because it has become systematic and imposed rather than an informal and individualized practice (Cullingford; Fairbanks et al., 2000). There are disparate uses of mentoring and certain components are important in the mentoring process which may differ from one setting to another (Conyers, 2004; Cullingford; Goldstein, 2004; Randi, 2004). In general, mentoring is viewed as a hierarchical 
relationship between a mentor and the protégé, where the mentor is viewed as "allknowing" and the protégé as a subordinate (Danielson, 2002). Historically, the practice of mentoring has been referred to as an apprenticeship, tutoring, and guided practice (Glazer \& Hannafin, 2006; Harrison, Dymoke \& Pell, 2006). A broad definition of mentoring is the establishment of a personal relationship for the purpose of professional instruction and guidance (Patton, Pagnano, Griffin, Dodds, Sheehy, Arnold, Henninger, Gallo, James, 2005). Furthermore, mentoring is linked to developmental activity in the workplace as a whole and generally acknowledges the psychosocial aspects (i.e., interacting with parents, students, and colleagues) as well as job-specific aspects such as planning lessons (Kram, 1983). Mentoring also includes components of counseling, friendship, and socialization (Bush, Coleman, Wall, \& West-Burnham, 1996).

Bova and Phillips (1981) conducted a study on mentors and protégés in both business and academia where they developed a list of characteristics inherent to any mentor-protégé relationship:

1. Mentor-protégé relationships grow out of voluntary interaction.

2. The mentor protégé relationship has a life cycle; introduction; trust building; teaching of risk-taking, communicating, and professional skills; transfer of professional standards; and dissolution.

3. People become mentors to pass down information to the next generation.

4. Mentors encourage protégés in setting and attaining short-and long-term goals.

5. Mentors guide technically and professionally. Mentors teach protégés skills necessary to survive daily experiences and promote career scope professional development.

6. Mentors protect protégés from major mistakes by limiting their exposure to responsibility.

7. Mentors provide opportunities for protégés to observe and participate in their work.

8. Mentors are role models.

9. Mentors sponsor protégés organizationally and professionally.

10. Mentor-protégé relationships end, amiably or bitterly (p. 4). 
Bova and Phillips' (1981) characteristics suggest both the protégé and the mentor are not forced into the relationship; they are both voluntarily involved in the mentoring process. Others agree with Bova and Phillips that the relationship that develops between the mentor and the protégé is an on-going process and takes time to develop (Fairbanks et al., 2000; Maynard \& Furlong, 1993; McIntyre \& Hagger, 1993, Vinz, 1996). Bova and Phillips also assert that the main reason people become mentors is to transfer their knowledge to a less experienced individual (i.e., the protégé). They describe the mentor as not only guiding the protégés in skills needed for their jobs but also in general professional development. They also believe mentors slowly increase the job responsibility of the protégés to protect them from making major mistakes; in doing so, they model the work while being observed by the protégés. Bova and Phillips point out the importance of the context of the organization and of the mentor as a role model sponsoring the protégé within that organization. Fairbanks et al. (2000) agree that mentoring consists of complex social interactions that mentor and protégés construct and negotiate for a variety of professional purposes in response to the contextual factors they encounter. Thus, according to Bova and Phillips, these characteristics are inherent to the mentoring relationship regardless of the type of organization in which it is implemented. Mentoring relationships, specifically in education, shape new teachers' professional practice in important ways (Hawkey, 1998).

\section{Mentoring in Education}

Many experts in the educational field have defined mentoring. One group described mentoring as "a relationship in which a person of greater rank or expertise teaches, guides, and develops a novice" (Alleman, Cochran, Doverspike, \& Newman, 
1984, p.329). The functions of mentoring include being a teacher, confidant, sponsor, “opener of doors," role model, developer of talent, protector, consultant, advisor, and successful leader (Alleman et al.; Schmidt \& Wolfe, 1980).

Further, mentoring includes a list of overlapping skills such as guiding, leading, advising, supporting, enabling, educating, organizing, managing, and counseling (Elliot \& Calderhead, 1995; Harrison et al., 2006; Hawkey, 1998; McIntyre \& Hagger,1993). These skills suggest that mentoring in education depicts a myriad of skills that at times relate to one another and exceeds the task limited to being a role model or sponsor. According to Hobson and Sharp (2005) and to Wang (2001), the mentoring experienced by participants in one field can be related to those of another field, since the strategies employed may differ based on context. Even within the field of education, the context and purpose of the mentoring relationship impacts the interaction of the mentor and the protégé (Harrison et al.; Hobson \& Sharp; Orland-Barak, 2002; Wang).

\section{Teacher Preparation Programs}

In the past 20 years, mentoring has become very popular in the field of teacher education. Traditional approaches to teacher education have come under attack from school districts, state legislatures, and even graduates of teacher education programs (Fullan, Galuzzo, Morris, \& Watson, 1998). Traditional teacher preparation programs tend to focus only on educational theories and pedagogical practices rather than guidance for transitioning into a professional career in a school environment (Daloz, 1986; McElroy, 2005; McIntyre \& Hagger, 1993; Vinz, 1996). Part of the criticism of traditional curricula is that they are not embedded in actual practice (Fullan et al., 1998; Holmes Group Consortium, 1986). 
The more recent interest in mentoring is related to the rapid social development that has created an increased demand for more professionalized staff in education (Cullingford, 2006; Scheetz, Waters, Smeaton, \& Lare, 2005). Despite the demands of society, there are few courses in academic institutions that concern social competence, individual maturity, ability to develop effective working relationships (for example with colleagues, students, and their parents), and professional development (Cullingford, p.153). Some argue that teacher education programs are too disconnected from actual classroom practice (Clark, 2001).

As more and more states offer alternative paths to licensure, the relevance of teacher education programs comes into question. One response in the 1990s was to create Professional Development Schools (PDS) that had a direct relationship to a college faculty. PDS had not had the success that was anticipated by its proponents at the end of the last century, but demonstrated the need for alternative approaches to teacher preparation (Mayes, 1998). According to Fairbanks et al. (2000), effective mentoring may help construct a bridge for pre-service and novice educators between their need to acclimate into their professional settings and effectively teach their content area (p. 206).

\section{Professional Development for Novices}

First-year teachers realize teaching goes way beyond spending time with children and sharing knowledge of subject matter. It means managing, communicating, understanding student behavior, keeping records, planning ahead, juggling priorities, and expressing a positive attitude all day long, regardless of the situation (Andrews \& Quinn, 2005; Brennan, Thames, \& Roberts, 1999; Harrison, Lawson \& Wortley, 2005; Keller, 2006; Scheetz et al., 2005). Tight teaching schedules allow little time for beginning 
teachers to meet and confer with other teachers, which may prohibit first year teachers from gaining support and knowledge from their colleagues. Lack of support is one reason why $30 \%$ of beginning teachers leave the teaching profession within the first 5 years (Brighton, 1999; Darling-Hammond, 1996; Montgomery, 1999).

More efforts are needed to keep highly qualified teachers from leaving the profession. In addition to the isolation or lack of support beginning teachers face, there is also pressure from many different sources (e.g., state departments of education, school districts, and school administrators) to raise test scores. This collides with the idealistic preconceptions of teaching novice teachers bring with them from their teacher education programs (Brennan et al., 1999; Harrison et al., 2005; Keller, 2006).

The literature on mentoring in the field of education is mostly on pre-service and beginning teachers (Chase, Germundsen, Brownstein, \& Distad, 2001; Fairbanks, et al., 2000; Giebelhaus \& Bowman, 2002; Glazer \& Hannafin, 2006; Grove, Strudler, \& O'dell, 2004; Harrison et al., 2006; McElroy, 2005; Wang, 2001). It takes 3 to 5 years for most beginning teachers to become effective; therefore, if almost a third of beginning teachers leave within the first 5 years, more efforts are needed to retain novice teachers in order to maintain a strong teaching force (Feiman-Nemser, 2001). In recent decades, mentoring increasingly has been used in training new teachers in school-based practice (Hobson \& Sharp, 2005; Tomlinson, 1995). Mentoring programs for teachers, especially beginning teachers, have been successful in improving the quality of their teaching and in decreasing the number of teachers who leave during those first 5 years (Andrews \& Quinn, 2005; Harrison et al., 2005; Keller, 2006; Scheetz et al., 2005). Despite the increased use of mentoring in the preparation and development of beginning teacher 
training and the success of some mentoring programs in certain areas, there is limited evidence about its effectiveness (Harrison et al., 2006).

\section{Mentoring Practices}

One aspect of mentoring that mentors use with beginning teachers is that of an apprenticeship model; it is a master-of-a-trade with particular skills to be passed on to the novice (Cullingford, 2006; Harrison et al., 2006). In addition to being instructional models, mentors become a source of advice and a sounding board for concerns about teaching as they challenge the protégés to expand their thinking about their practice in order to guide their professional development (Fairbanks et al., 2000). There are other dimensions to the mentoring role, such as transferring skills with an understanding of their purpose and place, and assisting the new teacher in acquiring particular values and attitudes within the workplace (Harrison et al., 2006). These dimensions depend on the mentor role-modeling as an important mentoring practice of the induction year. This model of mentoring implies the mentor works with the beginning teacher in the school context, specifically, in the novice's classroom.

Reflexive, systematic inquiry sustained by the opportunity to engage in extended conversations between mentors and protégés (i.e., between veteran teachers and preservice or beginning teachers) about teaching practice is a necessary aspect of mentoring (Wagner, 1997). Thus, the process of mentoring is an evolution from an apprenticeship to guided practice and co-inquiry, suggesting that mentors and protégés (i.e., veteran and pre-service or beginning teacher) continually adapt to the protégé's needs and the challenges they face while teaching (Fairbanks et al., 2000, p. 108). The mentoring relationship becomes more collegial than hierarchical. 
What characteristics makes one a good mentor? Simply having been a successful classroom teacher for a certain number of years does not qualify one as a "good" mentor (Wang, 2001). James Rowley (1999), identified six essential qualities of the "good mentor" (pp. 20-22) including:

1. Commitment to the role of mentoring

2. Empathy for the "protégé"

3. Skilled to provide support at whatever level

4. Effective in different interpersonal contexts

5. Shares knowledge in a collegial manner

6. Communicates hope and optimism.

Formal training of mentors as a prerequisite to mentoring that defines and emphasizes the importance of their mentoring role is critical (Andrews \& Quinn, 2005; Giebelhaus \& Bowman, 2002; Rowley, 1999). Effective mentoring programs include training for mentors in such areas as planning lessons and units with their protégés, observing and being observed by protégés and including pre and post observation conferences (Andrews \& Quinn; Giebelhaus \& Bowman). The mentor must be skilled to mentor a beginning teacher to improve performance regardless of the pre-service or beginning teacher's skill level (Anderson \& Shannon, 1988; Cullingford, 2006; Glazer \& Hannafin, 2006; Rowley). There is no perfect blueprint for mentoring that can be applied to every teacher (Fairbanks et al., 2000; Rowley). Each protégé has a unique learning style and personality. It is critical the mentor be able to gauge the best way to build an interpersonal relationship with the protégé (Glazer \& Hannafin; Rowley).

Mentor selection criteria, careful pairing of mentors with protégés, mentor training, and on-going support for the mentor are all important components of effective mentoring practices (Anderson \& Shannon, 1988; Cullingford, 2006). In England for 
example, beginning teachers have a set of nationally prescribed Induction Standards to acquire Qualified Teacher Status by the end of their third school term (Harrison et al., 2006). In order to become a mentor there to beginning teachers, there are certain selection criteria imposed, such as selective pairing of the mentor and protégé, initial mentor training, and support for the mentor throughout the process (Anderson \& Shannon; Cullingford). Some mentoring models in the United States suggest a framework for the selection and training of mentors in addition to opportunities for mentors and their protégé to work together, which includes observing each other teaching (Giebelhaus \& Bowman, 2002).

Experts on mentoring argue for the careful selection of mentors based on certain attributes such as personality characteristics, ability to recognize and communicate effective teaching, and similar grade and content specialization (Giebelhaus \& Bowman, 2002; Scheetz et al., 2005; Wang, 2001). In addition, Giebelhaus and Bowman claim the process of effective mentoring includes developmental observation and formative constructive feedback all within an appropriate and focused discussion framework.

\section{The Mentoring Relationship}

In the mentoring process, mentors are partners with the protégés (i.e., novice teachers) in learning how to become more effective teachers (Fairbanks et al., 2000; Rowley, 1999; Scheetz et al., 2005). This is not just a façade; mentor teachers recognize their capacity to learn from their less experienced colleagues, which is an indicator they do not have all the answers (Fairbanks et al.). Inevitably, good mentors learn from those they are mentoring, no matter how much teaching experience they may have (Patton et al., 2005; Rowley; Scheetz et al.). Good mentors are transparent about their own pursuit 
for professional growth and search for their own answers to problems (Fairbanks et al.; Rowley). They share new knowledge and daunting questions with their beginning teachers in a collegial manner (Fairbanks et al.; Rowley). They begin to develop a reciprocal relationship. The novice gradually plays a more active role in assessing practice, planning curriculum, asserting their own views, and shaping the professional dialogue (Fairbanks et al., p. 109).

As negative as a teaching situation can be, whether because of an unsupportive administration, pressure for higher standardized test scores, children with serious behavior problems or demanding parents, good mentors are positive and helpful in offering advice that can assist their protégé with balancing teaching and administrative duties (Fairbanks et al., 2000; Normore \& Floyd, 2005; Rowley, 1999). Such mentors also help identify problems as they arise in the real-life teaching context of the classroom (Glazer \& Hannafin, 2006; Normore \& Loughry, 2006; Patton et al., 2005). According to Rowley, good mentors capitalize on opportunities to affirm the human potential of their protégés (p. 22). They share their own struggles and frustrations and how they overcame those obstacles.

At the heart of the practice of mentoring is the conscious reflection of teaching with another individual (Chase et al., 2001; Fairbanks et al., 2000; Hole \& McEntee, 1999). In addition to verbal conversations, conscious reflection can be in the form of written dialogue (e.g., a portfolio, log or journal) where teachers discuss their practice through notes, concerns, and questions with the mentors (Brennan et al.,1999; Fairbanks et al.). Mentors can assist in finding appropriate teaching materials and other resources, lend an empathetic ear or shoulder, and discuss and reflect on content and pedagogy, all 
for the purpose of providing positive professional growth for the novice teacher (Glazer \& Hannafin, 2006). Support is fundamental to the give-and-take mentoring relationship (Fairbanks et al.; Patton et al., 2005; The Clearing House, 2005).

One of the most critical aspects of developing the mentor relationship is trust (Glazer \& Hannafin, 2006; Patton et al., 2005). Trust grows as the dependability of the mentor becomes evident (Harrison et al., 2006; Patton et al.). When novices "let their guard down" and perceive mentors as understanding their world, they begin to value their mentor's help and build even more trust (Patton et al; Scheetz et al., 2005). When trust develops, the perceived power difference between the mentor and the protégé shifts and the protégé becomes more like a colleague than a student of the mentor (Fairbanks et al., 2000; Patton et al.).

Thus, the protégé (beginning teachers) becomes more receptive and mentors become more committed to sharing knowledge (Harrison et al., 2006; Patton et al., 2005). To truly understand the interactive dynamic of the mentoring process/relationship between mentor and protégé, a discussion on social learning theories provides a framework to examine mentoring and its significance in improving one's practice. Social Learning Theories

Traditional views of learning postulate that learning is an individual process; however, social theories of learning view learning as an interactive process (Patton et al., 2005). Social theories of learning include situated learning and constructivism (i.e., socially mediated learning, social cultural perspective). The situated learning perspective assumes knowledge is inseparable from the contexts and activities in which it develops (Fairbanks et al., 2000; Patton et al.; Rovegno, 2003, Vygotsky, 1978). Vygotsky’s 
constructivist approach of socially mediated learning (Fairbanks, et al.; Patton et al.; Vygotsky) has been used to study mentoring in education. The protégé is being pulled along a zone of proximal development by the advice, demonstration, questioning, and support of the expert mentor (Fairbanks, et al.; Patton et al.; Vygotsky). The purpose of mentoring in teacher education is to guide the novice to become like the expert teacher who is mentoring him/her.

Although Vygotsky's (1978) social development theory was designed to explain the cognitive development of children, it also applies to the mentoring process because mentoring involves a social interaction that facilitates learning. Just as with children, pre-service and beginning teachers develop their teaching skills, on a social level and then on an individual level. According to Vygotsky, "All the higher functions originate as actual relationships between individuals" (p. 57). This interaction results in a "giveand-take" relationship between the mentor and protégé. It involves negotiation. It is a fundamentally dialogic process in which both mentor and protégé examine their aims, concerns, and expectations (Fairbanks et al., 2000, p. 206).

This type of interaction exemplifies a social cultural perspective of learning. A social cultural perspective of learning assumes knowledge is situated and developed in the context of its use (Brown, Collins, \& Duguid, 1989). Instructive knowledge is situated in the actual activity of teaching, and it is developed in the practice of authentic teaching situations (Perry, Walton, \& Calder, 1999). The social cultural perspective of learning suggests knowledge grows out of the contexts of its use (Brown et al., 1989; Vygotsky, 1978). In a mentor-protégé relationship, the socio-cultural perspective 
emphasizes interactions with the more experienced individual are critical in order for the novice to acquire knowledge beyond the level of exploration (Vygotsky).

In a mentoring situation, there is a consistent set of social interactions between the mentor and the protégé (Fairbanks et al., 2000). Specifically in mentoring educators, social interactions can take the form of conferences, team teaching, observations, etc. These social interactions take place within the context of the school site and in most cases in the actual protégé's classroom; hence, the context of its use, since the protégé is actually applying what is learned by immediately using it to teach students. This is what is called an authentic teaching situation, where knowledge of teaching is situated in the activity of teaching and grows out of practice in "real-life" situations (Grove et al., 2004, p. 87). In the situated learning perspective, the individual, the activity and the environment are one unit of analysis (Rovegno, 2003). The protégé, the mentoring process (activity), and the school context (environment) are critical and cannot be ignored. The mentoring process between the mentor and protégé within the context of the school environment becomes an interactive system.

\section{Benefits of Mentoring}

Ideally, mentors and their protégés spend a significant amount of time together and communicate often even between mentoring sessions. In addition to learning skills, protégés receive support and encouragement from their mentors. Through the constant social interaction of mentoring, actual relationships develop between mentors and their protégés in the context of the school environment. Communication is not only limited to the mentoring sessions but also includes informal contacts (e.g., telephone calls, e-mails, brief visits for clarifying questions) between mentor and protégé. This process fosters the 
development and knowledge of the protégé and strengthens the relationship between the mentor and the protégé (Fairbanks et al., 2000).

As an interactive system, mentoring benefits all participants (Scheetz et al., 2005). In the context of education, mentoring benefits the mentor, protégé (i.e., the pre-service teacher or beginning teacher), and school system. The mentor gains the satisfaction of being able to transfer skills and knowledge accumulated through professional practice (California State Board of Education, 1983; Krupp, 1984; Scheetz et al.). The discussion and reflection of the novice teacher elicits the reexamination of the mentor's own teaching practice and the impact of common instructional strategies on student learning (Cullingford, 2006; Scheetz et al.). That reexamination causes collaborative learning or a "mutual learning effect," since the mentor and the protégé are helping each other in the learning process.

There are three main ways the novice teacher benefits: faster acculturation into the school environment, the establishment of professional competence, and the induction to teaching as a continually developing, lifelong career (The Clearing House, 2005). The school system benefits in the decrease of teacher attrition rates (Driscoll, Kauchak, \& Peterson, 1985; The Clearing House). Further, this individualized guidance may assist the mentor in foreseeing problems or issues that could affect the instructional process and discourage the novice teacher (Fairbanks et al., 2000; Patton et al., 2005). Lastly, mentoring may empower the experienced teachers by giving them the opportunity to mentor and share their knowledge. This honors them as leaders and exhibits the educational institution's interest (i.e., school site, university program or school system) in 
an environment conducive to long term professional careers (Fairbanks et al.; Patton et al., Scheetz et al., 2005).

\section{Successful Mentoring Models}

After an extant review of the literature, there are varied opinions on the impact mentoring has on teacher learning (Ingersoll \& Smith, 2003). In brief, some successful practices based on studies are worth highlighting (Fairbanks et al., 2000; Wagner, 1997). Some key issues surrounding mentoring beginning teachers in the literature are the selection of mentors, how mentors and protégés are paired with each other, how formal or informal their relationship may be, how mentors may be rewarded, and where to find time for mentoring (Hargraves \& Fullan, 2000).

Effective mentoring in English education. A study on the role of effective mentors designed as a clinical partnership to learn to teach, where the pre-service teachers and their cooperating teacher/mentors served as both co-researchers and informants, exploring the significance of their evolving relationships (Fairbanks et al., 2000). That study emphasized the voices of cooperating teacher/mentors and pre-service teachers in understanding mentoring experiences while encouraging them to go beyond the limits of their own knowledge about teaching and professional growth (Fairbanks et al.). While recent studies have focused on the pre-service teachers' perceptions of the effects of the mentoring received, Fairbanks et al. discuss both the mentor and the student teacher's perceptions (Fairbanks et al.). The participants as co-researchers in that study discovered and rediscovered that learning to teach, like teaching itself, is neither simple nor explicit. Instead they were involved in learning what their roles were in the process (Fairbanks, et al.). 
Many of the mentors welcomed their student teachers into their classrooms. One mentor stated she appreciated the fresh view of her student teacher in lesson planning together (Fairbanks et al., 2000). Pre-service teachers stated their mentors provided models of interpersonal relationships that included interactions with both students and other professionals. They viewed the practices modeled by their mentors "as sources of principled professional knowledge that ought to be emulated, but not slavishly imitated" (Fairbanks et al., p.107). Furthermore, some of the mentors struggled with their uncertainties of practice and with ways of making their practice explicit. At times even allowing their student teacher access to the critical examination of their own practice was difficult for them (Fairbanks, et al., p.107). This critical examination allowed for preservice teachers to begin to recognize and understand the web of practical and pedagogical issues they may encounter as teachers (Fairbanks et al., p. 107). As a collegial team, they adapted old lesson plans, incorporated new materials; and as a result, developed new curriculum, which allowed them to learn from each other by asking questions, offering opinions, and providing suggestions. Pre-service teachers not only described the role the mentors played on their own teaching practice as effective but also as crucial to their success. The exchange of ideas through modeling, observation, dialogue, and experience fostered professional growth, not only for the novice, but also for the mentor as well (Fairbanks et al., p.109).

The Kentucky teacher internship. By statutory mandate, The Kentucky Teacher Internship Curriculum assigned beginning teachers a more experienced colleague as their mentor teacher. The primary goal of this initiative was to nurture and retain good teachers by providing all beginning teachers with meaningful mentoring to help develop 
skills to become more effective pedagogically (Brennan et al., 1999). A survey report of over 3,000 classroom teachers that had been teaching for 3 years or less stated mentoring was very helpful to them. Participants also indicated the experience helped them grow professionally and improve their practice (Brennan et al., 1999).

The professional development of subject induction tutors. In an English mentoring program, beginning teachers identified several attributes that in their perspective constituted an effective mentor: organized, positive, consistent source of help, easy to contact, readily available and approachable, encouraging, empathetic, and supportive (Harrison et al., 2006). Additionally, the beginning teachers discussed what a good mentor was. They described a good mentor as someone with whom they could collaborate, a role model for the planning, organization, and delivery of classroom work. In addition, they said a good mentor had to be a good listener and flexible, able to focus on issues, enable discussion and reflect on practice, open up opportunities for the beginning teacher to broaden their experiences, and recognize areas of weakness that needed to be worked through by the beginning teacher (Harrison et al.). All these attributes combined describe the mentors as possessing both professional and interpersonal skills.

Trained versus untrained mentors. Giebelhaus and Bowman (2002) compared trained mentors with untrained mentors to examine the effectiveness of a mentoring training program of pre-service teachers. They reported pre-service teachers who collaborated with trained cooperative teacher mentors were more effective at planning, teaching, and reflecting on practice than pre-service teachers who were mentored by a cooperating teacher mentor who did not attend a training program (Giebelhaus \& 
Bowman). The study results indicated there was a difference in the demonstration of effective teaching skills by the pre-service teachers mentored by trained cooperative teachers as compared to those mentored by untrained teachers.

A collaborative apprenticeship model. In a study by Glazer and Hannafin (2005), veteran teachers mentored novice teachers, who later became future mentors themselves, in order to sustain skills and strategies across a community of teachers. The premise of this model is teachers become empowered by teaching and learning by supporting one another during the school day. Another premise is learning experiences are enhanced when they are used in the context in which they will be needed. In this model, veteran teachers as mentors model instructional strategies, obtain feedback, offer suggestions to improve instruction, and along with the novices, develop a shared understanding of their school community. This model involves developing instructional expertise, fostering collegial relationships, and meeting the needs of the learner, the protégé. Although, inadvertent in a mentoring relationship, support and learning are mutual between the mentor and the protégé. The difference in this model is support becomes a mutual responsibility and learning is an expected outcome from both parties involved.

This model promotes successful peer collaboration in learning through discussions of interests and goals (Glazer \& Hannafin, 2006). Collaborative learning was a goal from the onset. Another practice used is brainstorming to gain insight into creating lessons, instructional strategies, or finding solutions to classroom challenges. The mentor initially manages the design and development process of a lesson, then scaffolds or mentors the teacher in the development, and assists her in the process. The two implement the lesson they created together and then reflect on the experience by 
discussing it in order to refine the design and strategies for future lessons. Ideally in this model, the level of guidance by the mentor is in phases where the more experience the teacher gains, the more the mentor relinquishes control of the process to the novice teacher, thus empowering him or her.

Glazer and Hannafin (2005) found mentors that facilitated the growth of their protégés promoted risk-taking, the generating of ideas, and freedom in discussions. Another finding is teachers who were mentored noted a sense of belonging, acknowledgement, and validation. Self-efficacy, one's judgment of one's capability to organize and execute courses of action required for the acquisition of designated types of performances can also be affected by a mentoring relationship. Generally, high selfefficacy tends to perpetuate success, while the opposite is true: low self-efficacy may promote failure (Glazer \& Hannafin). Teaching involves caring for students and forming relationships with them, which leads to another element of mentoring, the increasing need for emotional support. Receiving emotional support from a mentor may help build selfesteem and a desire to develop professionally for a person with low self-efficacy.

Therefore, mentoring goes beyond guiding novice teachers through teaching skills effectively. Emotional support may be one of the strongest needs of beginning teachers mentoring can provide (Glazer \& Hannafin, 2006; Hargraves \& Fullan, 2000). Another essential aspect is the accessibility of the mentor and time routinely set aside for mentoring that would allow the protégé to seek assistance to resolve problems efficiently and maintain an on-going dialogue (Glazer \& Hannafin).

Professional development schools. In a Professional Development Schools (PDS) study (Scheetz et al., 2005) classroom teachers were assigned a student teacher to mentor 
for a school year. For the first half of the year, the student teacher observes the mentor teaching her class and then gradually begins assuming the role of teacher and by the second half of the year takes on the full responsibility of student teaching (Scheetz et al.) PDS mentors reported because they had to model a variety of strategies and activities, they were always mindful of best practices that contributed to stronger classroom instruction. They also attributed reflection, discussion, and new instructional strategies as contributing factors to their stronger classroom practice and their own learning (Scheetz, et al.). Several PDS mentors noted the importance of pairing mentors and pre-service teachers to match the personalities as a requirement for successful mentoring. Most of the mentors indicated a heightened sense of professionalism and "mutual learning effect" caused by the opportunity to both improve their protégés' teaching and their own practice through reflection and discussion (Scheetz et al., p. 36).

In fact, the PDS mentors felt mentoring was such a professionally rewarding experience that all the mentors who participated in the study said they would mentor again if given the opportunity. As indicated above, PDS had not had much success in the late 1990s (Mayes, 1998). Interestingly, this PDS program study, unlike the earlier programs, included mentoring and was found to be successful. In fact, the more recent study concluded the role of the mentor was critical to successful PDS programs (Scheetz et al., 2005).

Driven by the development of standards, reform initiatives and educational debate have centered on creating opportunities for students to learn and providing the best education possible to all children (Patton et. al, 2005, p. 303). Mentoring has become a reform tool for improving schools by enhancing the quality of the teaching workforce 
(Feimen-Nemser, 2001). Mentoring as a reform tool is a vehicle for gratifying and sustaining skilled teachers while creating a renewed professional culture focused on improving teaching and learning (Feimen-Nemser; Huling \& Resta, 2001; Little, 1990). The current teacher shortage and the imminent need for teachers to become effective practitioners make the implementation of effective mentoring programs for beginning teachers imperative (The Clearing House, 2005, p.115). Furthermore, the crises in American education, the government's role in educational reform the last two decades, and the birth of the literacy movement provide a basis for effective mentoring and to address some of the challenges.

\section{The Literacy Movement}

This section traces the journey that led to improving the quality of literacy education in the subsidized childcare system, hence the Literacy Movement. A brief account of the history of America's awareness of its failures in education for the past half century is offered. The government attempts at legislative reform efforts are also depicted in this section. The section ends with a discussion on the importance of early literacy development on remedying the education crisis and its support from legislature.

\section{America's Education Crisis}

Since 1965 with the signing of the Elementary and Secondary Education Act (ESEA), the federal government has spent more than $\$ 130$ billion to improve public schools. Investment in education has not closed the gap between students from lower socioeconomic families and students who are from higher socioeconomic levels nor between minority and non-minority students (Harris \& Herrington, 2006). In a report in 1983, A Nation At Risk discussed falling test scores, decreasing standards, and how US 
schools were increasingly failing to stack up against other nations (Coeyman, 2003; Harris \& Herrington). State and local governments were not doing their jobs, therefore the federal government's role in education increased (Coeyman). The most recent education reform is the No Child Left Behind Act (NCLB) which was passed in Congress in January, 2002 to assure accountability of education programs receiving state funding (Harris \& Herrington, 2006; No Child Left Behind Act 2001: United States Department of Education, 2002). This accountability system is based on higher state standards in reading and in mathematics (Harris \& Herrington; No Child Left Behind Act 2001: United States Department of Education, 2002; Yeh, 2006).

NCLB created strong standards in each state for what every child should know and learn in Reading and Math in grades 3-8, including Adequately Yearly Progress (AYP) that measures student achievement (Harris \& Herrington, 2006; No Child Left Behind Act 2001; United States Department of Education, 2002; Yeh, 2006). NCLB focuses educational dollars on proven, research-based approaches that will help children learn. This includes the Reading First initiative which increased federal funding for research-based methods of reading instruction programs from $\$ 300$ million to more than $\$ 900$ million. NCLB also strengthens teacher quality by providing $\$ 2.8$ billion for local districts to hire new teachers, increase teacher pay, and improve teacher training and professional development (McElroy, 2005; No Child Left Behind Act 2001; United States Department of Education, 2002).

The Government's Response

One goal of NCLB is ensuring every child can read by third grade. Specifically in early childhood education, NCLB helped implement an early reading program to support 
early language and literacy, and pre-reading development of pre-school age children, particularly those from low-income families (Harris \& Herrington, 2006; No Child Left Behind Act 2001: United States Department of Education, 2002). Although reform efforts spawned from A Nation At Risk's and NCLB's numerous critics, one positive outcome is today's education is regarded as a national concern and a very vital one (Coeyman, 2003; McElroy, 2005). While some contend NCLB has serious flaws, most welcome the national effort to improve teacher quality, especially in disadvantaged communities (McElroy). When considering the U.S.'s need for retaining quality teachers, the need to change the professional development of teachers or any individual working with children in an educational setting becomes evident (Darling-Hammond, 1996; Moir \& Gless, 2001; Shulman, 1999; Sykes, 1999; The Clearing House, 2005). While systematic efforts by school districts provide professional development for teachers and other educational professionals involved in early literacy, childcare centers have limited if any professional development. Yet, early literacy development has been the focus of reform efforts to improve the language development of young children.

\section{Early Literacy Development}

There is significant national evidence language development is a crucial area for investment for later school success (Dickenson \& Tabors, 2001; Hart \& Risley, 1995; Lonigan, Burgess, \& Anthony, 2000; Podhajski \& Nathan, 2005; Purcell-Gates, 1988). Early literacy has been a major objective in the effort to improve the literacy ability of young children (Podhajski \& Nathan). Four year olds from low-income families begin pre-kindergarten at a one year deficit compared to 4 year olds from middle class or higher 
income families (Lonigan et al., 2000; Podhajski \& Nathan). Literacy gaps between these children and their peers widen over time (Podhajski \& Nathan).

Research on child development and emergent literacy identifies four key domains that are strong predictors of subsequent literacy development: oral language development, phonological sensitivity, print knowledge, and print motivation (Dickenson \& Tabors, 2001; Lonigan et al., 2000; Podhajski \& Nathan, 2005; Whitehurst \& Lonigan, 1998). Children who experience early difficulties in learning to read are at risk for later school failure (Dickenson \& Tabors; Hart \& Risley, 1995; Lonigan et al.; Podhajski \& Nathan; Purcell-Gates, 1988).

The declining literacy rates have been cited as a major cause of school dropouts and a host of other socially undesirable consequences (e.g., incarceration, poverty, teenage pregnancy) plaguing the American educational system (Brooks-Gunn, 2003; Podhajski \& Nathan, 2005). In fact, a staggering $35 \%$ of all children with reading problems eventually drop out of school (Podhajski \& Nathan). Therefore, with more than $60 \%$ of working mothers with children under the age of five in pre-kindergarten programs, in both the public school and childcare system, there has been a concerted effort on improving early literacy through the childcare system (Podhajski \& Nathan).

The Childcare System

This section begins with a brief history of the childcare system's challenges and continues with a description of the history of subsidized childcare funding. Later, the professional development of childcare providers is discussed. The section ends with a discussion on the mentoring of childcare providers. 
The world of childcare comes with special challenges. The childcare system has existed in the shadows of the educational system for many years (Behrman, 2002). Because it has been ignored, it suffers from systematic neglect (Halpern, 1987; Krueger, 2002). The system of subsidized childcare is the least funded of all government programs (General Accounting Office, Health, Education and Human Services Division [GAOHEHS], 1998; Lyter et al., 2002). Childcare subsidies go to the lowest socioeconomic families, parents who are receiving public assistance based on a range of factors (Behrman; Fuller et al., 2002; GAOHEHS, 1998; Lyter et al.). The majority of the families are headed by single parents who have less than a high school education, and make, on average, less than $\$ 16,000$ per year (Behrman; Davidson, 1990; Fuller et al.; GAOHEHS; Lyter et al.).

A host of other challenges accompanies these families. Parents typically have more than one job, are taking care of an extended family, and lack access to resources capable of changing the conditions of their lives (Behrman, 2002; Davidson, 1990; Fuller et al., 2002; GAOHEHS, 1998; Lyter et al., 2002). New immigrants receiving subsidized care confront the additional obstacle of a limited proficiency of English. This impedes upon their ability to pursue higher paying jobs and decent housing. Childcare centers may be the only vehicle to fulfill the children's immediate basic needs (i.e., hygiene, proper nutrition, adult supervision, etc.).

Due to all these barriers, in many instances not only may subsidized childcare centers be the only source able to meet the children's basic needs, but also the only source to build a foundation in the early literacy skills these children receive. High- 
quality early childhood education has the potential to ameliorate these challenges in the long-term by breaking the cycle of poverty for these families (Davidson, 1990). A strong foundation in early literacy can help these children have later school success and possibly prevent these children from dropping out of school early (Brooks-Gunn, 2003; Podhajski \& Nathan, 2005).

With the emergence of universal systems of early education, quality rating systems, and a call for higher standards for early childhood education, the public is left with few acceptable options in improving the childcare system (DeBord \& Boling, 2002; Gable \& Halliburton, 2003; Krueger, 2002; Walker 2002). Public schools cannot assume the full burden of pre-kindergarten education due to space constraints. Furthermore, American public schools are facing their own crises (Brennan et al., 1999; Hyun, 2003). What seems more likely to happen is a patchwork system of private, non-profit, and public systems that adhere to similar standards and regulations to meet the challenge of servicing these children (DeBord \& Boling). This would require much of the childcare system that exists today to raise its standards in early childhood curriculum and improve the development of professional knowledge of childcare providers. Many new teachers will be needed, but many existing childcare providers will have to be trained to meet the increased standards.

\section{Subsidized Childcare Funding}

Subsidized childcare is a growing sector of the early learning community. In 1996, Congress passed and President Clinton signed into law the Personal Responsibility and Work Opportunity Reconciliation Act (PRWORA), more commonly known as the Welfare to Work Initiative. This extended the widespread state experimentation of public 
assistance curricula, which began in 1988 under the Family Support Act (Gnezda, 1996). Momentum had been building since the Reagan years to "reform" welfare in an attempt to diminish or eliminate what was seen as a bloated system of entitlements. With the Republican Congressional victory in 1994 (The Contract with America), the stage was set to make wholesale changes in entitlement curricula for the country's poorest citizens. The proposed changes set strict limits on the number of years a person could remain on public assistance and gave states increased latitude to make decisions about how federal dollars would be spent. State Block Grants replaced federal curricula (Gnezda). Governors and states now have the freedom to craft their own policies and allocate their funding in order to improve education.

However, states did not want to just drop people off welfare without giving them a way to survive. Therefore, the PRWORA established work transition curricula, job training, and childcare for parents who were transitioning from welfare to work (Gnezda, 1996; Smith, Blank, \& Collins, 1992). The logic behind this provision was simple. A mother with children could not transition to low-skilled and low-paid work and afford childcare, especially if she had multiple children. The system of subsidized childcare funded by the newly created Child Care and Development Fund (CCDF) was established (Smith et al., 1992). This was not conceived as an early childhood quality initiative but as a practical way to make the Welfare Reform measure work. If states expect to "break the cycle of poverty," welfare reform must not only focus on getting parents into the workforce but also provide a strong foundation for early learning and development of children from welfare homes (Smith et al.). 
During the first several years of the block grant, many states assigned administration of subsidies to individual counties. Their job was one of monitoring more than educational improvement. Ratios, health laws, and safety regulations were the types of monitoring used by the county. In the late 1990 s, some states decided to do more than provide minimal care that might be potentially damaging to this vulnerable population. They passed the "school readiness acts," which created independent oversight coalitions throughout the state. These School Readiness Coalitions were charged with improving the quality of subsidized childcare by competitively bidding for services, assessing children's outcomes, and implementing interventions based on documented need (Smith et al., 1992). Thus, if improving quality in childcare has become synonymous with investing in early literacy, this then leads to exploring professional development of childcare providers.

\section{Childcare and Professional Development}

Many early literacy curricula have been developed to help increase children's early literacy skills. New curricula are now being used throughout the country in major research initiatives testing the idea at-risk preschool children can benefit from targeted literacy curricula (Brooks-Gunn, 2003; No Child Left Behind Act 2001: United States Department of Education, 2002). In these early literacy curricula, the need for support staff to successfully guide a classroom through the implementation process has been largely overlooked (Podhajski \& Nathan, 2005). Project REACH, a study in rural Missouri, found quality childcare instruction can be improved through intensive, individualized training approaches that take place in the care givers' classrooms (Matthews, Thornburg, Espinosa, \& Ispa, 2000). 
Most childcare center staff, especially those working with at-risk children, lack the experience and education necessary to effectively implement a comprehensive early literacy curriculum (Walker, 2002). Millions of children are at risk for school failure; therefore, quality early literacy delivered by better trained childcare providers can help reduce the risk of future reading failure (Brooks-Gunn, 2003; Podhajski \& Nathan, 2005). Providers in childcare centers are in a critical position to provide essential literacy skills through lessons and activities that can promote reading success (Burns, Griffin, \& Snow 1999). Professional development in the form of workshop training, the traditional format for teachers, is the least conducive for training childcare providers. However, onsite and intensive mentoring to supplement the workshop training best develop the literacy knowledge and skills needed for implementing an early literacy curriculum (Podhajski \& Nathan, 2005).

In considering the most effective professional development for childcare providers to implement curricula for early literacy, it is important to address the obstacle toward professional development that compound such an effort (Soodak, Erwin, Winton, Brotherson, Turnball, Hanson, \& Brault, 2002). First, childcare providers are nondegreed workers who do not have sufficient formal knowledge of early childhood. The lack of formal training may impede their ability to implement early literacy skills effectively. Another issue is the high turnover of providers in childcare centers (Walker, 2002). It takes time and effort to implement a new curriculum. Can these providers commit to professional development? One reason the turnover in childcare is so high and the overall number of professionals in the field regularly decrease is the low wages and difficult working conditions (Whitebrook \& Phillips, 1999; Todd \& Deary-Schmitt, 
1996). In general, these childcare providers work long hours with few breaks and duties beyond just teaching.

The lack of professionalism associated with childcare providers is another issue that presents some challenges for more structured professional development. Some childcare providers view the work as a career; while for others, childcare is work engaged in while their children are young (Krueger, 2002). Many childcare providers do not consider themselves professionals because of declining benefits and difficult working conditions. These childcare providers perceive the job as a temporary endeavor and only view their responsibilities as providing a nurturing, caring environment (Krueger; Taylor, Dunster, \& Pollard, 1999). Further, the childcare provider's own perception of professional status and knowledge base may be defined by her experience with children (Walker, 2002). Additionally, regulations about the amount and quality of training to work in family childcare vary greatly from state to state and can change within a state from year to year. The issue of childcare is significant and calls for dramatic change (Fleming \& Love, 2003).

Research indicates a link exists between staff development and the delivery of quality services to children and families (Horm, Caruso, \& Golas, 2003). In fact, early childhood education advocates have a longstanding belief that the field must become a profession in order to improve the overall quality of care for children (Krueger, 2002). How can efforts to improve the quality of professionals in the field be successful when work conditions are poor, the workforce is unstable with differing goals and situations, and regulations regarding training and education vary from state to state? A viable solution is to examine the conditions that influence interest in professional development 
and tailor curricula to meet diverse family childcare provider's needs (Cohen \& Mondigliani, 1990; Kontos, 1992; Taylor et al., 1999). Though this does not directly address the wage and work conditions that characterize flight from the field, it can enhance understanding of ways to support the professional development needs of those in the field and how to reduce barriers to training and continued education.

\section{Mentoring Childcare Providers}

Many childcare providers are reluctant to participate in the more formal, bureaucratic, professional development processes (i.e., a college degree), which for them takes too long (Krueger, 2002). They may not have the resources needed: time (competing responsibilities of work and family), money (tuition and books) or childcare for their own child (most candidates are young mothers), to accomplish this in the traditional method (Krueger; Walker, 2002). Another impediment is the lack of support from their childcare center administrator whose priority is the center's reputation among parents (Walker). Parents may be more interested in how the childcare provider cares for and interacts with their young child than their degrees and titles. Childcare providers may feel all this personal sacrifice in becoming more highly trained would result in little financial or social recognition (Walker).

Not all childcare administrators are reluctant to provide professional development for providers they employ. Many want to lead in the educational improvements of the center but, unfortunately, are forced to spend more time in administrative duties such as managing than in the professional development of their staff. The rising standards placed on childcare centers have forced even administrators against providing professional 
development for childcare providers to now acquire the necessary credentials. Childcare administrators need support in this endeavor.

Mentoring may be the vehicle to acquire these credentials in a way that is feasible for both administrators and childcare providers. Mentoring occurs at the childcare site. The process of mentoring is not a linear process; it can parallel the process of working systematically in a childcare center (Fleming \& Love, 2003). A visit from a mentor that takes place at least once every other week furnishes the childcare center provider with job embedded, individual support on a consistent basis.

Childcare providers and administrators are accustomed to visits from government agency monitors that assess compliance to the increased standards mentioned previously. The agency monitors assess and evaluate the centers and have the authority to report them for non-compliance. The goal of a monitor is evaluative, while the role of the mentor is professional development. The difference between agency monitors and mentors is a mentor is in a facilitator role and a monitor is in supervisor role. A positive relationship will more likely develop with a mentor. Through this trust the childcare center provider will hopefully develop self-efficacy, believing in their own capabilities (Soodak et al., 2002). Witnessing the progress their children make because of their efforts in improving their teaching will allow them to increase their vision and have great expectations for the future (Soodak et al.). Praise and encouragement for the childcare center providers' strengths fuel their energy, vigorously exerting effort in taking action, to continue to improve (Soodak et al.). All these facets combined strengthen their persistence (putting forth sustained effort) to becoming even more effective (Driscoll et al., 1985; Soodak et. al.). Thus, mentoring not only can improve the teaching skills of 
childcare providers but also will empower them to become professionals who choose to stay in the field.

Previous research indicates increasing the number of hours of training produces more developmentally appropriate behaviors in childcare staff (Fiene, 2001). According to Fiene, mentoring fits this model because it is an intensive one-on-one intervention in which the mentor and protégé are engaged in problem solving activities to improve the overall quality of the interactions and environment of the childcare curriculum" (p. 85). Early care has a decisive and long lasting impact on how children develop their ability to learn and their capability to regulate their emotions (Fleming \& Love, 2003). Mentoring impacts and helps improve quality in a childcare organization (Fleming \& Love).

Non-degreed childcare center providers need the assistance of mentors to provide them with both the knowledge base of theory and its connection to meaningful practice. This dialogic approach to learning of observed experience and theory creates a deeper conceptual meaning (Dixon-Krauss, 1996). A job embedded approach to professional development with a professional mentor or coach at its core has the advantage of going to where the childcare providers are, designing individual professional development plans, and giving the motivation and moral support needed. This approach has the potential to increase the level of competent teaching more quickly and effectively than traditional approaches to professional development.

A study by Podhajski \& Nathan (2005) concluded increased childcare provider knowledge leads to early reading success. The study investigated the potential benefits of professional development for childcare providers that included mentoring once a month in promoting pre-literacy skills in 3 to 5-year-olds (Podhajski \& Nathan). The study 
concluded that not only did the language intervention help increase pre-literacy skills for children in an "at-risk" category for reading failure, but it also served to decrease the number of these children who will remain in this "at-risk" category when they enter kindergarten (Podhajski \& Nathan). The difference between this study and most others on childcare providers is $51 \%$ of the providers that participated in this study had a fouryear college or advanced degree, $45 \%$ had some type of state-regulated teaching certificate, and all had an average of 11 years of experience in a field with a high attrition rate (Podhajski \& Nathan). Yet with this strong baseline of education and experience, the increased professional development included a mentoring component that made a significant impact.

Mentoring practices in teacher education encompass many different categories. In considering what mentoring practices would facilitate the professional development of childcare providers, these four areas (i.e., affect, environment, culture, cognition) taken from research on beginning teacher development are worth examining (Glazer \& Hannafin, 2006). In the area of affect, mentors that were non-threatening developed trust, were encouraging, and made the protégé comfortable in openly discussing their learning by asking questions and validating the protégé's feelings (Glazer \& Hannafin). This is a category of mentoring that may be transferable to all areas of mentoring, including mentoring childcare providers. Under the area of environment, mentors assisting the protégé in accessing available resources and organizing the physical environment to optimize student learning may also be considered a transferable mentoring practice for childcare providers (Glazer \& Hannafin). In the area of culture, mentors model a positive adult interaction in order to exhibit a greater sense of professionalism toward their peers. 
Having a shared curriculum promotes culture in providing ample opportunities for strategic planning and collaboration to provide optimal learning opportunities (Glazer \& Hannafin). This may not always be the case with mentoring childcare providers in general, but in any context where mentors assist providers in implementing a specific curriculum this may also apply. In the area of cognition, a shared understanding between the mentor and protégé is critical (Glazer and Hannafin).

Therefore, dialogue that promotes learning of how the individual, in this case the protégé, thinks and processes understanding is an important mentoring practice that may transfer to mentoring childcare providers as well. Most of the research on mentoring in education is geared toward the mentoring of degreed teachers. The above-mentioned mentoring practices are transferable in the childcare setting. Whether these practices are effective in childcare, specifically in this study will be explored.

\section{Summary}

Many childcare providers lack formal training in early childhood education (Behrman, 2002; Gable \& Halliburton, 2003; Todd \& Deery-Schmitt, 1996; Walker, 2002). Unlike their counterparts (pre-kindergarten teachers in the public school system), most childcare center providers have not earned a United States college degree in education. Mentoring may be the only plausible professional development option for low-skilled and low paid childcare providers who have little formal schooling and lack the resources and the motivation to attend formal classes outside of their work hours (Behrman; Gable \& Halliburton; Todd \& Deery-Schmitt; Walker). Effective mentoring, which includes on-site training, observations, modeling of lessons, reflection, and 
discussion may be the best way to ensure they will implement changes in their classrooms and improve pedagogical practices.

As the need for the improvement of knowledge and skills of early childhood educators increases, the best chance of filling the slots for expanded pre-kindergarten is to develop the skills of the childcare center providers who are already teaching children in the subsidized care system (Hyun, 2003; Todd \& Deery-Schmitt, 1996; Walker, 2002). These childcare providers are generally not good candidates for traditional 4-year teacher education programs (Brooks-Gunn et al., 2003; DeBord \& Boling, 2002; Gable \& Halliburton, 2003). If the system wants to keep them and develop their potential, they will have to accommodate their needs. Mentoring programs have been successful in ameliorating some of the causes of high attrition rates among teachers (The Clearing House, 2005, p. 110). Perhaps they can have the same effect on the higher attrition rates among childcare providers. These programs also assist beginning teachers to become more effective practitioners sooner; since time is a factor in the professional development of childcare providers, mentoring may be effective in this area as well (The Clearing House, p.110).

A closer look at specific mentoring practices or strategies the literacy coaches of this study describe are worth exploring. If a predictor of future school success in learners is the strength of literacy skills, then improvement of literacy skills is a crucial step in raising the quality of subsidized childcare. The professional development of these childcare center providers is key to raising the quality of subsidized care. While much of the literature focuses on the mentoring relationship between an expert teacher and novice, these dynamics can also be applied to the mentoring between literacy coaches and 
childcare providers. Little research in mentoring in education involves the childcare system and even fewer studies specifically address mentoring practices in literacy intervention projects in subsidized childcare. Thus, combining the two areas offers an opportunity for a look at both practices. Substantiated by a situated perspective of learning, the individual, the activity, and the environment are one inseparable unit of analysis (Rovengo, 2003).

The LIX study focused on the individual (the students) and the activity of literacy development (measured by student pre and posttests) in the environment of the childcare center. There was also a secondary focus with the childcare provider, as the individual and the activities of teaching and learning in the environment of the childcare center (measured by curriculum implementation rating scales). However, two more integral parts of this unit of analysis: the mentor (individual) and the mentoring (activity) were overlooked. The interaction of mentoring with early childhood, literacy curricula, low skilled childcare providers, and multilingual and multicultural settings gives this study its richness and significance. 


\section{CHAPTER III}

\section{METHODS}

The purpose of this study was to describe and explore the mentoring practices of nine literacy coaches from Literacy Intervention X (LIX). These literacy coaches mentored childcare center providers in implementing literacy curricula for 4-year old students in subsidized child-care. LIX was located in a large metropolitan city by a collaboration of national and local educational agencies. The focus of LIX centered on the effect of the implementation of literacy curricula on classrooms of 4-year-old students in the childcare setting. However, the role of mentoring by the literacy coaches in delivering the curricula to non-degreed childcare providers was not examined. Mentoring, in this case, is defined as the establishment of a personal relationship for the purpose of professional instruction and guidance (Patton et al., 2005), in an authentic teaching situation, where knowledge of teaching is situated in the activity of teaching and grows out of practices in "real-life" situations (Grove, et al. 2004, p.87). Mentoring practices can be defined as the exchange of ideas through modeling, observation, dialogue, and experience that foster professional growth, not only for the protégé, but also for the mentor (Fairbanks, et al., p. 109). As one of the literacy coaches in the study, I undertook the present study to examine the best mentoring practices in mentoring nondegreed childcare providers implementing literacy curricula in LIX.

\section{Research Design}

A qualitative research approach was used in this study (Creswell, 1998; Denzin \& Lincoln, 2003; Glesne \& Peshkin, 1992; Lincoln \& Guba, 1985; Merriam, 1998).

According to Creswell, there are several reasons to conduct qualitative research. He first 
points out qualitative research is undertaken to answer how or what questions concerning "what is going on" (p. 17). He postulates, this approach is appropriate when "the topic needs to be explored" or "there is a need to present a detailed view of the topic" (p.17). The fourth reason is to be able "to study individuals in their natural setting" (p. 17). The fifth is the writer's interest in bringing himself or herself into the study as the storyteller. The final reason to conduct a qualitative study is to "emphasize the researcher's role as an active learner who can tell the story from the participants' view rather than as an 'expert' who passes judgment on participants" (p. 18).

In this case, the nature of the research question deals with what the mentoring practices are doubling as the topic explored. As a detailed view of this topic, the mentoring practices of the LIX literacy coaches are presented in their natural setting, the subsidized childcare centers of LIX. In a qualitative research design, the researcher studies "things in their natural setting" and attempts to "interpret phenomena in terms of the meaning people bring to them" (Creswell, 1998, p. 15). People label and interpret situations based on their perceptions (Bandura, 1986). Thus, participants perceived their context through their own interpretation. As a participant in Literacy Intervention X, I believe mentoring was a major component to how the literacy coaches worked with the childcare providers. As a participant-observer, I am the storyteller and an active learner who seeks to tell this story from the perspectives of the nine literacy coaches.

One approach of qualitative research is a case study. A case study is a type of qualitative study denoting a "bounded system ... bounded by time and place." The case being studied can be a curriculum, an event, an activity, or individuals (Creswell, 1998, p. 61). In this study, it was bounded by the time frame of Literacy Intervention $\mathrm{X}$ and the 
place of subsidized childcare in a large urban community in one Southeastern state. A case study provides a detailed, in-depth picture of the case being studied by using multiple sources of information in data collection (Creswell; Denzin \& Lincoln, 2003; Glesne \& Peshkin, 1992; Lincoln \& Guba, 1985; Merriam, 1998). To understand the literacy coaches' mentoring practices, a qualitative case study was conducted using a combination of field notes, small focus groups, and a large focus group follow-up session. According to Creswell, "a case study is chosen to study a case with clear boundaries" (p. 39) such as the parameters of Literacy Intervention X from where this study was derived.

Merriam (1998) asserts a case study "offers insights and illuminates meanings that expand its readers' experiences" (p.41). In describing and exploring the mentoring practices, as the researcher I attempt to offer insight on the role of mentoring in Literacy Intervention X. Merriam further explains, "Educational processes, problems, and curriculums can be examined to bring about understanding that in turn can affect and perhaps even improve practice" (p. 41). The aim of this case was to provide an understanding of the mentoring practices used by literacy coaches to implement three literacy curricula in LIX for 4-year olds in subsidized childcare. A case study approach has proven to be "particularly useful for studying educational innovations, for evaluating curriculums, and for informing policy" (Merriam, 1998, p. 41). Recently, educational reforms have focused on improving the quality of the subsidized childcare system in this southeastern state, the setting of LIX. Taxpayers have voted on new legislation, Voluntary Pre-Kindergarten (VPK), which provides subsidized funding to teach 4-yearolds three hours of literacy skills each day. Mentoring in education is nothing new; 
however, mentoring non-degreed childcare center providers in a literacy intervention project can be considered an educational innovation.

More specifically, in this study, a descriptive case study approach was used to examine the mentoring practices of the literacy coaches. A descriptive case study in education presents a detailed account of the phenomenon under study (Merriam, 1988, p.

27). Such an account is helpful "in presenting basic information about areas of education where little research has been conducted" (Merriam, 1988, p. 27). As discussed in Chapter 2, a myriad of research is available on mentoring in education in general, but very little is available in mentoring childcare center providers in particular.

The Researcher as Research Tool

The researcher is a tool, the primary research instrument, operating as an active learner who tells the story from the participants' view as opposed to passing judgment on participants (Creswell, 1998; Denzin \& Lincoln, 2003; Glesne \& Peshkin, 1992; Lincoln \& Guba, 1985; Merriam, 1998). I had 10 years of public school classroom teaching experience when I was hired as one of the LIX literacy coaches who mentored childcare center providers to implement one of the three literacy curricula along with the other eight participants. I had earned a Bachelors degree in Elementary Education with an area of concentration in Early Childhood Education, a Masters degree in Teaching English as a Second Language (TESOL) and a Professional Certificate in Educational Leadership. I am state certified in the areas of Early Childhood Education, TESOL grades K-12, Elementary Education, and Educational Leadership. Prior to my work in this study, as an Early Childhood classroom teacher in grades Pre-K, Kindergarten, and First grade, I had been a peer teacher for three first year teachers in the areas of ESOL, Pre-K, and 
Kindergarten. I had also taught a TESOL course to teachers in the school system. In addition, I had undergone Clinical Supervision Training enabling me to mentor numerous interns from Teacher Preparation Curriculums field experience courses sent from neighboring colleges and universities throughout my 10 years as a classroom teacher. My interest as researcher and participant in this study was in examining the mentoring practices of the nine literacy coaches from Literacy Intervention $\mathrm{X}$ in preparing nondegreed childcare providers in implementing literacy curricula for 4-year-old students enrolled in subsidized care.

I had lived for over 30 years in the unique multicultural community where the study took place. I had worked with students, interns, teachers, administrators, and parents from diverse cultural and socioeconomic backgrounds. This contributed to not only my ability to work with the diverse backgrounds of the childcare center providers I mentored, but also to build a relationship with my colleagues, the participants of this study. This knowledge base and practical experience served to assist me in conducting focus groups integral to this study. In order for interviews to be successful, the nature of the relationships depends on two factors: rapport and subjectivity (Creswell, 1998; Denzin \& Lincoln, 2003; Glesne \& Peshkin, 1992; Lincoln \& Guba, 1985; Merriam, 1998). Simultaneously, this experience with individuals from diverse backgrounds allowed me to be aware of my own perceptions that may cloud what the other participants had to offer.

Rapport and subjectivity are related to the quality of interactions supporting research in the degree of the researcher's self-awareness to manage the impact of self on research (Glesne \& Peshkin, 1992). Rapport in this relationship includes building of trust 
between me, as the interviewer, and the participants, the literacy coaches. This trustbuilding helps the participants feel comfortable and lowers any anxiety they may feel about the process (Creswell, 1998; Denzin \& Lincoln, 2003; Glesne \& Peshkin; Lincoln \& Guba, 1985; Merriam, 1998). As one of the literacy coaches, I had the opportunity to build a relationship with the other eight participants. It was a relationship built on collegiality, thus fostering trust and comfort during the focus groups.

\section{Setting of the Study}

Literacy Intervention $\mathrm{X}$ took place in 108 childcare centers in a multi-cultural and rapidly growing urban community in one southeastern state. This metropolitan city community has a large minority group as the majority of the population. It is known for its diverse culture and ethnicities resulting in a large Latin American population and includes French Caribbean immigrants as well. While English is the primary language in this southeastern state, Spanish is commonly spoken in the workplace and various public settings such as post offices, hospitals, and community centers in this metropolitan city. The mentoring for the implementation of the literacy curricula in Literacy Intervention $\mathrm{X}$ took place between 2003 and 2005. The literacy coaches in Literacy Intervention X were mentoring 108 childcare center providers who were teaching 4-year old students in subsidized care.

\section{Participants}

The literacy curriculum teams were each composed of three members: a teacher sub-contracted from the public school system, a technical assistant provided by a local central agency, and a coordinator hired by the curriculum developer specifically for this national project. Based on the fact the teachers and technical assistants were evenly 
distributed and randomly assigned to each curriculum, mentoring became a critical emerging variable to focus on. The literacy coaches received training in the literacy curriculum they were helping implement. No specific mentoring training was given; thus, they learned how to mentor as they mentored. This challenged them to reflect and discuss within their teams and with the other mentor teams whether particular methods worked. The on-going deliberate analysis of these literacy coaches was the most fruitful data to spotlight in order to better understand the role and possible impact of mentoring in Literacy Intervention X.

Nine literacy coaches were subcontracted from one of three different sources for the 2 years of implementation of Literacy Intervention $X$. Three of the nine were subcontracted from a local central agency, another three from the public schools system, and the final three from each of the three curriculum developers. One from each source made up each of the three curriculum team of three members. The three literacy coaches subcontracted from each of the curriculum developers had the added responsibility of working as the coordinator for the team of three literacy coaches. All three coordinator/coaches are bilingual. Table 1 more clearly depicts the constitution of each curriculum team. It simplifies, for quick reference, the origin from which Literacy Intervention X subcontracted each of the literacy coaches. Each individual's previous profession is also given. 
Table 1

Participants Present and Previous Employment

\begin{tabular}{llll}
\hline \multirow{2}{*}{$\begin{array}{l}\text { Employment } \\
\text { Origin }\end{array}$} & \multicolumn{3}{c}{$\begin{array}{c}\text { Current Curriculum Teams } \\
\text { (Members' Previous Positions) }\end{array}$} \\
\cline { 2 - 4 } & $\begin{array}{c}\text { Add-on Literacy } \\
\text { Team }\end{array}$ & Literacy Plus & Techno-Lit \\
\hline $\begin{array}{l}\text { Contracted } \\
\text { by } \\
\text { Curriculum }\end{array}$ & $\begin{array}{l}\text { Coordinator/Coach } \\
\text { (Technical Assistant) }\end{array}$ & $\begin{array}{l}\text { Coordinator/Coach } \\
\text { (Certified Teacher) }\end{array}$ & $\begin{array}{l}\text { Coordinator/Coach } \\
\text { (Technical Assistant) }\end{array}$ \\
\hline $\begin{array}{l}\text { Public } \\
\text { School }\end{array}$ & $\begin{array}{lll}\text { CT Coach } \\
\text { (Certified Teacher) }\end{array}$ & $\begin{array}{l}\text { CT Coach } \\
\text { (Certified Teacher) }\end{array}$ & $\begin{array}{l}\text { CT Coach } \\
\text { (Certified Teacher) }\end{array}$ \\
\hline $\begin{array}{l}\text { Social } \\
\text { Service }\end{array}$ & TA Coach & $\begin{array}{l}\text { TA Coach } \\
\text { (Technical Assistant) }\end{array}$ & $\begin{array}{l}\text { TA Coach } \\
\text { (Technical Assistant) }\end{array}$ \\
\hline
\end{tabular}

\section{Research Questions}

The following research questions guided this study. The questions were derived from the literature review and from preliminary discussions with literacy coaches at project meetings.

Research Question: What are the mentoring practices used by Literacy Coaches to prepare subsidized childcare providers to implement curriculum in Literacy Intervention X?

Sub-Question 1: What preparation and training impact the mentoring practice of the Literacy Coaches?

Sub-Question 2: What mentoring practices do the Literacy Coaches perceive as producing the best results in preparing subsidized childcare providers to implement literacy curriculum? 
Sub-Question 3: $\quad$ Do differences in the three curricula influence the mentoring practices provided by the Literacy Coaches?

\section{Data Collection and Design}

Interviews may be the most common data collection strategy in qualitative research. A combination of three types of interviewing questions were used for the focus groups in this study; structured, open, and depth-probing (Creswell, 1998; Denzin \& Lincoln, 2003; Glesne \& Peshkin, 1992; Lincoln \& Guba, 1985; Merriam, 1998). According to Glesne and Peshkin (1992), the intent of such interviewing is to capture the unseen that was, is, will be, or should be; how respondents think or feel about something; and how they explain or account for something (p. 92). The multifaceted responses provide the affective and cognitive threads of the respondents' perceptions (Creswell; Denzin \& Lincoln; Glesne \& Peshkin; Lincoln \& Guba; Merriam). Bolman and Deal (1991) assert most individuals recognize their mental maps influence heavily what they see and how they interpret the world around them. The literacy coaches in this study all shared the experience of mentoring subsidized childcare providers in LIX. We had similar obstacles in assisting the childcare providers in implementing literacy curricula; however, we each had our own perspective in interpreting our experience.

The process of interviewing can be described as a social encounter with dialogue, as a means for participants to share their world view as the interviewer constructs meaning from the participants' point of view (Gubrium \& Holstein, 2002; Rossman \& Rallis, 2003; Rubin \& Rubin, 1995). As a participant-observer, I had the opportunity to engage in the same professional environment as the other eight literacy coaches. We conducted mentoring sessions with each of our childcare providers, an 
average of two sessions per month. The focus groups gave us an opportunity to listen to each others' experiences and learn from one another's standpoint. For this reason, I opted to use all 3 types of interview questions (structured, open, and in-depth probing) in the focus groups, the main data collection method.

The purposeful selection of participants represents a key decision point in a qualitative study design (Creswell, 1998, p.118). This is referred to as a purposeful sampling strategy (Creswell; Merriam, 1998; Miles \& Huberman, 1994). As the researcher in this study, I specifically chose criterion sampling, a type of purposeful sampling (Creswell; Miles \& Huberman). In this case, the criterion mandated all the participants of this study be literacy coaches in the Literacy Intervention $\mathrm{X}$ and all share the experience of mentoring childcare center providers. The participants were formally contacted, in person, at the project meeting. They were asked for consent in using the information they shared about mentoring at their literacy curriculum team meetings for the purpose of this dissertation study. Participants were recruited individually and in person. I assured anonymity and confidentiality with notice that pseudonyms would be used for not only the literacy coaches but also the curriculum teams and even the project name itself in reporting information. Confidentiality was further assured as raw data would only be seen by me (Creswell; Denzin \& Lincoln, 2003; Glesne \& Peshkin, 1992; Lincoln \& Guba, 1985; Merriam).

All of the small focus groups were conducted at each curriculum team's monthly meeting place. The large focus group took place at a geographically convenient location for the participants. The participants were invited via e-mail to each of the focus group sessions. They were given choices for dates and their team schedules were 
accommodated. I made every effort to accommodate the participants' schedules to maximize large focus group attendance. The large focus group was re-scheduled several times. The absence of three members at the large focus group was due to reasons beyond the participants' and my control. Three participants were unable to attend; two of the participants had moved to another city; and another had just suffered the loss of a family member.

Table 2 provides a brief synopsis of each type of data collection approach and the plan for participant involvement in its design. The table begins at the top with data collected from a single individual extending to the broadest category including all 9 participants in a larger group setting.

Each focus group session was audio taped on a cassette recorder carefully stored and not shared with anyone. After each focus group session, I listened to each audio tape and transcribed participants' responses. Most of the interview questions were overarching and allowed for descriptive responses from participants (Creswell, 1998; Denzin \& Lincoln, 2003; Glesne \& Peshkin, 1992; Lincoln \& Guba, 1985; Merriam, 1998). For example, some questions were open-ended; the participants elicited further topics than what was intended by the question. As a result, more information and clarification ensued. The overarching questions allowed me to obtain richer and clearer responses from the participants.

Briefly, all the focus group questions centered on the mentoring process and progress. A semi-structured technique provided a focused format for the focus groups while still allowing for open-ended questions that encouraged the literacy coaches to 
Table 2

Data Collection Design

Data Type Participants Description

Participant Observation Individual-Researcher $\quad$ Field notes

$\begin{array}{lll}\text { Documents } & \text { Individual-Researcher } & \text { LIX reports }\end{array}$

Small Focus Group 1

3 Literacy Coaches

Add-on Literacy Team

Small Focus Group 1

3 Literacy Coaches

Literacy Plus

Small Focus Group 1

3 Literacy Coaches

Techno-Lit

Small Focus Group 2

3 Literacy Coaches

Add-on Literacy Team

Small Focus Group 2

3 Literacy Coaches

Literacy Plus

Small Focus Group 2

3 Literacy Coaches

Techno-Lit

Large Focus Group

9 Literacy Coaches

All LIX Literacy Coaches

consider all components critical to effective mentoring (See Appendix for List of Questions). Since this process is exploratory in nature, more questions were generated by the answers given.

\section{Data Analysis}

As Creswell (1998) explains, interviewing, analyzing, and writing are "intermingled processes, not distinct phases in the process" (p. 20). The data analysis in this study began during the first forms of data collection: the field notes of my own mentoring and first round of small focus groups. The next phase was the second round of 
the small focus group. The last phase was the large focus group session. Unanticipated, conflicting, or adverse findings were carefully considered and interpreted as well as irregularities in the findings.

\section{Participant Observation and Field Notes}

As participant-observer, I constantly viewed my own mentoring introspectively. During my own mentoring sessions, I would write a "coaching log" entry required by the developers of my curriculum. This log entry form included a space for the childcare center provider to jot down issues or questions arising between sessions, the lesson taught, and suggestions for improvement. This coaching log became part of my field notes as the researcher. At the end of my daily mentoring session, I reflected on what was on this form, on the childcare provider's progress in implementing the curriculum, the children's response to her teaching, and the impact my mentoring had on all these areas.

Furthermore, I kept more detailed field notes not only on my experience as participant-observer but also of my note-taking during the focus group sessions. These notes were used to illicit more questions for the next focus group meetings (i.e. a total of seven focus group sessions) and as data collection.

\section{Focus Groups}

There were seven focus group meetings. Two small focus group sessions were held with each of the three curriculum teams (six small focus groups in total). Each curriculum team was interviewed separately for one hour for the first round focus group and then again for another hour during the second round of focus groups. For the seventh focus group, the large focus group, all nine participants were invited to a two-hour session. 
The large focus group took place almost a year after the project implementation ended. It allowed for the coaches to interact between and among curriculum teams. This provided a method to check on themes derived from the analysis of the two rounds of small focus groups. The open-ended questions of the discussion themselves caused even more analysis and elicited even more patterns and themes during the actual focus group session.

Similarities and differences across focus groups were examined. Supporting evidence of commonalities in patterns, constructs, and similarities was supported by quotes from focus groups using both themes and atypical responses. Exact sources were recorded and maintained. I also took field notes during the focus groups for clarification during transcription. I made marginal notes on recurrent patterns or themes of the focus group responses and wrote a narrative describing the data and its analysis.

\section{Verification of the Data}

To ensure trustworthiness and authenticity of findings, I took several measures. First to ensure dependability, I spent as much time on a focus group question until redundancy was apparent, that is, until no new information was being generated. Second, triangulation, or the use of multiple data sources and data collection techniques, reduced the risk of conclusions reflecting systematic biases of limitation of a specific technique (Creswell, 1998; Denzin \& Lincoln, 2003; Glesne \& Peshkin, 1992; Lincoln \& Guba, 1985; Merriam, 1998). Triangulation is also an attempt to secure in-depth understanding of, in this case, mentoring. Interview data related to number of mentoring visits, curriculum information related to mentoring, time spent at centers, and rating of the 
quality of childcare center providers' performance was crosschecked to documents shared with all involved in the project.

The study was designed to flow from the specific to the general with a mutually reinforcing data structure, hence, triangulation. The specific data in this study come from field notes of my own mentoring and participation in the focus groups. The general comes from two data sources, documents (i.e. LIX reports), and the transcripts of the seven focus groups. The interactions, behaviors, and attitudes of the literacy coaches and their perceived reaction from the child-care providers were examined through six onehour small focus groups, and field notes of my 640 hours of mentoring as a literacy coach in the project done over the 2-year study. The small focus groups helped shed light on the experiences of the participants in their role as mentors in providing professional development to the subsidized childcare providers and implementing literacy curriculums. These small focus groups assisted in determining connections between my experiences and those of the other literacy coaches. Eleven months after the study implementation ended, a 2-hour large focus group bringing the literacy coaches together took place. This allowed me to gain a comprehensive understanding of the participants' experience and search for recurrent patterns in their discussion to form themes or categories to be used in the data analysis (Creswell, 1998; Denzin \& Lincoln, 2003; Glesne \& Peshkin, 1992; Lincoln \& Guba, 1985; Merriam, 1998).

All data collection techniques were complementary: as focus groups enabled me as the researcher to draw conclusions based on what participants said, field notes from my own mentoring and participation in the focus group added behavioral dimensions whether in response to a question or an event (Yin, 1994). Focus groups, observation 
field notes, and project documents together gave a more complete picture than either one could by itself (Stake, 2000) and allowed for a deeper understanding of relationships between literacy coaches and childcare center providers.

Because the focus groups were done in teams, at times I would follow-up focus groups with telephone call to individual coaches. I was concerned redundant answers would be echoed from coach to coach during the team focus groups. This was not the case because each member although agreeing with teammate's responses, added to their replies and gave different answers as well. The open-ended question format enabled me as the researcher to add questions developed from the participants' discussions. Additional questions posed to one group were also added to other groups' list of questions to allow for comparing and contrasting during the data analysis phase.

\section{Limitations of the Study}

Denzin and Lincoln (2003) suggest qualitative researchers identify their own biases early on in the research. This discussion is what guides and shapes the study. As the researcher, it was my responsibility to simultaneously raise awareness of my values as I attempted to discover meaning in this study (Denzin \& Lincoln 2003). Through that awareness, I as the researcher, can avoid blinding myself from the facts and am able to keep myself analytically honest.

Keeping the right balance between having an insider perspective with an outsider viewpoint also becomes a challenge for the participant-observer (Denzin \& Lincoln, 2003). With all participatory research, the investigator must be able to hold these viewpoints simultaneously, comparing often-differing conclusions (Denzin \& Lincoln, 2003). On the one hand, I had to survey myself, my understanding, my own mentoring 
sessions, and my mentoring sites in an intimate and natural way subject to the partiality of an "insider perspective" (Denzin \& Lincoln, 2003). On the other hand, I had to take on the view of an outsider, not sharing the partiality and without taking into account the “insider knowledge” (Denzin \& Lincoln, 2003). The internal debate between these perspectives is what gives this type of methodology its strength and achieves critical distance, "which allows the insider the possible as well as the actual in their social world" (Denzin \& Lincoln, 2003). The conclusions may not be entirely satisfying to either one of the perspectives but contain a type of balanced compromise. This is what I as the researcher strived to achieve in my analysis of both my experience and that of the other literacy coaches.

In addition, the case study does not tell the whole story, but deals with the unity of the case, the unity of the experience in ways other research does not (Stake, 2000). This study attempted to define mentoring in a specific context. That context may or may not generalize to other settings - that is not the purpose. By helping to understand the process of mentoring in one context, this study helps to build upon a body of knowledge about mentoring eventually leading to a more comprehensive theory. The field, as it applies to early childhood education, is at the stage where it needs specific exemplars before expanding to large generalizable theories.

\section{Summary}

In summary, there were several reasons why I chose a qualitative design. First, "qualitative researchers attempt to make sense of or to interpret phenomena in terms of the meanings people bring to them" (Denzin \& Lincoln, 2003). In this case, it was the literacy coaches' perspective of their own mentoring practices. Secondly, qualitative 
research is most appropriate for a study where the goal is "understanding," since qualitative research focuses on the essential nature of things (Berg, 2001). In this study, the goal was to understand mentoring including the components literacy coaches perceived to be essential to mentoring. Another purpose of qualitative research is to make sense of personal stories and the ways those experiences intersect (Glesne \& Peshkin, 1992). This coincides with this study because the literacy coaches' individual accounts and the intersection of those accounts in focus groups were analyzed. Still another purpose in qualitative research is how the participants' perspectives on events influence their behavior (Glesne \& Peshkin). In this study specifically, this is the participants' viewpoint on their role and the consequences of their actions in influencing their own behavior and the behavior of the childcare providers they mentored.

Qualitative research explores the range of behavior and expands understanding of the resulting interactions (Glense \& Peshkin, 1992). Throughout the research process it is assumed social interaction is complex, and I attempted to uncover some of that complexity. A qualitative design was selected for the present study because it embraced the purpose of the study and offered a method of collecting data in the participants' natural environment. In addition, I was interested in the qualities of literacy mentoring; those hard to define personal elements that produce effective practice. 


\section{CHAPTER IV}

\section{FINDINGS}

This qualitative case study explored the role of mentoring in Literacy Intervention $\mathrm{X}(\mathrm{LIX})$ in order to investigate the best mentoring practices that facilitated the implementation of literacy curricula by the LIX childcare providers. In analyzing the data, four major themes emerged. The first major theme, impact of professional background and role expectations, describes the demographic data of each literacy coach, including their education and experience prior to LIX. This theme also includes how their professional background may have influenced their expectations. The second major theme, curriculum design and implementation, provides a synopsis of each curriculum, including the materials it provides and what is required for implementation. The third major theme, building relationships, examines the literacy coaches' relationships with the developers, among literacy coaches within curriculum teams and with childcare providers. It also includes the obstacles the literacy coaches encountered in LIX. The last major theme highlights the best mentoring practices from the perspective of LIX literacy coaches. This section includes what the literacy coaches view as indicators of mentoring success of the LIX project.

Professional Background and Role Expectation

The first major finding pertains to the education and experience of each of the nine literacy coaches prior to their hiring for LIX. It also discusses their expectations of their role as literacy coach at the onset of the project. The educational background and formal preparation was different between those who were technical assistants and those who were state certified public school teachers. Of the three coordinators, there were two 
who were former technical assistants and one who was a former state certified public school teacher. The data also describes variations in role expectation along those lines of demarcation (i.e., teachers versus technical assistants). Therefore, this section begins with getting to know each of the nine literacy coaches grouped by origin of employment (i.e., public school teachers, technical assistants and coordinators). Later the section ends with the literacy coaches' expectations of the role also grouped in the same manner.

Literacy Intervention $\mathrm{X}$ was a collaborative effort between the federal government, the local school readiness coalition, and the public school. The three literacy teams were each composed of two coaches and one coordinator/coach. Two of the literacy coaches in each curriculum team were subcontracted (Refer to Table 1: Participant's Origin of Employment) from collaborating organizations for the duration of the study. The certified teacher was subcontracted from the local public school district (i.e., CT Coach in each curriculum team) and the technical assistant was subcontracted from a central agency that administered childcare subsidies and monitored the childcare centers (i.e., TA Coach in each curriculum team). Each of the teachers and technical assistants were randomly selected and assigned to one of the three curricula. The coordinator coaches were selected and hired by each of the curriculum developers. The two coaches were responsible for a portion of the 36 schools assigned to the curriculum team, while the coordinator was responsible for assisting the coaches in all 36 schools and communicating information to the developers and the research agency.

\section{The CT Coaches}

In each curriculum team, the CT Coach was a certified teacher who had between 10 and 19 years of experience teaching in elementary school. All three earned a master's 
degree. One had completed a doctorate degree and another was at the dissertation phase of her doctoral degree (the researcher in this study). All three held a state teaching certificate in Elementary Education, TESOL (Teaching English as a Second Language) and Early Childhood Education. They were chosen for the Literacy Intervention X study out of a larger pool of public school teacher applicants. The LIX designers assigned a teacher to each of the curriculum teams in order to have one member who had recently taught in a classroom with young children.

I was the Add-on Literacy CT Coach and the researcher of this study. Prior to becoming a classroom teacher, I had 8 years of experience in the education of children from Pre-kindergarten to $7^{\text {th }}$ grade. I taught Catechism (grades 1-4, and 7) for my church community for 6 years, underwent 2 years of field experience (grades Pre-kindergarten-5) in public school (including a semester internship as a student teacher in $5^{\text {th }}$ grade), and upon graduation worked as a substitute teacher for the local public school district in all subjects and in grade levels Pre-kindergarten to 5. As a classroom teacher, I taught a Prekindergarten special education inclusion class, kindergarten and first grade (10 years combined) for the local public school system. My educational background includes a B.S. degree in Elementary Education, an M.S. degree in TESOL and I am ABD in an Educational Administration and Supervision doctoral program, from the same state university. I am state certified in Elementary Education, TESOL (grades K-12), Educational Leadership, and Early Childhood (Pre kindergarten-3).

Prior to becoming a classroom teacher, the Literacy Plus CT Coach worked as a Sunday school teacher for a year, did an internship in third grade in another school district in the same state, and worked as a second grade teacher in a private school in the 
LIX local community for 1 year. As a public school classroom teacher, she taught first grade for 8 years, kindergarten for 6 years and second grade for 5 years, which makes a total of 19 years of teaching experience in the local public school district. She had obtained an Associate in Arts degree from a local community college, a B.A. degree from a state university, and an M. S. degree in Reading. She is state certified in Elementary Education, TESOL, Early Childhood Education and Reading (K-12). In addition, she obtained state endorsement in the area of Gifted Education.

The Techno-Lit CT Coach taught pre-kindergarten in the local public school system for 19 years. She simultaneously taught Child Development Associate Certificate (CDA) classes to childcare providers and each summer was the administrator of a summer camp. She has a B.S. degree in Early Childhood Education, an M.S. degree in Reading from a local university and a Ph.D. in Educational Administration from a university in another state. She is state certified in Early Childhood Education, Elementary Education, Educational Leadership and TESOL.

\section{The TA Coaches}

The other coach hired for each team was a technical assistant from a central agency that employed social workers and others from related fields trained in childcare center monitoring, supervision and accreditation. According to the project designers, the technical assistants were chosen for LIX because they had experience with the culture of subsidized childcare centers and the monitoring system that guided them. These three coaches came from varied educational backgrounds and experience.

The Add-on Literacy's TA Coach earned a B.S. degree in Education from a west coast university in the United States. She later became a teacher assistant and then a 
preschool teacher in private schools in Ecuador. When she came to the U.S., she worked as a preschool teacher for about a year. She then worked for the central agency as a technical assistant for about a year and a half and then as an accreditation specialist for another year.

The TA Coach for Literacy Plus earned a B.S. degree from a university in Bogotá, Colombia in the area of Special Education, which included a one year internship as a speech therapist for autistic children in a hospital. She earned an M.S. degree in Early Childhood Education with a 1-year internship in a pre-school also in Bogotá. She worked as a pre-kindergarten teacher and speech therapist consultant in a Colombian private school for 9 years and was director of a preschool for 2 years. She moved to the United States and obtained early childhood assessment training from a local university. She worked for the central agency as a technical assistant for a year and a half before being subcontracted to LIX.

The CT Coach for Techno-Lit earned a B.S. in Early Childhood Education from a university in Colombia. In the United States, she was trained in assessments for children birth-5 years of age. She had 3 years of experience working at different childcare centers and had taught second and third grade for one year at a private school. She attended many workshop trainings during the 3 years she worked at the central agency as a technical assistant.

\section{The Coordinator Coaches}

The three coordinators have various backgrounds as well. The Add-on Literacy Coordinator earned a B.S. degree in Education from a university in her native country, Colombia, where she worked as a teacher for 8 years. She began at the age of 18 
teaching in a 3-year-old program, then in a second grade classroom, and finally worked as a director's assistant for 1 year. When she came to the United States she earned an M.S. degree in Reading from a private local university. Subsequently, she worked in a small local private school for four years as a Spanish teacher and then as a first grade teacher for 10 years. She worked for the central agency as a technical assistant for 2 years.

The Literacy Plus Coordinator earned a B.S. degree in Elementary Education, which included field experience, and an internship in pre-kindergarten throughout her studies at a top university in a northeastern state. She earned a M.S. in Early Childhood Education and later a second M.S. degree in Reading, both from another 4-year university in the same northeastern United States. She was state certified in Elementary Education and Bilingual Education. During her 4 years of college, she worked as an intern in elementary schools. She worked as a pre-kindergarten teacher for 5 years, then as a staff developer for the board of education of the same northeastern state for 3 years and as a trainer for Literacy Plus for another 4 years.

The Techno-Lit Coordinator earned a B.S. in the area of Psychology, including some courses in Child Psychology, from a southeastern state university. She worked 2 years in the field of Developmental Psychology and then pursued an M.S. degree in Early Childhood Administration from a private university in a southeastern state. This included a practicum where she implemented a literacy program in a preschool of 450 children. She worked for the central agency for two and a half years and then for a religious nonprofit organization that worked with the childcare centers for the next two and a half 
years. In those 5 years she had extensive training in the area of Child Development, focusing specifically on Early Childhood Literacy.

Tables 3-5 depict the background of each of the literacy coaches. The first column, entitled "Coaches", lists the pseudonym for each literacy coach, which includes their prior job title/role and their LIX Curriculum Team. The second column, entitled "Experience," includes their experience in the field of education. The third column, entitled "Education," includes degrees, training and state certifications held in the field of Education.

\section{Role Expectations of the Literacy Coaches}

Organized by the origin of employment, this section describes the expectations of the literacy coach role of the nine participants. The former section discussed each of the literacy coaches' professional background (i.e., education and experience). The literacy coaches perceived the absence of formal training, specifically in mentoring, to mean that the project designers assumed that it was not necessary. The literacy coaches interpreted this as meaning capable teachers or technical assistants can be capable literacy coaches.

Just because you are a good teacher or technical assistant that doesn't make you a good mentor. I would have liked to have some sort of mentor training, where someone told me these are the kinds of things a mentor does. (Literacy Plus CT Coach)

The only training the literacy coaches received was in each of their respective literacy curricula. Thus, expectations of that role varied based on prior experience. In light of their background, their expectations for their mentoring role in LIX were examined. When the LIX project began, The CT Coach from each curriculum team (public school teachers on temporary assignment) had little idea what to expect. From their own account, 


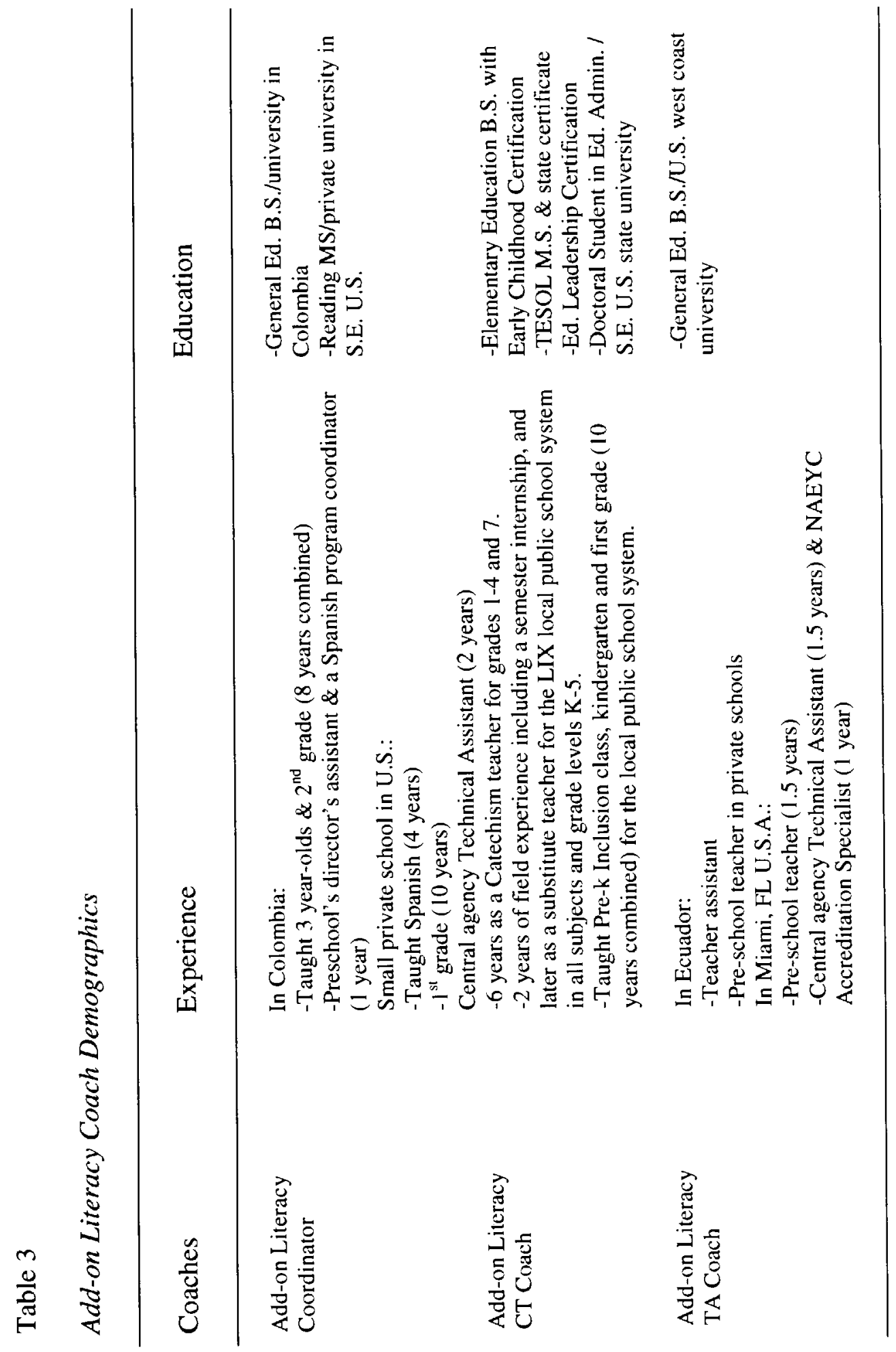




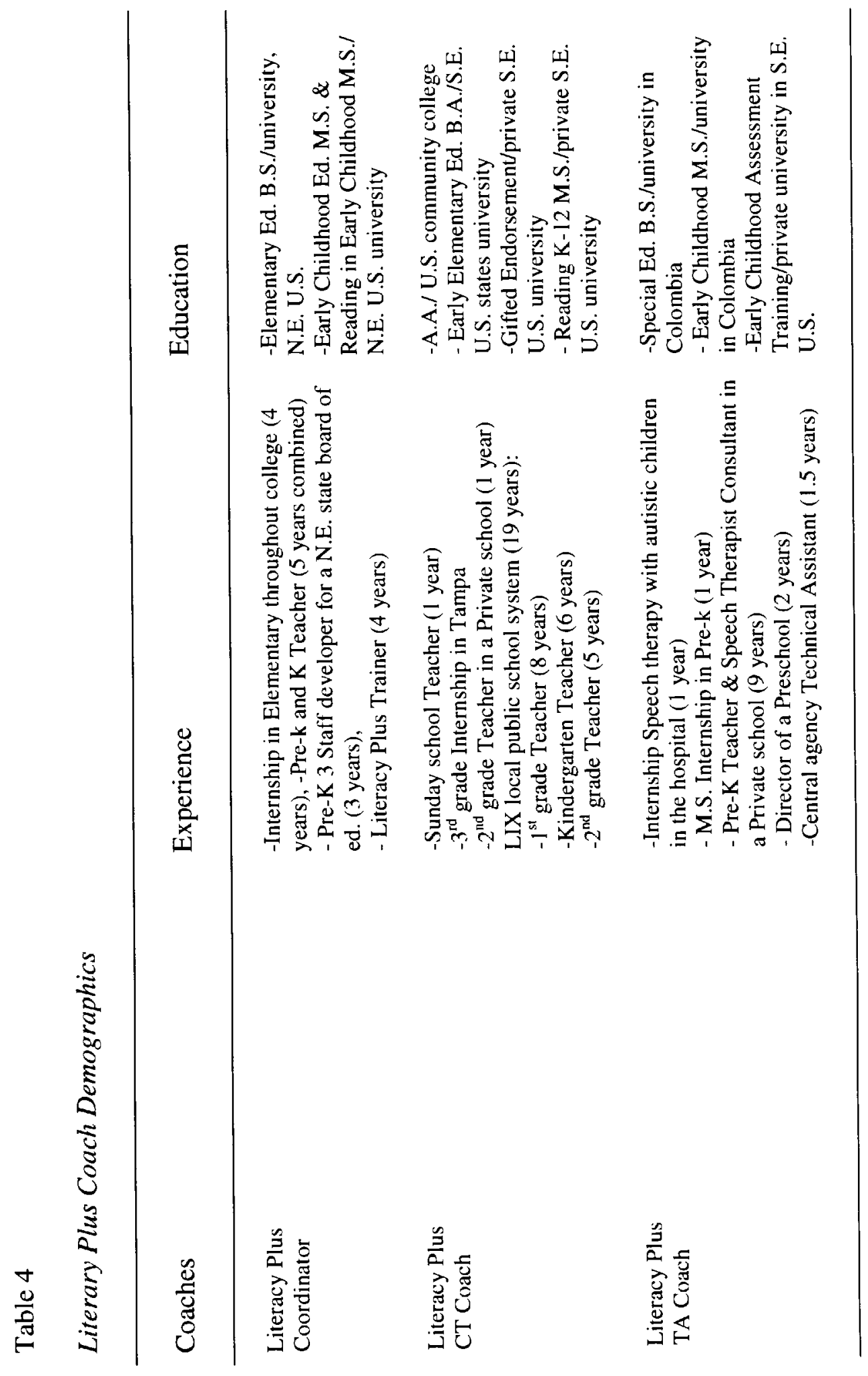

$n$ 


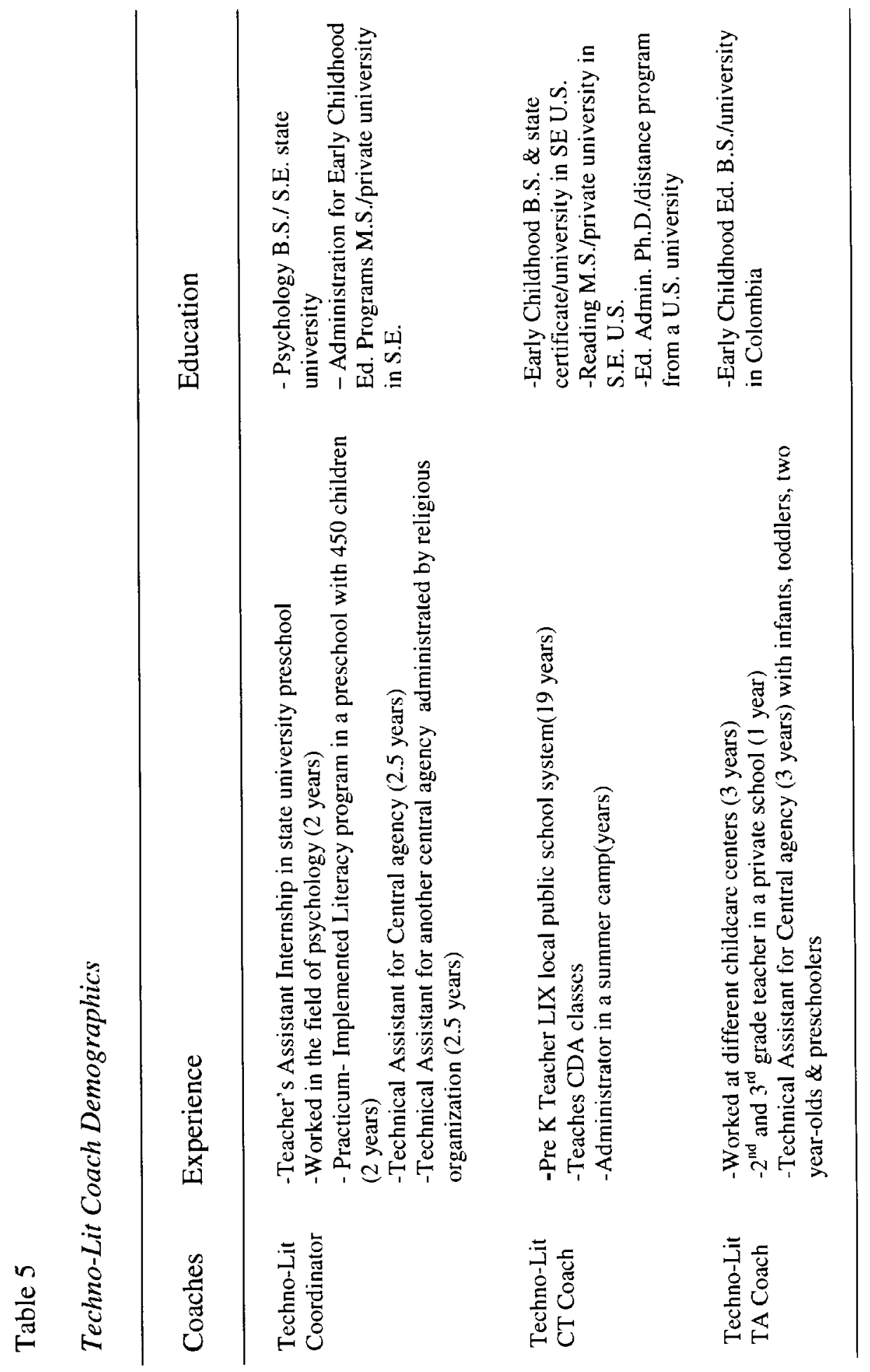

o 
all three had been mostly isolated in a classroom an average of 15 years, and as teachers they viewed mentoring in an instructive capacity.

I had no idea what to expect. I knew I was working on a national research doing something with literacy and driving around. I expected it to be a nice change from being in the classroom, but it was all still vague when we met initially. (Literacy Plus CT Coach)

They knew they were going to be assigned to a specific literacy curriculum and that they were responsible for its effective implementation in their assigned childcare centers.

I expected us to do more general training sessions than just two a year. I expected to work with specific things slowly and did not expect to do as many individual re-trainings to follow-up at each center because the childcare center providers were overwhelmed with so much new information all at once. (Techno-Lit CT Coach)

The TA Coaches viewed the childcare center providers as their students. All three teachers had experience with student interns from university teacher education programs; they expected this experience to be similar.

The CT Coach from each team (formerly a technical assistant in the central agency) had very different expectations of what their role in this project was going to entail. Out of the three former technical assistants, only one (Literacy Plus TA Coach) remained in the project throughout its duration. The other two began towards the end of Year One, when the local central agency closed unexpectedly. Because they abruptly changed job positions in an unforeseen circumstance, they both expressed that they did not have time to contemplate expectations.

I really did not have time to think, I had just lost my job, was offered a position and I took it. . I guess I assumed it would be similar to what I had been doing for the central agency, except with just 4-year-olds instead of children of all ages. (Techno-Lit TA Coach) 
"I expected to visit centers as I had done with the central agency, but it was more often and consistent than I had done before" (Add-on Literacy TA Coach).

Although the Literacy Plus TA Coach came from the same position at the same agency, her educational background and experience was different from the other two. This may have affected her expectations:

I expected this role to be a nice change from what I did in the central agency. I could finally do something that I could follow-up, stick to the same sites, and witness the process from beginning to end. In the central agency center assignments were changed often, now I have the chance to actually see the fruits of my work. (Literacy Plus TA Coach)

Both the TA Coaches from Add-on Literacy and Literacy Plus described their former positions as more of a monitoring role, responsible for evaluating centers, assessing what they had to do to improve in order to meet specific standards. As technical assistants, they had been assigned to monitor many centers, so they did not visit each center often enough to form a relationship with the childcare providers. They also worked with the childcare center in general, not just one specific classroom. Thus, even though they had experience with the childcare system which was new to the public school teachers, mentoring the childcare providers to implement a literacy curriculum was also new to them.

The consensus among all nine of the LIX literacy coaches was that their role was not clearly defined and that they did not know what to expect. The Add-on Literacy Coordinator, also from the central agency, expected her role to be more of an administrative position in the team.

I thought I would have more of an office position. I did expect to have to visit centers once in a while, but not as frequently. . . not every week 
visiting centers. I did not expect to work closely with the other two coordinators. (Add-on Literacy Coordinator)

She expected to organize the mentoring of the childcare centers assigned to Add-on Literacy with the two coaches doing most of the mentoring while she visited centers as needed. In contrast, the Techno-Lit coordinator expected to have more contact with the researchers and with the other two coordinators.

I thought we [the three curriculum coordinators] were going to work more closely with the research group, relaying information more often and interacting with each other. I did expect to visit each center at least once a month and only be in the office one or two days a week. (Techno-Lit Coordinator)

Additionally, the Techno-Lit Coordinator explained that the three coordinators were given an office to share with the two local research agency representatives. Of the three coordinators, only the Add-on Literacy Coordinator used the office on a daily basis with the local research agency representatives. The other two coordinators were out of the office visiting childcare centers daily. When they had to meet with their teams, they met at a geographically convenient location, which was usually not the office. They used the office space for storage of curriculum materials. Towards the end of Year One, the office was given to another project and there was no formal place for curriculum teams to store materials or meet.

The Literacy Plus Coordinator's experience included teaching in a large public school district and later mentoring many teachers on teaching Literacy Plus in that same district for 4 years.

I was used to visiting all the schools by myself training teachers on the curriculum, so I thought great now I will do the same except I have two people helping me. (Literacy Plus Coordinator) 
She was the only one of the nine that had extensive knowledge of the literacy curriculum (Literacy Plus) and years of experience assisting others in implementing it. Although she had the advantage of extensive experience in training teachers in her curriculum, this was still a different scenario (i.e., childcare centers vs. public school classrooms and another district in another state).

The Add-on Literacy and Techno-Lit Coordinators along with the TA Coach from each curriculum were former technical assistants. In their positions, they had not worked with the same childcare providers on a consistent basis at the central agency as they did as literacy coaches in LIX. "I think if there was something in writing that was definitive of what we were supposed to do and what our roles were, it would have been helpful" (Techno-Lit Coordinator). Although they had the advantage of experience with this specific county's childcare system, it was a different position from monitoring many childcare providers that they may only have visited a few random times.

The former public school teachers had the advantage of living and teaching in that community for many years (The CT Coach from each team). The public school teachers, including the Literacy Plus Coordinator, obtained advanced degrees and state certificates in more than one area of education. These former teachers had all helped guide other degreed teachers in the past, but they had not had experience with non-degreed childcare providers. There were some things that were a surprise to all the literacy coaches. An example is that mentoring childcare providers, in implementing a literacy curriculum, would require them to spend so much time teaching them how to manage their children's behavior. 
When we [the curriculum team] first got there, the kids were playing all day. They did not have a routine or schedule. They followed and there was no behavior management. Now [at the end of the project] teachers [childcare providers] follow a schedule and have a discipline plan. (Literacy Plus CT Coach)

Therefore, even though everyone had some experience in one aspect of the project, mentoring non-degreed childcare providers to implement literacy curricula in a 2-year intervention project was a new experience for all the literacy coaches.

Curriculum Design and Implementation

Another major finding pertains to differences in the curricula and implementation of the literacy curricula that had an influence on mentoring practices. The section provides a description by the literacy coaches of each curriculum, how it is to be implemented, and if those differences influenced their mentoring practice. First, all three curricula, although structured by the same basic literacy components, differed in their use of technology, intensity and pedagogical strategies. The three curricula included the following language and literacy components: oral language development, phonological awareness and print knowledge. Two curricula (i.e., Literacy Plus and Techno-Lit) were not limited to just literacy, they included other subject areas (i.e. math, science etc.). One of the curricula was considered an "add-on" literacy program that could be used as a supplement to a full day curriculum. The other two were full day curricula, with activities and lessons provided from morning until late afternoon (childcare center hours).

Add-on Literacy, the curriculum I helped mentor as a literacy coach, required no technology. Although technology could be used to practice skills taught in the program, it was neither required for full implementation, nor included in the curriculum materials provided by the developers. Unlike the other two curricula, Add-on Literacy was not a 
full day curriculum. It was considered a supplemental literacy program for an existing Pre-kindergarten curriculum. In essence, it could be used with an existing Prekindergarten curriculum as the Language Arts/Literacy portion of the day. The actual lessons (the Oral Language/Shared Reading and Phonological Awareness components) were taught in two non-consecutive 15-20 minute blocks, optimally as suggested by its developers, in the morning. The print knowledge component was included in those two lesson blocks and enriched by suggested activities with materials provided by the developers that could be infused throughout the day (i.e. center time, where children work in stations independently). The materials included a few suggested ideas and lessons for math, science, social studies, and art that were provided for each two-week story theme. These, however, were not required for full implementation, nor were there enough activities to provide daily lessons in each of these subject areas.

Add-on Literacy was more structured with less flexibility of options in teaching it for the childcare provider than Literacy Plus or Techno-Lit. There was a particular storybook order and a definite sequence of activities to be followed. These lesson plans, although specifically sequenced to assure that skills were taught, still warranted some freedom for the childcare provider (4-year-old classroom teacher) to adjust the lesson to the needs of students. Unlike Literacy Plus or Techno-Lit, Add-on Literacy had been used in the same community's public school pre-kindergarten program for 6 years at the start of Literacy Intervention X. The lesson plans had been adapted for the childcare center providers, rewritten in the more scripted way under the premise that many of the childcare providers did not have prior experience in following a traditional lesson plan. Another adaptation to the Add-on Literacy curriculum for LIX was although the program 
was to be taught in English, the first five lesson plans were available in both Spanish and English. According to the Add-on Literacy Coordinator:

The first five lesson plans were written in both Spanish and English in a simple format with step by step instructions of what to say and do, so that even providers with limited English and little educational training could follow and learn the lesson plan format.

In essence, the Add-on Literacy developers hoped that the childcare providers would progressively become less dependent upon the lesson plan and over time develop pedagogical skills to more creatively go beyond the lesson plan. The developers assumed they would become accustomed to the lesson plan format in their own language and by the sixth lesson plan, available only in English, would be able to understand it well enough to follow it.

Literacy Plus is an integrated language and literacy curriculum for pre-school children built around the theme of a series of weekly books. There is no particular book order for the 36 titles that come each with a planning guide. There is no specific order for the series of activities either. "We have a theme-based approach and we include crosscurricular activities for the content areas. The full curriculum includes math, science, dance, cooking etc." (Literacy Plus Coordinator). For each required component, shared reading, for example, there is guided small group activities, software that tailors instruction to each child's level and developmental centers of the curriculum with 5 or 6 suggestions to choose the most appropriate for their group. The rationale for this is Prekindergarten themes are usually according to the students' interest.

The required scheduled activities for Techno-Lit are: circle time, a movement activity, and "Book of the Week"/ shared reading (which includes: a read-aloud, a 
graphic organizer, and a writing extension activity at a table based on the graphic organizer). In addition, the children are then divided into three groups: a guided small group instruction, a group engaged in a developmental activity and a group using software that meets their individual needs. Techno-Lit is a curriculum that uses interactive electronic technology and thematically grouped children's trade books. It provides a variety of resources and enough daily activities to use the curriculum throughout the entire day. The childcare centers implemented its main literacy components throughout the morning from 9:00 a.m.-11:30 a.m. and then engaged in a few extra literacy enrichment activities in the afternoon.

Techno-Lit is not just limited to literacy, it includes science and math, but it is not required to teach those subjects for this study. One of the daily readings is encouraged for fun and one is required for the curriculum. Techno-Lit also includes videos. TechnoLit, although having more options in choosing what to teach, also provided a scripted lesson. "The teachers use a scripted lesson, which is divided into reading aloud, developing language, developing phonological awareness, beginning to write and recognizing letters" (Techno-Lit Coordinator). The Techno-Lit Coordinator further explains the flexibility in options for the childcare provider teaching the curriculum:

Either they [the providers] can teach lessons according to the literature books, or another way to follow the curriculum is by themes. There are teacher guides for either choice: literature based approach or theme based approach. Both guides are organized in order of difficulty, starting with basic skills and developing into ones that are more difficult. (Techno-Lit Coordinator)

Just as Literacy Plus, Techno-Lit did not have a particular book sequence. 
Table 6 is a brief reference that describes and summarizes each of the curricula.

The first column labeled "Curriculum", simply names each of the three curricula implemented by the three teams of Literacy Coaches. The second column labeled "Time Needed" briefly describes the amount of time in a school day devoted to teaching the curriculum, included activities required to be considered in full-implementation status as well as suggested enrichment activities for each curriculum. The third column labeled "Materials" briefly describes what materials are included with each curriculum package. The fourth column labeled "Structure" briefly describes the amount of flexibility on the part of the childcare provider in implementing the curriculum.

During the 2-year study, project designers advised the nine participants not to discuss details of their corresponding curriculum with each other as to avoid contamination of treatment. When LIX was over, at the final focus group follow-up interview, most of the literacy coaches still had limited knowledge of the other two curricula. The literacy coaches were asked if their mentoring would have been different if they had to implement one of the other two curricula.

Even though Add-on Literacy used some of the same storybooks as Literacy Plus, I know that it is more of a supplemental curriculum. It didn't take up the whole day, whereas Literacy Plus and Techno-Lit had enough activities for a full day. A lot of these children are at the childcare centers from 6:30 in the morning until 6:30 p.m. We worked with the teachers [childcare providers] in doing these activities for a full day. We even made them a calendar. So I think it would be different if I had worked in Add-on Literacy. (Literacy Plus Coordinator)

The same company published many of the storybooks used in Add-on Literacy and Literacy Plus; therefore, they had stories and themes common to both. The difference was in all the additional activities the Literacy Plus coaches had to teach (i.e., 
Table 6

Curriculum Comparison

$\begin{array}{llll}\text { Curriculum } & \text { Time Needed } & \text { Materials } & \text { Structure }\end{array}$

\begin{tabular}{|c|c|c|c|}
\hline Add-on Literacy & $\begin{array}{l}\text { Half day (plus } \\
\text { suggested } \\
\text { activities): } \\
\text { REQUIRED: } \\
\text { Two } 15 \text { minute } \\
\text { blocks: Shared } \\
\text { Reading (SR) \& } \\
\text { Phonological } \\
\text { Awareness (PA) }\end{array}$ & $\begin{array}{l}-19 \text { Titles (SR):2 week } \\
\text { lesson plans for each } \\
-5 \text { Nursery Rhymes (PA } \\
\text { I):two-week lesson plans } \\
\text { for each } \\
-26 \text { Letter } \\
\text { Charts/Rhymes (PA II): } \\
\text { one-week lesson plans } \\
\text { for each }\end{array}$ & $\begin{array}{l}\text {-Specific sequence for: story, } \\
\text { rhyme and letter. } \\
\text {-Specific Activity order for } \\
\text { each lesson. } \\
\text {-Scripted lesson plans with } \\
\text { leeway to add to activities, but } \\
\text { not substitute or omit } \\
\text { activities. }\end{array}$ \\
\hline Literacy Plus & $\begin{array}{l}\text { Full day } \\
\text { REQUIRED: } \\
\text { Shared Reading, } \\
\text { Guided small } \\
\text { group activities, \& } \\
\text { Computer activity; } \\
\text { includes math, } \\
\text { science, dance } \\
\text { cooking, fine \& }\end{array}$ & $\begin{array}{l}\text {-36 titles each with } \\
\text { planning guides } \\
\text {-software that tailors } \\
\text { instruction to each child's } \\
\text { level } \\
\text {-CDs with poster } \\
\text {-posters for each letter } \\
\text { (letter sound) }\end{array}$ & $\begin{array}{l}\text {-No specific sequence for } \\
\text { story, books or activities } \\
\text {-Specific letter order } \\
\text {-Choice between using themes } \\
\text { or literature books as a guide. } \\
\text {-Non-scripted lesson plans for } \\
\text { each component } \\
\text {-5 or } 6 \text { suggestions for small } \\
\text { group activity }\end{array}$ \\
\hline
\end{tabular}

Techno-Lit Full day -centers with 3 different types of electronic REQUIRED:

Literacy Activities devices alphabet sounds all morning plus p.m. suggested literacy activities $\&$ a plush interactive stuffed animal -flip books with images \& math \& science \& CDs related to lesson -No specific sequence for stories, activities or Letter order.

-Scripted lesson plan -Choice between literature based or theme based approach

math, science, cooking etc.) which required a longer mentoring session. In other words, what the Literacy Plus coordinator was alluding to was, it was not so much about the differences in content, as much as it was about the amount of time the curriculum required for implementation in a school day. 
Another member of the team felt that her mentoring practice would not have been different no matter what curriculum she was assigned to since it is about the professional development of teachers, not the content of the curriculum.

I think it would not have been different because my job was to get teachers familiar with a curriculum and then help them teach children. Getting teachers to do those extra things that they can do that make them see sparks in their [children's] eyes. (Literacy Plus CT Coach)

She felt it was about pedagogy and increased teaching skills, going beyond the curriculum.

Not knowing very much about the other two curricula, as an Add-on Literacy coach, I had assumed they had to spend more time on technical assistance and computer related issues. I was under the impression that they had to devote a significant part of their mentoring session to training the childcare providers on how to use the technology. Like me, our curriculum team's coordinator did not know much about the other curricula. She, however, believed strongly in Add-on Literacy. She felt it concentrated on the foundation of literacy and was easier to learn for the childcare providers.

There are childcare centers that don't even have computers in the room. All the things I taught in Add-on Literacy I had taught at some point before, but never organized in sequence in such a wonderful program. But I think if I had been chosen to do another curriculum, I still would have done a wonderful job, because it all ends up on you. (Add-on Literacy Coordinator)

Therefore, even though she felt in the other curricula the amount of time devoted to technology may have taken time from mentoring childcare providers on how to teach the basics, the curriculum would not have affected her mentoring. The following is a response from a Techno-Lit coach to the difference of having technology in the curriculum. 
Technology in our curriculum was more like a resource. Ours had the same content as Add-on Literacy, except now they [the children] had all these extra electronic devices they could play with in the different centers just like toys. (Techno-Lit CT Coach)

Before this project, the Techno-Lit CT Coach had actually taught Add-on

Literacy in the public schools for six years. A literacy coach from Literacy Plus agreed with her. She said that the technology portion of her curriculum was a computer assessment program that the children themselves could do. Periodically, the children played a "game" that would get more difficult according to their performance. She continued to explain how it was not an issue, even with childcare providers who were not technologically inclined:

The teacher doesn't have to take any time for that part ... the computer assessment part. At the beginning of the project, the program was set up and we modeled how to use it by teaching the children, but it's very user friendly. Some of these teachers didn't know a mouse from an elephant, but they caught on right away. It didn't take up any of our time in the mentoring sessions. (Literacy Plus CT Coach)

To summarize, in the opinion of these literacy coaches, working with a curriculum that had technology did not affect their mentoring practices. However, according to the Literacy Plus coordinator, the difference in whether it was a full day or supplemental curriculum may have affected the length of time of the mentoring sessions.

\section{Building Relationships}

Another major finding is the importance of building relationships as they relate to mentoring in this literacy intervention project. This category, building relationships, can be further delineated into sub-themes, based on with whom the literacy coach is building the relationship. The first sub-theme describes the relationship between the team of literacy coaches and the curriculum developers. The second sub-theme discusses the 
relationship among the literacy coaches within the curriculum teams. The third subtheme examines the relationship between each team of literacy coaches and the childcare providers they mentored.

\section{Coaches and Curriculum Developers}

The relationship between each team of literacy coaches and their developers varied from one curriculum team to another. One difference that emerged was the amount of financial and moral support from the developers. There was a connection between their relationship and degree of support to the communication between the developers and their team of literacy coaches. The developers' communication with their respective teams went from frequent and systematic to seldom and unstructured.

Developer's support. Support refers to the assistance given to each of the teams of literacy coaches by their corresponding curriculum developers. This assistance includes financial and/or material resources available to the literacy coaches throughout LIX. The support also includes the encouragement and emotional support given to the literacy coaches throughout the two years of LIX. This support is further reflected in the farewell each curriculum team gave the childcare providers at the end of the 2-year project.

In brief, Add-on Literacy developers were three local college professors whose curriculum had been implemented for 6 years at the onset of LIX in the local public school systems' Pre-Kindergarten program. The Literacy Plus developers were a married couple who met when they were working on a doctorate degree in Speech and Language Pathology. He was a former attorney and his wife, although not a teacher, had experience teaching children. Together, they became entrepreneurs and created a nationally known 
curriculum used in elementary schools across the country. The Techno-Lit developer is a large international corporation that had not used its curriculum in a context like this before. It had been implemented neither in the context of a large-scale study, nor in subsidized childcare. They did sell their curriculum to schools along with technical support and training, but not in a model with intense support (mentoring) like this one.

Add-on Literacy had the least financial resources available of the three curricula, but had the commitment of its developers. In fact, the developers at times used their own money as funding for any extra resources not covered by the federal grant funding LIX. According to one of the developers of the curriculum, they were cautioned to relinquish control to the curriculum team of literacy coaches so as not to have an unfair advantage, since they were the only developers that lived in the LIX community.

Our developers are always available and very supportive. We met with them as a team, about once a month in Year One and whenever we needed to in Year Two. We [the literacy coaches] had access via e-mail, telephone or in person to communicate with them whenever we needed. One of the developers visited each of our centers at least once during the two years of the [LIX] project. (Add-on Literacy Coordinator)

Literacy Plus' developers were well financed, highly involved and provided support for the LIX team with their national staff. The developer (referring to the husband in the couple of Literacy Plus developers) maintained constant communication with the Literacy Plus Coordinator and was aware of the weekly progress of the centers. He was informed of any major issues that occurred with centers assigned to Literacy Plus. He visited each of the centers at least once during LIX. "The developer visited every center at least once during the project. As the coordinator I had to turn in monthly reports and communicate with him on a consistent basis" (Literacy Plus Coordinator). 
Techno-Lit had the most financial resources available, since it was developed by a corporation. However, it lacked the personal commitment of the developers in comparison to the other two curricula.

We almost pulled out of LIX for Year Two, because they [the corporation] felt the investment would not be financially profitable. The summer between Year One and Year Two, the research team and our corporate developers discussed it back and forth. Thankfully, they decided to stay. (Techno-Lit Coordinator)

Techno-Lit is better known for its interactive electronic educational devices sold in toy stores for children. It is not as popular as a school curriculum, due to the high cost of purchasing the materials needed to implement this curriculum in a school.

Ending the project. The way in which each of the curriculum teams ended the LIX project with their childcare center providers exemplifies the level of support and assistance from their developers. The Add-on Literacy team along with the developers invited all the childcare center providers (4-year-old classroom teacher and assistant) and the directors to a lunch at a local restaurant. During the luncheon, the developers expressed their appreciation for the childcare providers' hard work and gave out certificates of appreciation.

The Literacy Plus team also, along with their developers, planned an evening banquet at a nice hotel ballroom to celebrate the end of the LIX project. They invited not only all the childcare center providers and directors, but also all the members of the research agency, university project partners, and all collaborating agency partners. The celebration included awards for childcare center providers as well as speeches from the developer and other project leaders. The CT Coach even wrote a poem specifically for the event that honored the childcare center providers' hard work. 
The Techno-Lit developers almost abandoned the project in the summer between Year One and Year Two. Therefore, any kind of farewell from Techno-Lit was entirely up to the team of literacy coaches. They planned no formal thank you event gathering all childcare center providers together at the end of the LIX project. What they did do as a team was visit each of the Techno-Lit centers with a small gift for each of the childcare center providers as a token of their appreciation and to bid them farewell.

This fits with the way that the three curricula were administered. Add-on Literacy is the least funded but has the commitment of its authors/developers. Literacy Plus is well funded and has the enthusiastic support of its developers. Techno-Lit was well funded from a corporate standpoint, but lacks the personal commitment of the other two.

\section{Coaches Within the Curriculum Teams}

In analyzing the data within the relationship theme, the relationship among the literacy coaches within the curriculum teams constantly emerged as an integral part of the other two relationship contexts. The "coaches within team relationship" is further divided into two areas of the relationship: structure and dynamics, and communication and interaction. The final sub-theme describes how through these areas, each team dealt with obstacles.

Structure and team dynamics. The structure refers to the degree of organization and how systematically the team mentored the childcare providers as designed by the developer and guided by the coordinator. The team dynamics refers to structure within the team, how the literacy coaches related to each other. An example that depicts both the team's structure and dynamics is a description of each curriculum team's monitoring system. Each curriculum team utilized a system of recording and rating implementation 
progress and provided instructional feedback to childcare providers. These systems were used to alter mentoring practices to better meet the needs of the childcare providers in order to effectively implement each of the three curricula. Each team's monitoring system reflects the developers' ideas about key components of the curriculum and effective strategies to communicate them. It helped the literacy coaches identify areas of weakness that needed improvement. The use of these monitoring systems, including their formality and degree of consistency and accuracy, may give a sense of the mentoring practices of each curriculum team and the organization and style of its coordinator coach. The following is summarized from the account of each coordinator coach's description of their curriculum's progress monitoring system.

Add-on Literacy used what they called a "portfolio". This was a binder that was kept in the childcare classroom. During every visit, the literacy coach and childcare provider used the portfolio to record the mentoring communication between them. The portfolio was divided into different sections: classroom profile, lesson log, coaching log, observations, and monthly reflections. The classroom profile section included a pre and post diagram of the physical classroom (i.e., the arrangement of centers and areas, at the beginning and at the end of Literacy Intervention $\mathrm{X}$ ). The lesson log is where the childcare provider briefly wrote down what was taught daily, in order to know what was covered and where to continue the next day's lesson. The coaching log is where the childcare providers write questions or comments between visits from the literacy coach that can wait until the next session. The coach reviews the questions and/or concerns and addresses them during the session, both in conversation and in a written response in that same $\log$ sheet. The coaching $\log$ is also where the literacy coach writes suggestions for 
improvement and positive aspects of the Shared Reading and Phonological Awareness lessons she observed.

The observations section includes a checklist of points that could be included in the lesson. This is where the literacy coach marks what the childcare providers did well from a list of what an ideal lesson may include. The more points from the list marked off, the better the lesson. However, the checklist included positive points for many different types of lessons. Therefore, no one lesson could include all the points on the checklist. There would not be a consistent measure to follow. A literacy coach would not be able to score the observation (i.e., nine out 10 checklist points equals a score of 5).

Each visit, a coaching log entry including suggestions for improvement was written, the observation checklist was filled in, their [the provider's] lesson log was checked and their posted calendar with what book and rhyme they were supposed to be teaching that week was initialed by me, the coach. (Add-on Literacy CT Coach)

In the last section, monthly reflections, the childcare provider was to write a journal entry on reflections of her progress in implementing the program at the end of each month. The literacy coach was to read the childcare provider's reflections. The monitoring system for Add-on Literacy was qualitative in nature with narrative statements and anecdotal notes to record progress.

Literacy Plus used a database system, which enters calendar visits and calculates percentages of visits per site to monitor their progress in relation to the number of mentoring visits. The "Four Essential Practices Checklist" tells where each of the sites falls in progress, (non effective to most effective), in order to tailor visits according to needs. 
As a team we also discussed our observations from our visits at our monthly meetings to determine what each site needed and what the focus will be for the next month's visits. Then we would decide from that discussion if a particular site's needs warranted more frequent visits or a team visit, etc. (Literacy Plus Coordinator)

In addition, a monthly narrative entry for each site describes what is going well in the implementation process, what still needs more support, and what the goal is to get them where they need to be. A classroom observation form to get a sense of where they are in the implementation scale is used to create the four essential practices checklist and the monthly narratives to input on the database. In addition, during Year Two, childcare providers (the four-year old classroom teachers) completed a self-assessment (i.e. teaching checklist, writing checklist etc.), which allowed for increased accountability on the part of the childcare providers.

Similarly, the Techno-Lit team used an assessment tool that begins with setting up the classroom environment. The assessment then focuses on the interaction between the teacher and students and later the curriculum. The Techno-Lit coaches used an observation list with an assigned score from 0 to 35 . The childcare providers are not aware of the score, only the mentoring team knew what the score was in order to better meet the needs of each teacher in their specific areas of weakness. At each visit, the Techno-Lit coaches would follow-up the recommendations from the previous visit. However, they did not force the implementation of the curriculum until the environment and interaction were in place already. "Our assessment tool begins with the environment and interaction then later the curriculum" (Techno-Lit Coordinator).

Using the assessment tool, the literacy coach developed recommendations. The team also used the strengths and weaknesses of some centers to help other centers by 
modeling to their peers and visiting each other's centers. "We also shared samples of what is working in the centers (i.e., childcare providers' student work or projects etc.) to create training kits that we used in re-trainings at centers" (Techno Lit Coordinator).

According to the Techno-Lit CT Coach, the childcare providers whose work was shown as an example were very proud of themselves and this inadvertently became an incentive for them to continue setting the creativity bar higher.

Another incentive that Techno-Lit offered was at the end of each year of the study, they chose a "Teacher of the Year" amongst all the participating childcare center providers. Yet this did not hinder the childcare providers from helping their peers. The childcare providers would visit each other's centers to get ideas or improve their curriculum. All three curricula shared model projects by childcare providers with other centers in some way and encouraged childcare providers to visit each others' centers and network.

In order to plan for monthly visits, the Literacy Plus team discussed the progress of each childcare center as a team using their observation forms as a guide. Then, they determined what mentoring strategies were needed to improve an area that needed improvement. The coordinator said the following about whether length of time, frequency or consistency of visits was most important in planning mentoring visits to a childcare center:

It depends on the center. If it's a center that has had turnover [a new provider teaching the four-year olds classroom] then we need to go more frequently to provide on-site training. If it's a childcare provider that is doing fairly well, then the frequency is not as important, but the length of time and the consistency. (Literacy Plus Coordinator) 
They combined all the information and as a team created a monthly calendar to coordinate center visits and ensure that the centers that needed the extra help get it. All three curricula were required to turn in a report rating the progress of the centers assigned to them about four to five times per year during the two years of LIX. Each curriculum used its monitoring system to decide on a numerical rating (i.e., 0-5) for each center. Each curriculum coordinator was responsible for sending their team's report to the LIX researchers. Since, for the most part, the Add-on Literacy coaches, visited only the centers assigned to them, each coach was responsible for rating their own centers and sending it to the coordinator. In contrast, for Literacy Plus and Techno-Lit, the coordinator and the coach assigned to the center together (along with input at times from the other coach) determined a rating according to their monitoring system, since they visited each others' centers. Add-on Literacy and Literacy Plus developers would discuss strategies with the teams on how to better assist the childcare centers that rated low.

Communication and interaction. The three curricula not only varied in the developers' support for the literacy coaches and their structure and dynamics, but in their communication and interaction. This sub-theme describes frequency and amount of communication and interaction among literacy coaches within each curriculum team. Each team developed their own system for mentoring, which was influenced by the coordinator's style. For example, the Techno-Lit team met once a week, while the Literacy Plus team met formally once a month, but they constantly communicated via email and telephone. In addition, the coordinator usually saw each coach at a childcare center at least once a week. On some occasions, they visited schools as a team to assist 
weak centers. Techno-Lit occasionally made team visits as well, to assist low-rated centers.

In contrast, the Add-on Literacy team met whenever it was needed. In Year One, Add-on Literacy met about once a month. In Year Two, during the first couple of weeks, the Add-on Literacy team met several times while moving offices and planned the general training workshop as did Literacy Plus and Techno-Lit. However, as a team, Add-on Literacy formally met about four times in Year Two (i.e., they met in January and then did not meet until April). Between formal meetings, the Add-on Literacy team rarely communicated neither through e-mail nor on the telephone. Their communication was limited to solving issues that a coach and the Coordinator had to discuss. What was done at the mentoring sessions with childcare providers was not discussed with fellow Add-on Literacy team members. The only exception would be a brief synopsis of the progress of each center or a good idea a literacy coach mentioned at the infrequent team meetings. What was done at a particular session was solely to the literacy coach's discretion with rare input from the team. Each Add-on Literacy coach was almost autonomous in their mentoring of the childcare providers.

The relationship categories overlap and interconnect in some areas. This is why in discussing the within team relationship of the literacy coaches, as exemplified above, references to their relationship with developers and providers are unavoidable. The next section delves deeper into that mentoring relationship.

\section{Coaches with Childcare Providers}

The teams differed in their mentoring relationships with childcare providers. Each curriculum team had a different way of distributing the 36 centers assigned to the 
team. At times, centers were re-assigned from the first year and the second year of the project. There were also differences in how many mentoring visits each team made to their centers on a monthly basis. The researchers, at the beginning of LIX, had said that the two coaches would be assigned half the childcare centers each (18 centers) and were to visit their centers twice a month or more often if needed. The coordinator of each team would be visiting all 36 centers assigned to the curriculum once a month. However, each developer and coordinator had the freedom of altering the team distribution, assignments and frequency of visits as they deemed fit.

Collaboration and center distribution. The teams differed in the level of collaborative support the literacy coaches provided for each other in mentoring the childcare providers. Two teams followed a systematic way to collaboratively plan support for their fellow literacy coaches while the other team's literacy coaches just supported each other when asked by the developer or a fellow literacy coach.

Literacy Plus followed this plan for center distribution with minor alterations where needed. The Literacy Plus centers were assigned half to the CT Coach and half to the TA Coach, with the coordinator visiting all centers at least once a month. The center assignments and distribution remained the same throughout the 2 years of the study. The coordinator had this to say about visits to the centers:

The center assignments remained the same, but there was overlapping among centers. Either the coaches visited the center with the coach assigned to it or to a center they were not assigned to on their own for extra support. (Literacy Plus Coordinator)

In addition to their average two visits to their own centers, the literacy coaches also visited each others' centers either with their fellow literacy coach or on their own 
depending on what they decided was needed to provide extra support. At times, this even included team visits with the coordinator as well.

An example of our team visits might have the literacy coaches taking on different responsibilities like, one teaches the class, while another observes and conferences with the teacher and the third rearranges the classroom. We also made visits together at the end of the school year and holiday time. (Literacy Plus Coordinator)

The Literacy Plus coaches visited the centers an average of twice a month. The number of visits was dependant on the progress of the childcare center. "I would visit my centers twice a month on average, but I would visit the centers that needed more assistance, every week" (Literacy Plus TA Coach). Another CT coach similarly said, "I would visit all my centers twice a month, but if they needed more assistance then I would visit them every week or as many visits as needed with the help of my team members" (Literacy Plus CT Coach). At their monthly meetings, Literacy Plus planned the following month's visits. They created a schedule to synchronize visits that had to be done in pairs, by the team or by a coach not assigned to a particular center, to provide extra support for centers that needed it. They organized their time in a way that assured that all centers were visited at least twice a month by the coach and once by the coordinator.

Techno-Lit originally followed the plan of dividing the centers in half between the two coaches. However, because the CT Coach did not speak Spanish and had five Spanish speaking centers (centers whose childcare providers all spoke Spanish only), the Coordinator decided to re-assign herself those five centers in Year One. 
In Year One, I took on five centers as their coach, that were Spanish speaking, because the CT Coach is not bilingual. The rest of the TechnoLit centers I visited as a Coordinator. I also took one from TA Coach in Year Two to even the distribution a little more. (Techno-Lit Coordinator)

The original TA Coach did not speak Spanish as well, but the replacement TA Coach had been assigned as her translator in those Spanish-speaking centers the first five months of the project. The coordinator offered much assistance to the replacement TA Coach when she replaced the original in the last months of Year One. Throughout the two years, the Coordinator visited all the Techno-Lit centers at least twice a month and Techno-Lit coaches also visited each others' centers in pairs or as a team. "When centers scored very low, there was more modeling of lessons and the team made extra visits to that center" (Techno-Lit TA Coach).

At their weekly meetings, they came up with a plan to help each other in mentoring childcare providers at centers that were not doing well according to their progress monitoring system. They coordinated visits to each other's centers in pairs or as a team to supply their childcare providers with extra assistance the following week. "At our weekly meetings, we also discussed strategies to help centers and we might give a center extra visits on a weekly basis" (Techno-Lit CT Coach).

Each member of the team had a copy of each others' schedule of visits, including particular visits that were to be done with a partner or as a team. In discussing strategies, they learned what each others' areas of expertise were. "Sometimes a coach is having trouble helping a teacher [provider] in a specific area and another coach assists that center with the specific issue and is successful" (Techno-Lit Coordinator).For example, if a literacy coach was better at, or more comfortable with room arrangement (i.e., organizing 
the learning centers and creating a functional classroom environment) she would assist with a center assigned to her counterpart that had a deficiency in that area. The TechnoLit coaches demonstrated teamwork by using their differing areas of expertise to better meet childcare providers' needs.

Add-on Literacy's center distribution and assignment not only changed from Year One to Year Two, but during each of the two years. I was the CT Coach for Add-on Literacy; therefore, the following is an account of my experience as a participant taken from my field notes and LIX documents (specifically Add-on Literacy center assignments). In Year One, I was assigned 16 centers, the TA Coach was assigned 15 centers and the Coordinator was assigned 5 centers, a total of 36 centers. In the first 3 months of LIX, a center was removed from the study due to the director's refusal to uphold her responsibilities (i.e., not allowing the provider/teacher to attend trainings etc.). This decreased the number of the centers assigned to me to 15 and the total number of centers to 35 .

At the beginning of Year Two, the Add-on Literacy coordinator distributed the centers in the following manner: 16 centers assigned to me, 16 centers to the TA Coach and she assigned 3 centers to herself. Shortly after she made the center assignments (within the week), the developers redistributed the centers in the following manner: I remained with 16 centers, the TA Coach remained with 12 of her centers (the lowest ratings of the 16) and the Coordinator was assigned 7 centers (four of the highest rating of the 16 plus her three). The rationale for this, according to one of our curriculum developers, was that the TA Coach rated only seven out of her 16 centers as fully implementing the program at the end of Year One. The TA Coach had only worked with 
these centers in the last 3 months of Year One. When she replaced the former TA Coach from the central agency, there was a gap in time during the switch when centers were not visited at all. The developer's plan was that the coordinator was to work closely with the TA Coach in Year Two to help those 12 centers rise to the level of full-implementation. Within a month of starting Year Two, I lost a center, again due to an uncooperative director. I remained with 16 centers because one of the coordinators' centers was reassigned to me. She was left with six centers. Four months into Year One, the coordinator determined that there was enough improvement in most of the TA coach's centers, so she reassigned them back to her and remained with the 3 centers she had in the original Year Two distribution.

Centers were reassigned again throughout Year Two, even in the last 2 months of the project, due to a director's refusal to cooperate with the coordinator. The developer reassigned those centers to me. The distribution of centers assigned at the end of the project was 15 centers to me, 13 centers to the TA Coach and 6 centers to the Coordinator. The rationale the developers used in making these reassignments was to allow the TA Coach and the Coordinator more time to visit those 15 centers, providing frequent and consistent support to help them improve as much as possible before the end the project. Throughout the 2 years of LIX, there were 12 centers that remained assigned only to me and 3 centers that remained assigned only to the coordinator. The TA Coach was assigned 10 centers from the time she started the last 2 months of Year One.

The Add-on Literacy coaches assumed that fellow team literacy coaches visited their assigned centers minimally twice a month. However, we did not have a monthly schedule of each others' visits. The coordinator did collect from our (the two coaches') 
calendar of visits at the beginning of each month via e-mail, but we had no idea of each others' schedule or the coordinator's schedule. "Each coach visited the centers an average of two times per month, unless the center had a problem or needed extra help, then three times per month" (Add-on Literacy Coordinator). "Each coach (CT Coach and TA Coach) visited the centers two or three times per month, I do not know how many visits the coordinator made to the centers" (Add-on Literacy TA Coach). As a coach for Add-on Literacy myself, I made on average two visits per month to 12 out of the 16 centers assigned to me. I decided a quarter of the centers, the remaining four centers, required a weekly visit (four visits per month) either because the teacher (childcare provider) was new or needed extra help.

If the coordinator made a visit with us to a center it was scheduled that same week. The coordinator made only two center visits with me throughout the two years of LIX. The TA Coach and I never visited a center together. The Add-on Literacy coordinator admitted to having difficulty in her relationship with her fellow literacy coaches. She stated the following midway through Year Two:

At times I had disagreements with the way things should be done with both of the literacy coaches. I learned that I needed to be more open to their suggestions and realized that the relationship within the team was just as important as the teams' relationship with the providers. (Add-on Literacy Coordinator)

An example that further illustrates the lack of systematic structure and collaboration in the Add-on Literacy team is the following. During a week when I was on Spring Break for the public school system, the coordinator was scheduled to conduct a mini-training in one of my childcare centers that had a new teacher. When I returned from Spring Break, she had not done so. This caused me to change my schedule around and take away a 
visit from a center to do the training myself. I did not say anything to the coordinator, so as to not cause problems between us.

The Literacy Plus and Techno-Lit teams differed from Add-on literacy, in that for the most part, the centers assigned to each literacy coach remained assigned to that literacy coach for the duration of LIX. In addition, in Year Two, project documents depict that the Add-on Literacy coordinator did not visit almost one third of Add-on Literacy centers, while both the Literacy Plus and Techno-Lit coordinators visited each of the centers in their curriculum at least once a month each year. The low-rated centers at times received additional monthly visits from the Literacy Plus and Techno-Lit Coordinators.

In training childcare providers, for example, each curriculum developer provided three offsite training sessions for all providers (4-year-old classroom teachers), their classroom assistant involved in implementing the curricula, and the center directors. If there was a new childcare provider (teacher) at a particular center, the responsibility of training was shared by the coach and the coordinator of Literacy Plus and Techno-Lit. "I would usually be the one to do the trainings, on-site, for three mornings for about 4 hours each" (Techno-Lit Coordinator).

The coach assigned to that center would assist the coordinator in the training and transition; but the coordinator would be the one to take on the extra time to minimize the disruption in visits to the other 17 centers the coach was responsible for mentoring. In the Add-on Literacy team, the coach assigned to that center was responsible for new childcare provider (teacher) training with some assistance if needed from the coordinator. As a literacy coach for Add-on Literacy, it was frustrating and overwhelming to take 
away one of the bi-weekly visits from my other childcare centers in order to train a new

teacher. I felt those childcare providers, although doing well, needed my visit to have the opportunity to show-off what they were doing and receive my praise and encouragement to continue to do well. When I would tell them I could not come because I had to train a new teacher, they expressed their disappointment.

A strategy used by both Literacy Plus and Techno-Lit where support for each other is exemplified was when a coach needed assistance helping a teacher in a specific area that was not the forte of that coach, the other literacy coaches would assist the center with that specific issue. Each of the literacy coaches in both Literacy Plus and Techno-Lit developed a relationship with all the childcare providers assigned to their respective curriculum, which allowed for interchanging and combining literacy coaches at center visits with little disruption to the level of comfort and objectives of the visit.

All our childcare providers knew and felt comfortable with anyone of us in the team. They had a relationship with all three of us since we visited all the centers as needed to give extra intervention. Establishing rapport and trust between all the members and each the childcare providers helped the providers know we were there to help them, not criticize them. (Literacy Plus Coordinator)

The Literacy Plus and Techno-Lit coaches knew the childcare providers that were assigned to their partnering literacy coach well enough that they could discuss strategies to help each center as a group.

Dealing with obstacles. Mentoring childcare providers was a new endeavor for all the coaches. Unexpected issues arose and finding ways to deal with them was a learning experience for all three teams. Most obstacles were common to all three curriculum 
teams, such as many childcare providers speaking little or no English. The way in which each curriculum team dealt with these obstacles was different at times.

The unexpected closing of the central agency, which provided one of the members of each team, was an obstacle all curriculum teams faced. However, two of the teams, Add-on Literacy and Techno-Lit, were especially affected. A team member (the TA Coach) was replaced by another former technical assistant from the same agency towards the end of Year One. Both coordinators were able to give input on who the central agency replacement would be, since both worked for the central agency in the past; they knew most of the technical assistants there. Techno-Lit, however, was fortunate because before the closing of the central agency, the replacement TA Coach had been purposefully assigned as a technical assistant in the same centers as the original TA Coach by the central agency as a translator. This was because most of the centers assigned to the TA Coach were Spanish-speaking and the replacement TA Coach would schedule her visits to be available to translate for her. "The switch in the TA Coach position really did not affect our team because the replacement TA Coach had already been helping our centers with the original TA Coach" (Techno-Lit CT Coach).

Therefore, her transition into the literacy coach position may have been smoother in that she was already familiar with the work the original TA Coach was doing. She had established, to some degree, a relationship with some of the Techno-Lit childcare centers since she had been visiting them as a technical assistant from the central agency and as a translator for the original TA coach she was part of the mentoring conversations. Another problem that affected all of the teams almost equally was that of childcare provider turnover. Although, to reduce this issue, childcare providers (the 4-year-old 
classroom teachers) who remained in the centers the duration of the school year received a $\$ 500$ stipend at the end of Year One, and at the end of Year Two it was still a problem. In Year One, provider turnover was $44 \%$ in Add-on Literacy classrooms, $42 \%$ in Literacy Plus classrooms, and $28 \%$ in Techno-Lit classrooms. This caused all three teams to have to train new teachers throughout Year One.

When a new teacher begins, both the coach assigned to the center and I train the teacher. We have to rearrange our schedules that month to dedicate four morning sessions [2-3 hours each] to conduct the training. (Literacy Plus Coordinator)

Because the mentoring relationships take time to develop, new teachers would not only be lagging behind in experience with the literacy curriculum, but in developing a relationship with their literacy coach as well.

The childcare providers' lack of classroom management skills was yet another issue that was common to all three teams as well. All the literacy coaches concurred that classroom management is critical in teaching. The consensus among the coaches was that if children do not have rules or any type of structure in their classrooms, learning cannot take place. "Year One we spent so much time on behavior management and the environment, that Year Two was when we could really focus on the curriculum" (Literacy Plus Coordinator).

In my own experience as an LIX literacy coach, there were childcare centers where parents dictated how they were run. There were no consequences to disruptive student behavior, in fear of complaints from parents, since they could opt to take their child to another center. The literacy coaches helped directors, childcare providers, and even parents, to understand the importance of the literacy skills the children needed to 
learn and the structure that was needed to teach those skills. "Behavior had been an issue at the beginning and now [at the end of the project] they [the childcare providers] have better classroom management" (Techno-Lit CT Coach). Some literacy coaches did this by assisting childcare center directors and providers; they planned parent-information meetings and at times even spoke at these meetings.

Still another issue, which is inherent of the setting, a multicultural county, was language. A large portion of childcare center providers either did not speak English well or did not speak it at all. In this case, most of these childcare providers spoke Spanish. Trainings and lesson plans needed to be available in both Spanish and English. This caused the coordinators to have to do more work in planning trainings and translating lesson plans and other materials. "Out of 37 centers, six centers only spoke Spanish. I never expected to have to translate lesson plans into Spanish" (Techno-Lit Coordinator).

For the Techno-Lit team, this was even further complicated, because they were assigned a Haitian-Creole center that felt "left out" since they didn't have equal support in their language. "The Haitian Creole center was upset because they had no material translated for them. They had some teachers and students that didn't speak English or Spanish" (Techno-Lit CT Coach).

All three coordinators were bilingual (Spanish and English). The original central agency coaches for Add-on Literacy and Techno-Lit were not bilingual and neither were the public school teachers for Literacy Plus and Techno-Lit. The coordinators of all three teams did the difficult task of translating lesson plans and trainings.

Another obstacle that was continuous and inherent to this project was the overwhelming task of motivating these underpaid overworked childcare providers to put 
forth a great amount of effort to not only learn a new curriculum, but implement it effectively. "I can't believe the amount of work that these underpaid teachers do. They clean the classroom and feed the children in addition to trying to teach" (Literacy Plus CT Coach).

None of the childcare providers had earned a college degree in education. Many of these childcare providers, even those that spoke English proficiently, lacked the skills to teach literacy to young children. Furthermore, some had not been trained in early childhood development, let alone pedagogical practices. Teaching a literacy curriculum was a huge challenge for many of the childcare providers. "Many of the childcare providers conducted developmentally inappropriate activities before we came along" (Techno-Lit CT Coach).

Many childcare providers worked long hours, from early morning to early evening. It was not uncommon for a childcare provider to work 10-12 hours a day. "Teachers [childcare providers] complained about the pressure to teach curriculum, administer assessments, and learn a new curriculum while still getting paid minimum wage" (Techno-Lit TA Coach). Even with the lack of experience or formal education, the majority (two-thirds) of the centers across all three curricula, in Year Two, achieved full implementation.

Indifferent and uncooperative childcare directors had little interest in improving the quality of their center. This was yet another obstacle all teams faced.

I was surprised by the lack of interest of some directors and teachers [providers]. Some teachers complained that they had no choice but to participate, because their director decided for them. They did not expect all this work: trainings, planning and fulfilling expectations. It was a big 
change for teachers who had been working differently for so long. (Techno-Lit TA Coach)

Childcare centers were not forced to participate in Literacy Intervention X; they were randomly selected from a list of centers that voluntarily agreed to participate in the study. Therefore, the literacy coaches expected them to be willing to comply with what was expected of them. This was not the case some directors made it difficult for their childcare providers to implement the curriculum.

There are the few that don't care about teaching or children and are wasting crucial time in these children's development. I was also disappointed by the materials, support, and time going to waste. (Literacy Plus CT Coach)

Directors went as far as keeping materials locked up in closets that were not accessible to teachers, let alone to the students they were meant to serve. "In the centers with directors that were not supportive, I had to work harder to encourage and support the provider" (Literacy Plus Coordinator). Across all three curriculum teams, for the most part the childcare centers they rated high had supportive directors and childcare centers they rated low had a director that was not supportive. However, in some cases childcare center providers were still successful, despite indifferent or unsupportive directors.

All of the literacy coaches echoed the perspective that the number of agencies collaborating in this project made working cohesively difficult. In Year Two, this was heightened by the change of administration of the local coalition, since one of its former administrators was an individual credited with initiating this project. The new local coalition administrator was not very supportive of the project leader, a coalition employee. One of the curriculum coordinators said she did not expect there to be such a 
"disconnect" among the members of the project and such little contact with the research agency and the local coalition.

I wasn't sure if I was doing what I was supposed to, for this project. I felt that with so many organizations involved, there was not enough communication between them... from the beginning there were no clear roles for anyone: the research agency, the local early learning coalition, the central agencies, the coordinators, or the coaches. (Literacy Plus Coordinator)

There was a lack of systematic communication between the collaborating agencies and the curriculum teams. The number of agencies involved resulted in information requested from teams at the last minute, instead of knowing what was expected upfront. An example of this occurred in the beginning of Year Two. We were asked for a monthly rating for each childcare center on a $0-5$ rating scale (after the fact).

Still another obstacle was that the setting of LIX is a large county and childcare centers were spread out. Some were twenty miles from each other. Some coaches complained about the stress of driving in traffic.

The only negative aspect that really got to me in LIX was the distance of most of the childcare centers from my home or from each other. Most were about 20 miles away. I found myself getting home after 6 p.m. because of traffic. (Techno-Lit TA Coach)

"I spent too much time driving long distances in traffic. It really took a toll on me" (Techno-Lit Coordinator). However what made it an obstacle was attempting to visit an extra center that needed help, if the center the literacy coach was scheduled for was far away. The distance between centers made it difficult to sometimes give centers more frequent visits.

These obstacles may have been negative aspects of the LIX project; however, learning how to deal with them helped the literacy coaches turn them into a positive 
outcome. The literacy coaches themselves developed professionally as mentors from what they learned. Through the process, they improved their mentoring practice as well. The following section highlights what they consider to be the best mentoring practices of LIX.

\section{Best Mentoring Practices}

This last section begins by highlighting the best mentoring practices in LIX, from the perspective of the literacy coaches. As was mentioned before, mentoring childcare in a 2-year study was a new experience for all the participants. Along the way, there were things they learned. They became aware of successful aspects of the practice of mentoring within this context. This section includes indicators of success, the evidence the curriculum teams observed as proof of success in mentoring.

The most critical aspect of mentoring from what the LIX literacy coaches shared from this experience is building relationships which included trust, mutual respect, support, empathy, and encouragement with the childcare providers, the center directors and with fellow literacy coaches. When asked about motivating low paid, overworked childcare providers to put forth a great effort in learning and effectively implementing a new curriculum, one coordinator stated, "The relationship with the literacy coach made the providers feel committed to doing a better job" (Literacy Plus Coordinator).

The literacy coaches knew how childcare providers felt about them, by their interaction and conversations with them during mentoring sessions.

Teachers [childcare providers] would tell me how nice it was to hear from me what they were doing right, instead of what they were used to from other people that visited them that only pointed out all they were doing wrong. (Techno Lit CT Coach) 
Just like a coach for athletes, these literacy coaches used encouragement and support to mentor childcare providers in teaching the curriculum better. "Even at the worst rated centers, I would search for something positive to say to the providers to build their confidence and promote improvement" (Literacy Plus CT Coach).

Mutual respect between the literacy coach and the childcare providers was something the coaches expressed to be important in building a relationship with them. "Teachers [childcare providers] often told me that now [at the end of LIX] they felt like 'real teachers' instead of 'babysitters"” (Literacy Plus TA Coach).

Throughout the study, the literacy coaches referred to the childcare providers as teachers, not providers.

I knew where they were coming from, maybe I had more formal preparation in my education, but I knew what it was like to teach 4-year olds in this community. Some of my teachers [childcare providers] at the end were better than any public school Pre-k teacher. I feel as though if I would go back to the classroom, I would be a better teacher than I was before the project. (Techno-Lit CT Coach)

Although they did not meet the criteria to be a teacher (i.e., a B.S. degree in Education and state certificate), they were always treated as teachers by the literacy coaches.

Further, the participants articulated that clear, constant, and consistent communication with the childcare providers is a vital element in building a relationship between the literacy coach and childcare provider. The Techno-Lit Coordinator expressed, "The providers were able to communicate with the literacy coach assigned to them via telephone calls and e-mail in between consistent visits every other week."

The literacy coaches would state specific recommendations they would like to see in their next visit, both verbally and in written form. This fosters a level of comfort and 
security. Childcare providers were not intimidated by the coach; they were glad to see them as explained by the Literacy Plus CT Coach. "They were happy to see us, we would get there and the provider would welcome us with hugs and kisses." Their level of comfort and security was also evident in that they were not afraid to ask questions or clarifications.

Another practice that the Literacy Plus team highlighted as critical to effective mentoring is the relationship within their team of literacy coaches. Literacy Plus was the most consistent, cohesive, and collaborative team as demonstrated by the frequency of their communication and interaction and their mentoring visit plans. They met formally on a monthly basis, but they visited the centers as pairs or as a team more often than Addon Literacy and Techno-Lit. The Literacy Plus Coordinator also spoke with the coaches on the telephone daily. They also had the advantage of consistency in that the TA coach remained for the duration of LIX, unlike her counterparts: the TA coach in Add-on Literacy and Techno-Lit, who were both replaced in the last 2 months of Year One. They did not always agree, however, this is what the Literacy Plus CT Coach had to say about how they dealt with disagreements:

Because we all came from different backgrounds with different ideas, we made a pact at the beginning of the project that if we disagreed on something, we had to come to a consensus in making the decision and we had to stick to it.

When asked about positive experiences in LIX, the Literacy Plus team members' first remarks were, "I was so satisfied and happy to work with such a great team" (Literacy Plus Coordinator) and "The team work was great, it made my job a lot easier. We have 
different personalities and ideas, but we worked well together, thanks to our coordinator" (Literacy Plus CT Coach).

According to all three team members, their personalities complemented each other and they respected one another. They listened to each others' ideas and although they did not always agree, came to a consensus on what they were going to do. However, Techno-Lit was also a collaborative team with a coordinator that, like the Literacy Plus coordinator, treated her fellow literacy coaches as equals.

Our coordinator treated us like equals and every decision that was made was a team effort. Our input [the two literacy coaches] was just as important as her input. For everything, she would ask us: "What do you think?" If we disagreed and it was justified, then the decision was changed. (Techno-Lit CT Coach)

She always asked for her teams input and came to a consensus on decision making. The Techno-Lit TA Coach had this to say about her team's collaboration, "Having the support from my team to be able to visit the centers more often and intensively has really helped our weakest centers" (Techno-Lit TA Coach). She believed that team work is what really made the difference in meeting the needs of the centers they rated low in the implementation of the Techno-Lit curriculum.

A practice critical to mentoring, echoed by most of the coaches was they viewed themselves as co-learners in the mentoring process. They grew professionally along with the childcare providers they mentored. This was something they realized because of the reflections many of them practiced throughout the process.

I developed certain skills that I was not using when I was in the classroom. I was able to reflect on my teaching career and look at the things that I could have done to improve on as a teacher myself. At the same time, I also looked back and said to myself "I did a good job in that area". Being in the classroom, you really don't get to go out and compare yourself to 
other teachers, you are isolated. I feel like I have grown by helping other teachers [childcare providers]. I grew along with my teachers. (TechnoLit CT Coach)

As a coach myself, I have to agree with that point. As a researcher in this study I was constantly reflecting on my own mentoring, which forced me to improve my practice. Like the Techno-Lit CT Coach, I too could not help but compare my teaching to the childcare providers. At times, I felt good about my teaching skills, yet at other times, I thought to myself, "Wow, I should have done this or that when I was teaching in my own classroom" (referring to something I observed a provider do).

Still another best practice that can be attributed to both the literacy coaches and their support from developers and collaborating organizations, is the ability to meet childcare providers needs in a timely manner. "Unlike other organizations I had worked for before, solving problems that were time sensitive by being able to "cut the red tape" with the help of our developer, was a big positive of LIX" (Add-on Literacy Coordinator).

The literacy coaches felt more in control when making decisions to help the childcare providers, unlike when working for either the central agency or a large school system where certain protocols must be followed before making a decision. "I was so happy for the flexibility I had and for being given the opportunity to be in control of what I was doing" (Techno-Lit CT Coach). The Literacy Plus CT Coach said the following after LIX was over and she had worked in a mentoring position for the school district for almost a year. "I was extremely satisfied while working in LIX, the team work was great. A lot was left up to my own initiative, unlike working in the school system district office" (Literacy Plus CT Coach). In LIX, they did not stumble upon the "red tape" 
associated with most large bureaucratic organizations. This, according to the LIX literacy coaches, helped them meet the childcare providers' needs more efficiently.

The nine participants extracted these best mentoring practices from the practices they considered successful in their mentoring of the childcare providers. To support these practices as best strategies, they had to have evidence of success from applying them. This evidence was found in the success they observed because of their mentoring. In addition to LIX researchers' evaluations of progress, such as: student yearly pre and posttests and childcare center environment observation scores, there were also observable indicators of success for each curriculum. The success of centers demonstrated by LIX measures may be attributed to the variables of both the curriculum and the mentoring. The following section discusses some of the indicators of success that the literacy coaches attribute mostly to their mentoring.

The centers that the literacy coaches rated as successfully implementing their curriculum possessed some common attributes. The childcare providers in those successful centers became accustomed to planning, using available resources and materials and adequately preparing those materials so that they would be accessible to them during the lesson. "A validator from a national accreditation association for childcare centers, was very impressed with success of one of our childcare provider's ability to use various resources, plan lessons and improve her teaching skills" (TechnoLit Coordinator).

For all three curricula, teaching childcare providers behavior management skills was challenging and greatly influenced how effective the curricula was implemented. The consensus among the literacy coaches was that the more consistent the routine and 
adherence to the lesson plan and of the structure of the curriculum, the better the behavior, and vice versa. "Behavior management was an ongoing issue that had a major impact on the curriculum implementation. The better they stick to the curriculum and schedule, the better the behavior and implementation" (Literacy Plus Coordinator).

The literacy coaches observed evidence that the childcare providers were internalizing what they were doing, reflecting upon it, and coming up with ways to improve their teaching. This evidence was a combination of the following: discussions with the childcare provider, interactions between the providers and their students, improvements in the classroom environment, observations of lessons, and ultimately the monitoring of students' learning. As a literacy coach, while observing a childcare provider during mentoring sessions, I would frequently see her add something to the lesson or to the environment that we had discussed at a previous session.

All the literacy coaches experienced the satisfaction of witnessing the progress in childcare centers receiving accolades in Year Two from the neighboring public school kindergarten teachers of the Year One students that had mastered those readiness skills. These same childcare centers began LIX with no objectives or standards to follow. The Techno-Lit TA Coach further explains:

They [the childcare providers] had positive feedback, not only from the directors and parents, but also from the kindergarten teachers of the Year One students as well. They noticed that they were better prepared than the groups that had come from the center in prior years.

This feedback was given to the childcare providers, and they in turn relayed it to their literacy coaches. Whenever the childcare providers received positive feedback from 
parents, the director, or anyone, they proudly shared it with their literacy coach. This is something all nine participants experienced.

Having been recognized for their success, most childcare providers for the first time sought professional development on their own. The Techno-Lit CT Coach explains, "These providers felt empowerment by LIX. I watched them transition from viewing themselves as babysitters to 'teachers', many of them have enrolled in English classes, CDA courses and even college courses."

Childcare providers, some with no experience or formal education preparation beyond high school, were motivated to enroll in English classes, Early Childhood Classes, and take Child Development Associate Certificate (CDA) and Teacher Education classes at the college level. The Literacy Plus Coordinator recalls what a childcare center provider told the team.

When you came into my life, I felt like a babysitter. The kids were clean and I fed them. The center remained clean. We showed them some movies, and the parents were happy. But I was just a babysitter. Now I feel like a real teacher, because I can compare when I got them [the students] to where they are now. Having assessments that I can show parents this is where they were and now they here. This is so rewarding and it is a direct part of the mentoring process. (Literacy Plus Coordinator).

According to the literacy coaches' perspective across all three curricula, many of these non-degreed childcare providers at the end of LIX were teaching at the same level or even better than a degreed teacher.

An indicator of the success of the project in general across all three curricula is the quest of childcare center providers and directors in improving quality. This was evidenced by the number of childcare centers that became accredited or were working 
towards accreditation. There was an increase of centers working towards accreditation across all three curricula centers according to LIX project documents. The literacy coaches attribute this quest for quality improvement both to the success of the curriculum implementation and mentoring. They felt that the encouragement they received from the literacy coaches reassured them they were capable of taking that next step.

In presenting the findings according to the themes that emerged from the data, several points of discussion were elicited that will be analyzed further. The next chapter continues to examine these themes in relation to the research questions that guided this study. The section will delve deeper into the themes and the possible conclusions that can be made from the data analysis and implications for further research in this area. 


\section{CHAPTER V}

\section{DISCUSSION, CONCLUSION AND IMPLICATIONS}

The findings from this case study are primarily based on the data concerning the perceptions of the LIX literacy coaches. As a participant-observer in the study, my perceptions are included. This chapter discusses the findings and interprets how the results relate to the literature and research questions. As the researcher, I drew conclusions and lessons learned from the LIX mentoring practices. In addition, implications of perceived best mentoring practices are drawn from this study for designing and implementing other literacy intervention projects that involve mentoring in a subsidized childcare system. Finally, recommendations for mentors, project designers, and future research are proposed.

The purpose of the study was to describe and analyze the experiences of nine Literacy Intervention X coaches in order to identify the best mentoring practices of LIX. The mentoring by the literacy coaches in assisting the implementation of the literacy curricula to non-degreed childcare providers, were not examined by the LIX study. This purposive group was selected because it represents an intact group that shared the experience of mentoring childcare providers in a literacy intervention project, specifically LIX. Research shows that children who experience early difficulties in learning to read are at risk for later school failure (Dickenson \& Tabors, 2001; Hart \& Risley, 1995; Lonigan, 2000; Podhajski \& Nathan, 2005; Purcell-Gates, 1988). As a result of this research, there have been numerous literacy intervention programs that are currently being implemented in childcare centers throughout this multicultural setting. These endeavors demonstrate a need for improving the quality of instruction of early literacy in 
the childcare system. In exploring the role of mentoring, as the researcher, I investigated literacy coaches' perceptions concerning what best mentoring practices facilitate the implementation of literacy curricula by childcare providers.

\section{Responses to Subsidiary Research Questions}

While three of the categories that emerged from the data can be directly linked to the subsidiary research questions, relationships emerged as a category during the focus groups. This chapter is organized to convey responses to the research questions and its corresponding category. The fourth category, relationships is discussed in the same manner.

\section{Subsidiary Research Question One}

The first subsidiary research question asked about the impact of preparation and training on the mentoring practices of the literacy coaches. Preparation and training alludes to the formal education and experience in the field of early literacy education that these literacy coaches brought with them when hired for LIX. However, it can also denote the training that they received once they were hired. The impact this preparation and training had on the mentoring practices includes their expectations at the onset of the project.

At the beginning of the project, the literacy coaches' expectations factored out more on professional affiliation (public school teachers versus technical assistant) than literacy curriculum affiliation. Their initial affiliations were related to differing roles in their former position-one as a monitor, and the other as an instructor. When interviewed about initial expectations, each literacy coach expressed an ambiguous understanding of her role in the project. All of them discussed their perspectives based 
upon their former positions. Therefore, the certified teachers described their expectations of the role to be in an instructive capacity developing pedagogical skills, whereas the technical assistants described it in a monitoring capacity of meeting standards.

Two of the coordinators were former technical assistants (Add-on Literacy and Techno-Lit), while the other was also a certified teacher (Literacy Plus). The two coordinators that were former technical assistants viewed their job as monitoring in an administrative capacity. Each expressed that they were responsible for mentoring two literacy coaches assigned to their curriculum. However, the administration of that mentoring for the Techno-Lit Coordinator was a hands-on approach where she expected to be out in the childcare centers on a daily basis along with her team members. The opposite is true of the Add-on Literacy Coordinator who expected the role to be more of an office position overseeing the mentoring of the literacy coaches in her team.

Unlike the other eight literacy coaches, the Literacy Plus Coordinator had the advantage of 5 years experience assisting others in implementing the curriculum. Although her experience was in a different context (in another state with degreed teachers in a public school system), she had extensive experience in teaching others how to implement it. She would work with about 80 degreed teachers for a period of 3 years in implementing Literacy Plus. Her expectation was that working with 36 childcare center providers more intensively (frequently visiting them on a consistent basis) with the help of two other individuals, in her own words, "Would be great!" She began with a very organized, systematic plan and expected her role to be guiding the other two literacy coaches in working collaboratively. According to the data derived from the focus groups, 
all the Literacy Plus team members repeatedly referred to her role as accomplishing the goal of collaboration.

In addition, project designers gave the literacy coaches a vague description of what their role entailed. Therefore, each literacy coach's understanding of what was expected of them was based on what limited information they were given. They were not given a detailed job description. From previous studies, clearly defined roles and expectations are an important mentoring practice (Andrews \& Quinn, 2005; Rowley, 1999; Giebelhaus \&, Bowman, 2002). In this current study, only the Literacy Plus Coordinator had a clear definition and understanding of her role as a literacy coach and coordinator in comparison to the other literacy coaches. She understood that the childcare centers would be divided in half and assigned to the two coaches who would provide assistance with visits a minimum of once a month. She had the experience of training teachers how to teach the curriculum, yet expected that assisting non-degreed childcare providers would require more consistent and frequent visits. From the onset of LIX, she organized a systematic structure that assured each childcare center would receive a minimum of three visits per month (two from the coach and one from her).

Formal training of mentors as a prerequisite to mentoring that defines and emphasizes the importance of their mentoring role, is critical in effective mentoring programs (Andrews \& Quinn, 2005; Giebelhaus \& Bowman, 2002; Rowley, 1999;). There was no formal mentoring training in LIX. The only training each of the literacy coaches received was in their respective literacy curricula. The literacy coaches agreed that being a capable technical assistant or a capable teacher, does not necessarily qualify one as a capable LIX literacy coach. The project designers failed to provide formal 
training in mentoring. Mentoring as defined in the literature, encompasses many functions in addition to monitoring progress and teaching pedagogy. The role of mentoring includes: being a teacher, confidant, sponsor, "opener of doors," role-model, developer of talent, protector, successful leader, consultant and advisor (Schmidt \& Wolfe, 1980). Whether they were aware of it or not, each of the literacy coaches was charged with the task of defining the role of mentoring either on their own or with their team.

Differences in professional background and experience may have been viewed as a benefit to cohesive teams open to each others' ideas but; on the contrary, it added to the divisiveness of un-collaborative teams. Cohesive teams, like Literacy Plus and TechnoLit composed of literacy coaches from different backgrounds, collaboratively defined what the mentoring role was, by combining their prior experience and knowledge to this new situation, LIX. The opposite is true of Add-on Literacy, where the lack of collaboration and cohesive decision-making caused differences in experience to breed more disagreements and a power struggle.

The advantage of the technical assistants is that they had prior experience in the childcare system. They understood regulations that must be followed and standards that must be met. They knew what to expect at a childcare center, and the culture of the childcare system in this particular community. Some had even worked with particular directors and providers in the past. They spoke their "language" and understood their world. Their experience, however, was working with the childcare center in general, from infants to preschoolers, not specifically teaching the four year old classrooms. Most of the former technical assistants had worked in childcare centers themselves in the past. 
Unlike the technical assistants, the certified teachers had many years of experience. They also had the experience of instructing 4-year old students and assisting student teachers and beginning teachers in pedagogical skills and classroom management. They were former early childhood teachers in the public school system that would eventually receive these childcare center children as their students. Thus, they were very aware of the readiness skills that the childcare providers needed to teach. Therefore, although working in the childcare system may have produced some "culture shock" at first, they contributed with their knowledge of strategies of teaching instruction.

The literacy coaches from each of the two collaborative teams, Literacy Plus and Techno-Lit, drew from their prior experience to collectively create a definition of mentoring as a team. The Add-on Literacy team members, on the contrary, did not benefit from what their team members had to contribute. On the contrary, the definition of the role and the mentoring strategies of each Add-on Literacy team members varied and became a source of tension. As the only certified teacher in the Add-on Literacy team, I had the experience of interacting with my team and felt the tension that existed between the coordinator and me. We did not always agree on mentoring strategies, and unlike other teams, disagreements were not fully discussed until common ground was reached. In other words, unlike the other two literacy teams that came to a consensus when there was a disagreement on a particular mentoring practice, the Add-on Literacy team members each had their own mentoring style and strategies. Therefore, the mentoring practice was not consistent within our curriculum team; each literacy coach held her ground and mentored the way she saw fit. 
The second subsidiary question asked about the mentoring practices that the Literacy Coaches perceived as producing the best results in preparing subsidized childcare providers to implement literacy curriculum. Of the mentoring practices employed by the LIX literacy coaches, there were some that they perceived as most effective as measured through indicators of success, such as curriculum monitoring systems (including observations) and LIX student assessments. These were the best mentoring practices that either all or the majority of the nine LIX literacy coaches highlighted as having more impact.

All the literacy coaches agreed that to mentor someone, you need to have had a similar experience or "been in their shoes." In some way, all the literacy coaches had a similar experience to the childcare providers they mentored. The TA coaches had the experience of working in a childcare center. The CT coaches had the experience of teaching 4-year old students. Having the experience of the protégé helps the mentor empathize and understand the protégé, thus building trust in the relationship (Rowley, 1999). One of the most critical aspects of developing the mentor relationship is trust (Glazer \& Hannafin, 2006; Patton et. al, 2005). In order to build trust, novices must feel comfortable, feel that the mentor understands their role, and perceive the mentor's assistance as valuable (Patton et. al, 2005; Scheetz et al., 2005). It is important for the mentor to know where the protégé is coming from in order to share their own struggles and frustrations and how they overcame those obstacles.

Another best mentoring practice identified by the CT coaches was becoming colearners in the mentoring process. In the literature on mentoring, mentors are partners 
with the protégé (i.e. novice teacher) in learning how to become more effective teachers (Fairbanks et al., 2000; Rowley, 1999; Scheetz et al., 2005). This was not just a pretense on the part of the LIX literacy coaches they would actually express to the childcare providers how much they were learning from them as well. Mentors recognizing their capacity to learn from their less experienced colleagues, is an indicator that they do not have all the answers. That is a critical aspect of effective mentoring (Fairbanks et al.). Inevitably, good mentors learn from those they are mentoring, no matter how much teaching experience they may have (Patton et al., 2005; Rowley, 1999; Scheetz et al., 2005). The CT Coaches (former public school teachers) all mentioned acquiring some good ideas from the childcare providers. All the CT coaches also mentioned at one point having told some of the providers that their teaching was at the same level or better than she or any public school teacher. Good mentors are transparent about their own pursuit for professional growth and search for their own answers to problems (Fairbanks et al., 2000; Rowley). As mentors who were learners too, the protégés (i.e., childcare providers) were able to see themselves as a co-teacher with the mentor.

One practice that all LIX literacy coaches did that indirectly demonstrates their treatment of the childcare providers as an equal partner was referring to them as "teachers" when speaking to them or about them. This in itself made the childcare providers feel more professional. Many of the childcare providers actually thanked the literacy coaches for helping them feel like a real teacher as opposed to a babysitter at the end of LIX. Self-efficacy, defined as the judgment of one's capability to organize and execute courses of action required for the acquisition of designated types of performances, can also be affected by a mentoring relationship (Glazer \& Hannafin, 
2006). Generally a high self-efficacy tends to perpetuate success, while the opposite is true; a low self-efficacy may promote failure (Glazer \& Hannafin). Taking the stance of a co-learner and partner, the LIX literacy coaches, both in words and actions, fostered a high self-efficacy for childcare providers. This high self-efficacy not only made them feel capable of implementing a literacy curriculum as well as their counterparts could (degree public school teachers), but some even went beyond that to take college courses.

\section{Subsidiary Research Question Three}

The third subsidiary research question asked if differences in the three curricula influenced the mentoring practices provided by the Literacy Coaches. This question alludes to differences in curriculum as a variable in mentoring practices, whether the curriculum differences made a difference in the mentoring practices from team to team. All three Curricula shared the same four basic literacy components. Research on child development and emergent literacy identifies these four components as the key domains that are strong predictors of subsequent literacy development: oral language development, phonological sensitivity, print knowledge and print motivation (Dickenson \& Tabors, 2001; Lonigan et al., 2000; Podhajski \& Nathan, 2005; Whitehurst \& Lonigan, 1998). The three curricula, while grounded in a common set of research findings, differed in intensity, pedagogic strategies and use of technology.

The literacy coaches did not feel that differences in curricula affected their mentoring practice. What one literacy coach suggested was that the intensity or amount of time spent at a center for either of the two full-day curricula (Literacy Plus and Techno-Lit) affected the mentoring practice in increased time spent at the childcare center. Research indicates that increasing the number of hours of training produces more 
developmentally appropriate behaviors in childcare staff (Fiene, 2001). Thus, the curriculum requiring more time spent (i.e., intensity) at the center mentoring for full implementation, may have made a difference, more than other curriculum differences (i.e., technology or pedagogic strategies).

Increased time spent at the center inevitably causes increased interaction between the literacy coach and the childcare provider. Add-on Literacy coaches on average spent two hours a day at a center; whereas literacy coaches for the other two curriculum teams spent minimally four hours a day at a center. The Literacy Plus team frequently spent the full day at a center, especially in the first year. In the second year, at times they were able to visit one center in the morning and another in the afternoon. This increased interaction and communication contributes to the building of a relationship.

Another difference between curricula that had no connection with its literacy components was the level of structure of each team's monitoring system. This may have affected the mentoring practices, hinting to how structured mentoring sessions varied from one curriculum team to another. For example, Add-on Literacy's portfolio was not well-structured. Space was provided for anecdotal notes that answered brief questions about the lesson. In addition, the Add-on Literacy team rarely reflected as a team or discussed in a consistent, formal manner, ways of meeting their childcare center providers' needs. Literacy Plus and Techno-Lit teams both had formal monitoring systems and met often to reflect on a consistent basis. These teams also visited each other's centers and created a mentoring style for their team. These monitoring systems and constant reflective practices structured the mentoring visits in a more formal and consistent manner within those two curriculum teams. 


\section{Relationships}

By the end of the 2-year intervention, the attitudes, expectations, and allegiances were more squarely aligned by curriculum teams than by their original affiliation. As the findings showed the Add-on Literacy and Literacy Plus developers were very supportive of their literacy coaches. However, the findings also report that the Add-on Literacy team was not a cohesive, unified team like Literacy Plus and Techno-Lit teams. Thus, unlike the other two, any allegiance for the Add-on Literacy team was more likely due to their loyalty to the curriculum developers than their fellow literacy coaches. The teams differed in the level of collaborative support the literacy coaches provided for each other and frequency of communication in mentoring childcare providers. Two teams followed a systematic way to collaboratively plan support for their fellow literacy coaches, while the other team's literacy coaches just supported each other when asked by the developer or a fellow literacy coach.

As a member of Add-on Literacy myself, I have no idea what my fellow team members did during their mentoring sessions, simply because we rarely discussed it. Unlike Literacy Plus and Techno-Lit, the Add-on Literacy team rarely made center visits in pairs and did not visit centers as a team at all. The visits were neither planned nor executed in a systematic way by each team member. Each literacy coach planned her own bi-weekly visits for the childcare centers assigned to her without input from team members, unless there was a center with a serious issue that was discussed with the developer.

Even the distribution of the centers was inconsistent and very different from the Literacy Plus and Techno-Lit teams. They did not have half the centers assigned to each 
of the literacy coaches like Literacy Plus or the coordinator visiting all of them at least once a month like the Literacy Plus and Techno-Lit teams did. The Add-on Literacy reassigned centers throughout both years of LIX. Of the three curricula, the most consistent in center assignments was Literacy Plus.

The Literacy Plus and Techno-Lit teams also met and discussed mentoring strategies as a team and assisted each other in mentoring their lowest rating centers. This may have attributed to a more consistent mentoring style and practice in the centers assigned to those two teams as opposed to those assigned to Add-on Literacy. Furthermore, if there were to be a change in center assignment, the transition would be smoother than for Add-on Literacy, because the literacy coaches of the other two teams in visiting each others' centers, developed a relationship with all the childcare providers assigned to their curricula. This was not the case for Add-on Literacy, when centers were reassigned since most of the centers assigned to the CT Coach were never visited by the TA Coach and vice versa. They had to build the relationship from scratch.

Reassignments in Add-on Literacy throughout the project may have affected the building of relationships between literacy coaches and with childcare providers. Research in mentoring indicates that building mentoring relationships is an on-going process that takes time to develop (Fairbanks, et al., 2000; Fairbanks \& Meritt, 1998; Maynard \& Furlong, 1993; McIntyre \& Hagger, 1993, Vinz, 1996). Relationship building between Add-on Literacy coaches and providers were not only affected because of starting over with a new literacy coach, but also because of the lack of a systematic and consistent method among all three literacy coaches in mentoring childcare providers in the Add-on Literacy team. The mentoring of childcare providers was almost 
completely the independent duty of each of the literacy coaches with little or no input from team members. Therefore, each Add-on Literacy coach did things differently.

The Add-on Literacy Coordinator towards the end of the project admitted that in Year One, she had difficulties leading the team. She had worked with the central agency with the original Add-on Literacy TA Coach, but in a different capacity as a technical assistant. She admitted that team disagreements were not addressed properly and that she should have been more open to suggestions from the other Add-on Literacy coaches. The role of coordinator was not the administrative role she was familiar with in the central agency. The administrative duties of the LIX coordinators, was the organization of team structure and the data collected for the researchers. Both the Literacy Plus and Techno-Lit coordinator understood their role from the beginning to be one of three in a team with extra duties and responsibilities. The coaches from both these teams mentioned their coordinator valuing their input and treating them as equals. Their team structure and support from team members demonstrated that systematic, collaborative, and cohesive view, whereas, the Add-on Literacy coach did not. This demonstrates the overlap in clearly defining the role and its impact on relationships.

The Add-on Literacy TA Coach was at a disadvantage in terms of relationship building with the childcare providers because of the lack of collaborative support and of systematic structure of her team. She replaced the original TA coach in the last two months of Year One. During the first two weeks of the hiring of the TA Coach, the Addon Literacy Coordinator met with her daily in the office to help her organize her childcare center files, instead of visiting centers as did the other replacement TA Coach with her coordinator. The centers assigned to her suffered a gap in visits of about a month 
between the time the original TA Coach left her position and the time she began visiting centers. One of the most critical aspects of developing the mentor relationship is trust (Glazer \& Hannafin, 2006; Patton et. al, 2005). When protégés realize that they can depend on the mentor, trust grows (Harrison et al., 2006; Patton et. al, 2005). The TA Coach had to start building a relationship with all the childcare providers assigned to her, who had been abandoned by the curriculum team for about a month. After spending over a month without any mentoring visit support, the message these childcare centers received was they could not depend on the Add-on Literacy team.

Thus, if trust grows from dependability, and it is one of the most critical aspects of the mentoring relationship, it is no surprise that 9 out of the 16 Add-on Literacy childcare centers rated low at the end of Year One. When she began visiting the centers, there were only 2 months of mentoring left for Year One. Thus, all she could possibly do was begin the relationship building before the long summer break.

Variables, such as attending the general Add-on Literacy training sessions and receiving the curriculum materials, were the same for the rest of the Add-on Literacy childcare centers. The one difference was the absence of support from the mentor. The fact that more than half of the centers were not at full implementation can be attributed to the lapse in mentoring because all other variables (i.e., receiving the general curriculum training session and the curriculum materials) remained the same in these childcare centers.

The other curriculum team that replaced the TA coach in Year One was TechnoLit. However, they had the technical assistant that acted as a translator for the original TA Coach take over almost immediately. There were only a couple of weeks of a lag in 
replacement. During those weeks, the Techno-Lit coordinator visited the TA coach's centers that were due a visit to not disrupt consistency. When the replacement TechnoLit TA Coach began visiting the centers as their new literacy coach, she already had developed a relationship with most of the providers since she had been the translator. The Techno-Lit coordinator went with her to the few childcare centers that were assigned to her for the first time to introduce the new team member (the replacement TA coach) and in the transition (from the original TA coach). Thus the Add-on Literacy TA Coach had the greater disadvantage in relationship - building of the replacement TA coaches.

\section{Response to Primary Research Question}

The primary research question asked about the mentoring practices used by Literacy Coaches in preparing subsidized childcare providers to implement curriculum in Literacy Intervention X. The mentoring of childcare providers in LIX included: developing a positive relationship with the childcare center providers and directors, monthly observations of the childcare provider teaching a lesson with structured feedback, assuring that all necessary resources and materials are available to implement the program, and modeling of lessons by the coach. This support took place in the real world setting of the childcare center. Mentoring visits to the childcare centers took place on average two times per month.

At the heart of the practice of mentoring is the conscious reflection of teaching with another individual (Chase et al., 2001; Fairbanks et al., 2000; Hole, 1999). In addition to verbal conversations, conscious reflection can be in the form of written dialogue (e.g., a portfolio, log or journal), where a protégé discusses their practice through notes, concerns and questions with the mentor (Brennan, 1999; Fairbanks et al., 
2000). In LIX this conscious reflection of practice was demonstrated by all the literacy coaches with the childcare providers. All three curricula had a monitoring system that included some type of written account of the mentoring session and what was needed for improvement.

Additionally, the Literacy Plus and Techno-Lit teams also engaged in the conscious reflection of practice of the mentoring itself with fellow literacy coaches. This was also done both verbally and in written form in their monthly calendar and plan for the following month's mentoring visits of their childcare centers. This contributed to collaborative effort in improving the practice of mentoring for these two curriculum teams.

Another mentoring practice that these cohesive teams, Literacy Plus and TechnoLit engaged in, was collaborative planning and support that benefited from the differences in experience and professional background. Conversely, the Add-on Literacy team did not collaboratively plan or support each other, and these differences were sometimes a source of disagreements that added to the divisiveness of the team. Literacy Plus and Techno -Lit literacy coaches suggested that mentors work better as small cohesive teams. Mentors themselves need to have colleagues to not only encourage them, but offer them support when they need it (Patton et al., 2005). The two cohesive teams capitalized on each other's talents when assisting a fellow literacy coach's childcare center. For example, if a team member was an expert on room arrangement, she would help any center assigned to the curriculum that had difficulty in that area, either on her own, as a pair or as a team. 
From the beginning, the Literacy Plus team accepted their different backgrounds and expected disagreements. However, they made a pact to always come to a consensus on their mentoring practice. The Add-on Literacy team's disagreement on mentoring strategies and practice stemmed from differences in their prior experience. Instead of acknowledging each other's experience and coming to a consensus on how to better assist low rating centers, each member did what they saw fit, which only harbored further independence. The mentoring research experts agree that on-going support for the mentor is an important component of effective mentoring practices (Anderson \& Shannon, 1988; Cullingford, 2006). This is why the original LIX mentoring design of half the centers assigned to each of the two coaches with the coordinator providing ongoing support by visiting all the centers worked so well for Literacy Plus.

Research on mentoring in education indicate that mentoring practices include assisting in finding appropriate teaching materials and other resources, lending an empathetic ear or shoulder, and discussing and reflecting on content and pedagogy, all for the purpose of providing positive professional growth for the novice teacher (Glazer \& Hannafin, 2006). Mentoring practices in LIX included finding resources, making materials, listening and empathizing with childcare providers. LIX mentoring practices also include: discussing and reflecting on the literacy curriculum and pedagogy with the goal of effectively implementing literacy curricula and providing positive professional growth for the childcare provider. Therefore, even though the literacy coaches were unclear at first with what to expect from the mentoring role, they discovered what mentoring entailed through the actual process of mentoring. 


\section{Findings}

The findings of the LIX study show that two of the three curricula, Literacy Plus and Techno-Lit, had significant impacts on all four measures of emergent literacy outcomes for children. The impact of the two effective curricula was much greater for children in classrooms with Spanish-speaking childcare providers than for Englishspeaking childcare providers. According to LIX researchers, this greater impact on Spanish-speaking childcare providers may have been attributed to the interactive technological devices (i.e., computer programs and electronic games) that modeled proper pronunciation in English. These devices may have helped both childcare providers and their students in learning how to speak English. All three curricula within six months of the LIX project produced significant impacts on childcare providers' behavior and interaction. By the end of the LIX project these impacts were more pronounced, and there were more significant impacts on the number of classroom activities that involved literacy, and on literacy resources in the classroom. The LIX findings also report that as a result of the training and mentoring, less educated childcare providers looked remarkably similar to their better-educated counterparts (i.e., degreed teachers) in the extent to which they provided activities that supported literacy.

\section{The Childcare Centers Post-LIX}

As a reform tool, mentoring is a vehicle for gratifying and sustaining skilled teachers, while creating a renewed professional culture focused on improving teaching and learning (Feimen-Nemser, 1996; Huling \& Resta, 2001; Little, 1990). Sustainability is a goal of mentoring, sustaining the new professional culture focused on improving teaching and learning. In this study, sustainability refers to the childcare providers who 
continued to implement the curriculum after (the literacy coach is no longer providing consistent bi-weekly visits) the two years of mentoring in LIX were completed. This would be an indicator of the success of the project. Therefore, the number of childcare centers implementing the curriculum in that third year would be an indicator of the success of LIX. We (the LIX literacy coaches) did not know how many of the TechnoLit centers continued that third year. Literacy Plus developers did fund a third year of maintenance support from the coordinator. She visited all the sights less frequently than in Year One. Each site was visited three times during the entire school year. However, she was also available to them via telephone or e-mail if they had any questions. They provided this extra year of support because it is the model ( 3 years of support) they used when any elementary school across the country adopted their series. Therefore, from the onset of LIX, childcare providers were offered this third year of support. All the Literacy Plus centers had continued implementing the program, except one that had been sold to a new owner.

As an afterthought, since funding became available from the local coalition, the Add-on Literacy developers decided to hire me, the Add-on Literacy CT Coach, to provide the third year support. The developers' rationale was to "wean the childcare providers off" mentoring by visiting them once a month instead of the two visits per month they received during the LIX study. I was to offer this assistance to all the Add-on Literacy centers that were still implementing the curriculum that third year. Exactly half, 18 of the centers out of 34 centers ( 16 of those 18 were assigned to me during LIX), were still implementing the curriculum. Even though two of the 18 centers that continued that 
third year were not assigned to me, I had established a relationship with those particular childcare providers and their director during the LIX general training sessions.

The Literacy Plus childcare centers were promised from the onset of LIX that they would have that third year support, whereas Add-on Literacy's extra year was never mentioned. Therefore, perhaps the expectation of the third year support is what influenced the Literacy Plus childcare centers to continue implementing the program that third year. In fact, Add-on Literacy's support was made possible by unexpected funding and began a month into the school year. Unfortunately, after only 4 months, the Add-on Literacy third year support ended abruptly due to issues in the local coalition.

In visiting the Add-on Literacy childcare centers in the third year, I discovered two of the highest rated childcare centers assigned to me during LIX had done something similar to the Collaborative Apprenticeship Model by Glazer and Hannafin (2005) described in detail in Chapter 2. Glazer and Hannafin (2005) conducted a study where veteran teachers mentored novice teachers who later became future mentors in order to sustain skills and strategies across a community of teachers, sustainability, again being the critical goal. The childcare provider (4-year-old classroom teacher), I mentored became the Lead Teacher, mentoring the rest of the providers in her center on how to teach literacy. In mentoring a childcare provider in a literacy program, not only did they continue the program, but they also actually used the childcare provider's experience, knowledge and success in her professional development to in turn mentor her peers.

\section{Conclusions}

Collaborative support within literacy curriculum teams, reflection of practice and building a relationship with the protégé (i.e., the childcare provider) were critical 
mentoring practices in LIX. Both Literacy Plus and Techno-Lit were strong in these three areas, while Add-on Literacy was not. This may have attributed to the LIX results that displayed Literacy Plus and Techno-Lit as effective in student literacy gains and Add-on Literacy as not effective.

As far as the relationship with fellow literacy coaches, Literacy Plus was the most consistent, cohesive and collaborative team. The Literacy Plus team had an advantage of consistency in that the TA Coach remained for the duration of LIX, unlike her counterparts, the TA Coaches in Add-on Literacy and Techno-Lit who were both replaced in the last 2 months of Year One. They met formally on a monthly basis, but they visited the centers as pairs or as a team more often than Add-on Literacy or Techno-Lit. The Techno-Lit coordinator also spoke on the telephone with the literacy coaches on a daily basis. When the Literacy Plus Coordinator was asked about positive experiences in LIX, her first remark was how satisfied and happy she was to have worked with such a great team.

The Literacy Plus Coordinator was the most experienced at mentoring and had the most extensive experience with the curriculum she helped implement ( 5 years versus being trained in the curriculum for LIX). Although she had mentored degreed public school teachers in this curriculum, not providers, her past experience and educational preparation had helped her be very organized and systematic in planning visits with her team according to the needs and progress of the Literacy Plus childcare providers.

Mentors work better if they are given freedom to innovate. When working for large organizations, as it usually is in the field of education, making change is slowed by red tape. One of the joys these literacy coaches enjoyed was being able to make 
reasonable decisions about what had to be done to meet the needs of childcare providers and children on the spot and having the resources and permission to do so. The support from both their developers and the collaborating agencies in allowing the literacy coaches to take the initiative and not have to ask for permission every time they had to make an on-the-spot decision, expedited meeting the needs of all involved: the childcare providers, children, the center and the project as a whole.

The on-going reflection of the majority of the literacy coaches made LIX an authentic learning experience. As participants in this research, the literacy coaches were prompted to reflect even further on lessons learned from this project. This reflection allowed for the challenges and hindrances of mentoring to become a learning experience that may help future literacy intervention project mentors learn lessons as well.

According to Wagner (1997), reflection of practice is described as reflexive, systematic inquiry sustained by the opportunity to engage in extended conversations between mentors and protégés (i.e., literacy coaches and childcare providers) about teaching practice as a necessary aspect of mentoring. All three curricula had some sort of monitoring system that provided guidelines for reflection at the mentoring session. These systems varied in the degree of structure from one curriculum to another. The more systematic and purposeful the structure, the more intentional and systematic the reflection of practice will be. The process of mentoring according to Fairbanks et al. (2000) is an evolution from an apprenticeship to guided practice and co-inquiry, suggesting that mentors (i.e,. literacy coaches) continually adapt to the protégé's needs and the challenges that they face while teaching (p. 108). Meeting the needs of the childcare providers to effectively implement the curricula was a priority in LIX. Literacy 
Plus and Techno-Lit worked as a team using the areas of expertise of individual literacy coaches to constantly adapt their mentoring with strategies that met the individual needs of their childcare providers. The act of having a fellow literacy coach assisting in the mentoring is a message from these two curriculum teams to providers that the literacy coaches did not have all the answers and they were learning in the process as well. Additionally, for the most part LIX literacy coaches were transparent about their learning. Mentoring relationships through their evolution become more collegial than hierarchical (Fairbanks et al., 2000).

Literacy Plus and Techno-Lit coaches both attributed success in mentoring to reflection of practice both as a team and with their childcare center providers. As a team, they formally reflected on the practice of mentoring on a weekly or monthly basis (Techno-Lit team and Literacy Plus team respectively). However, in addition they established an on-going dialogue of reflection. For example, the Literacy Plus team spoke on the telephone and communicated via e-mail daily. This constant analyzing and evaluative discussions of their own practice helped them work harder as a team to meet their centers' needs. They used this same method formally, when mentoring their childcare providers an average of twice a month. They used their curriculum team's monitoring system guidelines in addition to what they planned to do for the visit in their team discussion, as a guide for the mentoring session with the childcare provider. Both teams felt that being able to reflect and discuss with a colleague is a critical mentoring practice, as well as a structured guide to reflection of practice in the mentoring session with a childcare provider. 
There was no detailed mentoring model to use as a guide; therefore each group developed their own style of mentoring through the guidance of their coordinator. Experts on mentoring argue for the careful selection of mentors according to certain attributes. One such attribute is content specialization (Giebelhaus \& Bowman, 2002; Scheetz, et al., 2005; Wang, 2001). The only one of the nine literacy coaches who had extensive content knowledge of the literacy curriculum was the Literacy Plus coordinator. The Literacy Plus team had an advantage; the coordinator had extensive experience in teaching others how to implement the curriculum. Contrarily, the other teams' literacy coaches, other than a general curriculum training, were practically learning the curriculum and mentoring others in implementing it at the same time.

\section{Implications}

The best mentoring practices by the LIX literacy coaches have been discussed. The LIX coaches identified best practices that they perceived as the most effective in mentoring childcare providers to implement literacy curricula. To determine best mentoring practices, there were indicators of successful implementation that the literacy coaches used as a measure of their success. If there are such successes, there must have also been areas of the project that hindered success as well. This section includes lessons learned, which allows the literacy coaches to give input on what areas of this mentoring model did not work. Therefore, these suggestions can be taken into consideration for future literacy intervention studies involving mentoring childcare center providers.

One lesson learned is all the literacy coaches agreed that two years was too short a time to sustain the implementation of a literacy curriculum in a childcare center by nondegree-holding childcare providers. They felt that one more year was needed, instead of 
just 2 years. The first year was consumed with developing a relationship (trust, mutual respect, collegiality etc.) and dealing with general education issues outside of the curriculum, such as classroom environment (room arrangement) and behavior management (including a scheduled routine). The second year was consumed with learning how to teach the curriculum. The literacy coaches felt they needed that third year for sustainability. A third year would consist of less frequent visits to "wean the childcare providers off" of mentoring, so they could fully stand comfortably alone as "teachers".

The literacy coaches also felt that the number of childcare providers was not ideal in effectively mentoring the implementation of a literacy curriculum. The ideal number depends on the geographic distance between the location of the childcare providers and on what the goal of the mentoring is (e.g., implementing a new program or general professional development). There is no specific number for how many childcare providers a literacy coach should work with; it depends on the needs of the childcare providers, the goal of mentoring, the physical distance between childcare centers, the length of time needed for the mentoring session, etc. In deciding what the ideal number is, what must be determined is how many childcare providers a literacy coach would consider manageable in order to be able to communicate with them when the need arises or meet in person with them on a consistent basis (once a month, every other week). The frequency of the visits depends on what is necessary to accomplish the goal of the mentoring.

The LIX literacy coaches all felt that a formal training on mentoring would have helped clarify what was expected of them and define their role. Research agrees with this 
formal training of mentors as a prerequisite to mentoring that defines and emphasizes the importance of their mentoring role as critical (Andrews \& Quinn, 2005; Giebelhaus \&, Bowman, 2002; Rowley, 1999). Other mentoring researchers agree with initial training as an important criterion in becoming a mentor and add another criteria, support for the mentor throughout the process (Anderson \& Shannon, 1995; Cullingford, 2006). In LIX, there were several sources of support for mentors other than fellow team members.

Thus, a final implication is the need for a support system for the mentor. In LIX, curriculum developers, project administrators, the central agency, the LIX researchers, and the coalition were all sources of support for the literacy coaches throughout the project. The curriculum developers' support was the only one from this list that varied from team to team. As explained in detail in Chapter 4, Add-on Literacy and Literacy Plus benefited from moral support from their developers. Literacy Plus benefited from extra financial support in, for example, the lavish farewell banquet and the full third year support. The Techno-Lit developers almost withdrew from the study in the second year. Their support was not at the level of the other two curricula. The literacy coaches referred to a support system as critical to effective mentoring.

Recommendations for Future Study

Many literacy intervention projects which include mentoring are underway in the subsidized childcare system of the LIX setting. Most of these projects do not require formal training in mentoring. The training provided is in the curriculum the childcare providers need to teach. The literacy coaches hired for these projects are either former teachers or technical assistants. The assumption continues to be, if one is effective in 
those former positions, one can also be an effective literacy coach or mentor. Based on the findings of the present study, this assumption should be further investigated.

Further study is recommended to compare subsidized childcare intervention program designs in the LIX county, comparing literacy coaches that undergo "formal mentor training" with programs that do not include this training. These formal mentor trainings should clearly define the role of mentoring and provide on-going support throughout the mentoring in the project. The mentor training and the program should also have infused careful selection criteria of mentors that strive to assist literacy coaches from the different background experiences to use their knowledge in a collaborative mentoring structure.

\section{Summary}

This study was undertaken to gain a deeper understanding of the mentoring practices from the perspective of nine literacy coaches in effectively implementing literacy curricula in the subsidized childcare centers of the LIX project. The best mentoring practices were discussed as identified by the nine literacy coaches of the LIX study. The best mentoring practices identified and the lesson learned may help improve literacy intervention projects in subsidized childcare that involve mentoring.

The best mentoring practices highlighted in this study demonstrate effective professional development that builds on the strengths of providers and does not disrupt the childcare centers or the ability of subsidized childcare programs to continue serving the needs of children and families. The experience of these nine literacy coaches, including their perceptions of effective mentoring practices along with lessons learned about relationships, mentoring team structures, and general project design, will hopefully 
shed light on the challenge of mentoring subsidized childcare providers in future literacy intervention projects. Furthermore, the best mentoring practices highlighted in this study can serve as a model for future literacy intervention programs in similar regional contexts (e.g., large urban multicultural communities). 


\section{REFERENCES}

Alleman, E., Cochran, J., Doverspike, J., \& Newman, I. (1984). Enriching mentoring relationships. The Personnel and Guidance Journal, 62, 329-332.

Anderson, E.M., \& Shannon, A.L. (1988). Toward conceptualization of mentoring. Journal of Teacher Education, 39(1), 38-42.

Andrews, B., \& Quinn, R.J. (2005, Jan-Feb). The effects of mentoring on first year teachers' perceptions of support received. Clearing House, 78(3), 110.

Bandura, A. (1986). Social foundations of thought and action: A social cognitive theory. Englewood, NJ: Prentice Hall.

Barnett, W.S. (2003, March). Better teachers, better preschools: Students achievement linked to teacher qualifications. NIEER Preschool policy matters, National Institute for Early Education Research, 2, 1-11.

Behrman, R.E. (2002). Children and welfare reform. Future of Children, 12(1), 214.

Berg, B.L. (2001). Qualitative research methods for the social sciences (4th ed.). Boston: Allyn \& Bacon.

Bolman, L.G., \& Deal, T.E. (1991) Reframing organizations: Artistry, choice and leadership. San Francisco, CA: Jossey-Bass.

Bova, B.M., \& Phillips, R.E. (1981) The mentor relationship: A study of mentors and protégés in business and academia. ED 208233.

Brennan, S., Thames, W., \& Roberts, R. (1999, May). Mentoring with a mission. Educational Leadership, 49-52.

Brighton, C. M. (1999). Keeping good teachers: Learning from novices. In M. Scherer (Ed.) A better beginning: Supporting and mentoring new teachers (pp. 197-301). Alexandria, VA: Association for Supervision and Curriculum Development.

Britzman, D. (1991). Practice makes practice. Albany: State University of New York Press.

Brooks-Gunn, J., Fuligni, A.S., \& Berlin, L.J. (2003). Early childhood development in the $21^{\text {st }}$ century: Profiles of current research initiatives. New York: Teachers College Press.

Brown, J.S., Collins, A., \& Duguid (1989). Situated cognition and the culture of learning. Education Researcher, 18(1), 32-34. 
Burns, M.S., Griffin, P., \& Snow, C.E. (1999). Starting out right: A guide to promoting children's reading success. Washington, DC: National Academy Press.

Bush, T., Coleman, M., Wall, D., \& West-Burnham, J. (1996). Mentoring and continuing professional development. In D. McIntyre, H. Hagger, \& M. Wilkin (Eds.), Mentoring: Perspectives on school based teacher education (pp. 69-85). London: Kogan Page.

California State Department of Education. (1983). California mentor teacher program. Program Advisory. ED 241473.

Charles, C.M. (1995). Introduction to educational research ( $2^{\text {nd }}$ ed.). San Diego, CA: Longman

Chase, B., Germundsen, R., Brownstein, J.C., \& Distad, L.S. (2001, Spring). Making the connection between increased student learning and reflective practice.

Educational Horizons 79(3), 143-147.

Clark, C.M. (2001). Talking shop: Authentic conversation and teacher learning. New York: Teachers College Press.

Coeyman, M. (2003, April 22). Twenty years after "A Nation at Risk”. The Christian Science Monitor, 13.

Cohen, N., \& Mondigliani, K. (1990). The family to family evaluation report. New York: Families and Work Institute.

Conyers, J.G. (2004). Thinking outside to support newcomers. School Administrator $6(6), 18-21$.

Creswell, J.W. (1998). Qualitative inquiry and research design: Choosing among five traditions. Thousand Oaks, CA: Sage.

Cullingford, C. (2006). Mentoring in education: An international perspective. Burlington: Ashgate Publishing.

Cunningham, A.E., \& Stanovich, K.E. (1998, Spring/Summer). What reading does for the mind. American Educator, 22, 8-15.

Daloz, L (1986). Effective teaching and mentoring. San Francisco: Jossey-Bass.

Danielson, L. (2002). Developing and retaining quality classroom teachers through mentoring. Clearing House Washington DC: ERIC Clearinghouse on Teaching and Teacher Education. (ERIC Document Reproduction Service No. EJ646863) 
Darling-Hammond, L. (1996). The quiet revolution: Rethinking teacher development. Educational Leadership, 53(6), 4-10.

Davidson, D.H. (1990). Childcare as a support for families with special needs. Young Children, 45(3), 47-48.

DeBord, K., \& Boling, K. (2002). The fabrics of quality childcare: Weaving together a professional development system. Child and youth care forum, 31(5), 295-305.

Denzin, N.K., \& Lincoln, Y.S. (2003). Strategies of qualitative inquiry $\left(2^{\text {nd }}\right.$ ed.). Thousand Oaks: Sage.

Dickenson, D.K., \& Tabors, P.O. (2001). Beginning literacy with language. Baltimore, MD: Paul H. Brooks Publishing.

Dixon-Krauss, L. (1996). Vygotsky in the classroom: Mediated literacy instruction and assessment. White Plains, NY: Longman.

Driscoll, A., Kauchak, D., \& Peterson, K (1985). Designing a mentor system for beginning teachers. Journal of Staff Development, 6, 2.

Eaton, D.E. (2002, January). Family child care accreditation and professional development. Young Children, 23.

Elliot, B., \& Calderhead, J. (1995). Mentoring for teachers' development possibilities and caveats. In T. Kerry \& S. Mayes (Eds.), Issues in mentoring. New York: Open University Press.

Evenson, J.S. (1982). Workplace mentoring. Far West Laboratory for Educational Research and Development. (ERIC DocumentReproduction Service No. ED 246182)

Erickson, F. (1986). Qualitative methods in research on teaching. In M.C. Wittrock (Ed.), Handbook of research on teaching ( $3^{\text {rd }}$ ed., pp.119-116). New York: Macmillan.

Fairbanks, C.M., Freedman, D., \& Kahn, K. (2000). The role of effective mentors in learning to teach. Journal of Teacher Education, 51(2), 102-112.

Fairbanks, C., \& Merrit, J. (1998). Preservice teachers' reflections and the role of context in learning to teach. Teacher Education Quarterly, 25(3), 47-68.

Feiman-Nemser, S. (2001, April). From preparation to practice: Designing a continuum to strengthen and sustain teaching. Occasional Paper Series, No.5. New York: Bank Street College of Education. 
Fiene, R. (2001). Improving child care quality through an infant caregiver mentoring project. Child \& Youth Care Forum, 79-87.

Fleming, J., \& Love, M. (2003, Fall). A systematic change model for leadership, inclusion, and mentoring (SLIM). Early Childhood Education Journal, 31, 53-57.

Francis, D.J., Shaywitz, S.E., Steubing, K.K., Shaywitz, B.A., \& Fletcher, J.M. (1996). Developmental lag versus deficit models of reading disability: A longitudinal, individual growth curves analysis. Journal of Educational Psychology, 88, 13-17.

Fullan, M., Galuzzo, G., Morris, P., \& Watson, N (1998). The rise and stall of teacher education reform. AACTE Publications. (ERIC Document Reproduction Service No. ED 415201)

Fuller, B., Kagan, S., \& Loeb, S. (2002). New lives for poor families? Mothers and young children move through welfare reform. The growing up in poverty wave 2 findings: California, Connecticut, and Florida. Technical report. Berkeley, CA. (ERIC Document Reproduction Service No. UD034944)

Gable, S., \& Halliburton, A. (2003). Barriers to childcare providers' professional development. Child and Youth Care Forum, 32(3), 175-193.

General Accounting Office, Health, Education and Human Services Division. (1998). Welfare reform: States' efforts to expand childcare programs. United States general accounting office report to the ranking minority member, subcommittee on children and families, committee on labor and human resources, U.S. Senate (Report No. GAO/HEHS-98-27). Washington, DC: U.S. General Accounting Office, Health, Education and Human Services Division. (ERIC Document Reproduction Service No. PS026366).

Giebelhaus, C.R., \& Bowman, C.L. (2002). Teaching mentors: Is it worth the effort? The Journal of Educational Research 95(4), 246-254.

Glazer, E.M., \& Hannafin, M.J., (2006). The collaborative apprenticeship model: Situated professional development within school settings. Teaching and Teacher Education, 22(2), 179-193.

Glesne, C., \& Peshkin, A. (1992). Becoming qualitative researchers: An Introduction. White Plains, NY: Longman.

Gnezda, M.T. (1996). Public policy report. Welfare Reform: Personal responsibilities and opportunities for early childhood advocates. Young Children, 52(1), 55-58. 
Goldstein, J. (2004). Making sense of distributed leadership: The case of peer assistance and review. Educational Evaluation \& Policy Analysis 26(2), 173-197.

Grove, K., Strudler, N., \& O'dell, S. (2004). Mentoring toward technology use: Cooperating teacher practice in supporting student teachers. Journal of Research on Technology in Education, 37(1), 85-109.

Gubrium, J.F., \& Holstein, J.A.(2002). Analyzing interpretative practice. In N.K. Denzin \& Y.S. Lincoln (Eds.), Handbook of qualitative research $\left(2^{\text {nd }} e d\right.$, pp. $487-$ 508). Thousand Oaks, CA: Sage.

Halpern, R. (1987). Major social and demographic trends affecting young families: Implications for early childhood care and education. Young Children, 42(6), 3440.

Hargraves, A., \& Fullan, M. (2000). Mentoring in the new millennium. Theory into Practice, 39(10), 50-56.

Harris, D.N., \& Herrington, C.D. (2006). Accountability standards, and the growing achievement gap: Lessons from the past half-century. American Journal of Education, 112(2), 209-238.

Harrison, J., Dymoke, S., \& Pell, T. (2006). Mentoring beginning teachers in secondary schools: An analysis of practice. Teaching \& Teacher Education: An International Journal of Research and Studies, 22(8), 1055-1067.

Harrison, J.K., Lawson, T., \& Wortley, A. (2005). Mentoring the beginning teacher: Developing professional autonomy through critical reflection on practice. Reflective Practice 6(93), 419-441.

Hart, B., \& Risley, T.R. (1995). Meaningful differences in the everday experiences of young American children. Baltimore, MD: Paul H. Brooks Publishing.

Hawkey, H. (1998). Mentor pedagogy and student teachers professional development: A study of two mentoring relationships, Teacher and Teacher Education, 14(6), 657-670.

Hobson, A.J., \& Sharp, C. (2005). Head to head: A systematic review of the research evidence on mentoring new head teachers. School Leadership and Management, 25(1), 25-42.

Hole, S., \& McEntee, G.H. (1999, May). Reflection is at the heart of practice. Educational Leadership, 34-37. 
Holmes Group Consortium (1986, November). Preparing tomorrow's teachers. The Education Digest 52, 12-15.

Horm, D.M., Caruso, D.A., \& Golas, J. (February 2003) Head start teaching center: Differential training effects for head start personnel. Child \& Youth Care Forum, 32(1), 23-46.

Hulling, L., \& Resta, V. (2001). The benefits of mentoring. Educational Leadership, 58(8), 85-86.

Hyun, E. (2003). What does the "no child left behind act" mean to early childhood teacher educators? A calling for a collective professional rejoinder. Early Childhood Education Journal, 31(2), 119-125.

Ingersoll, R., \& Smith, T.M. (2003). The wrong solution to the teacher shortage, Educational Leadership, 60(8), 30-33.

Keller, B. (2006, May). New mentoring program helpful for novice teachers in N.Y.C. Education Week, 25, 7.

Kontos, S. (1992). Family day care: Out of the shadows and into the limelight. Washington, DC: National Association for the Education of Young Children.

Kram, K.E. (1983). Phases of the mentor relationship. Academy of Management Journal, 26(4), 608-625.

Krueger, M. (2002). A further review of the development of the child and youth care profession in the United States. Child and Youth Care Forum, 31(1), 13-26.

Krupp, J.A. (1984, April). Mentor and protégé perception of mentoring relationships in elementary and secondary schools in Connecticut. Paper presented at the annual meeting of American Educational Research Association, New Orleans, LA. (ERIC Document Reproduction Service No. ED 245 004)

Kvale, S. (1996). Interviews: An introduction to qualitative research interviewing. Thousand Oaks, CA: Sage.

Lincoln, Y.S., \& Guba, E.G. (1985). Naturalistic inquiry. Beverly Hills, CA: Sage.

Little, J.W. (1990). The mentor phenomenon and the social organization of teaching. In C. Cazden (Ed.), Review of research education (Vol. 16, pp. 297-351). Washington DC: American Educational Research Association. 
Lonigan, C.J., Burgess, S.R., \& Anthony, J.L. (2000). Development of emergent literacy and early reading skills in preschool children: Evidence from a latent variable longitudinal study. Developmental Psychology, 36, 596-613.

Lyter, D., Sills, M., \& Oh, G. (2002). Children in single-parent families living in poverty have fewer supports after welfare reform. (Report No. D451). Washington DC: U.S. Institute for Women's Policy Research. (ERIC Document Reproduction Service No. PS031005)

Matthews, M.C., Thornburg, K.R., Espinosa, L., \& Ispa, J. (2000). Project REACH: Training rural child care providers. Young Children, 55(3), 82-87.

Mayes, C. (1998). The Holmes reports: Perils and possibilities. Teaching and Teacher Education, 14(8), 775-792.

Maynard, T., \& Furlong, J, (1993). Learning to teach and models of mentoring. In D. McIntyre, H. Hagger, \& M. Wilkin (Eds.), Mentoring: Perspectives on school based teacher education (pp.69-85). London: Kogan Page.

McElroy, E.J. (2005). The highly qualified teacher. Teaching PreK-8, 2, 8.

McIntyre, D., \& Hagger, H. (1993). Teachers' expertise and models of mentoring. In D. McIntyre, H. Hagger, \& M. Wilkin (Eds.), Mentoring: Perspectives on school based teacher education (pp. 87-102). London: Kogan Page.

Merriam, S.B. (1988). Case study research in education: A qualitative approach. San Francisco, CA: Jossey Bass.

Merriam, S.B. (1998). Qualitative research and case study applications in education. San Francisco, CA: Jossey Bass.

Miles, M.B., \& Huberman, A.M. (1994). Qualitative data analysis: A sourcebook of new methods (2nd ed.) Thousand Oaks, CA: Sage.

Moir, E., \& Gless, J. (2001). Quality induction: An investment in teachers. Teacher Education Quarterly, 28(1), 109-114.

Montgomery, J. (1999). Easing the way for new teachers. In M. Scherer (Ed.), A better beginning: Supporting and mentoring new teachers (pp. 13-18), Alexandria, VA: Association for Supervision and Curriculum Development.

No Child Left Behind Act of 2001, Pub.L.No.107-107-110,115 Stat.1425 (2002). Retrieved Sept. 7, 2006, from http://www.ed.gov/legislation/eseao2/ 
Normore, A. H., \& Floyd, A. (2005). A roller coaster ride: The twists and turns of a novice teacher's relationship with her principal. Phi Delta Kappan, 86(10), 767771.

Normore, A. H., \& Loughry. K. (2006). Avoiding the pitfalls of the rookie year: How a mentor can help, Kappa Delta Pi Record, 43(1), 25-30.

Orland-Barak, L. (2002). What's in a case? What mentors' cases reveal about the practice of mentoring. Journal of Curriculum Studies, 34(4), 451-468.

Patton, K., Pagnano, K., Griffin, L.L., Dodds, P., Sheehy, D., Arnold, R., Henninger, M.L., Gallo, A.M. and James, A. (2005). Chapter 2: Navigating the mentoring process in a research-based teacher development project: A situated learning perspective. Journal of Teaching in Physical Education, 24, 302-325.

Perry, N.E., Walton, C., \& Calder, K. (1999). Teachers developing assessments of early literacy: A community of practice project. Teacher Education and Special Education, 22(4), 218-233.

Podhajski, B., \& Nathan. B. (2005). Promoting early literacy through professional development for childcare providers. Early Education and Development, 16(1), 23-41.

Purcell-Gates, V. (1988). Lexical and systematical knowledge of written narrative held by well-read-to-kindergarteners and second graders. Research in the Teaching of English, 22, 128-160.

Randi, J. (2004). Teachers as self-regulated learners. Teachers College Record, 106, 1825-1853.

Rossman, G.B., \& Rallis, S.F. (2003). Learning in the field: An introduction to qualitative research. Thousand Oaks, CA: Sage.

Rovegno, I. (2003). Teachers' knowledge construction. In S.J. Silverman \& C.D. Ennis (Eds.), Student learning in physical education: Applying research to enhance instruction (pp.295-310). Champaign, IL: Human Kinetics.

Rowley, J., (1999). The good mentor. Educational Leadership,56 (8), 20-22.

Rubin, H.J., \& Rubin, I.S. (1995). Qualitative interviewing: The art of hearing data. Thousand Oaks, CA: Sage.

Seidman, I. (2006). Interviewing as qualitative research: A guide in education and the social sciences. New York: Teachers College Press. 
Scheetz, J., Waters, F., Smeaton, P., \& Lare, D. (2005, Fall). Mentoring in a PDS program: What's in it for me? Kappa Delta Pi Record, 42 (1), 33-37.

Schmitt, R.A., \& Wolfe, J.S. (1980). The mentor partnership: Discovery of professionalism. NASPA Journal, 17(3), 45-51.

Shulman, L. (1999). Forward. In L. Darling-Hammond \& G. Sykes (Eds.), Teaching as the learning profession (pp. i-xiv). San Francisco, CA: Jossey-Bass.

Smith, S., Blank, S., \& Collins, R. (1992). Pathways to self-sufficiency for two generations: Designing welfare-to-work programs that benefit children and strengthen families. New York: Foundation for Early Childhood Development.

Snow, C.E., Burns, M.S., \& Griffin, P. (1998). Preventing reading difficulties in young children. Washington, DC: National Academy Press.

Soodak, L., Erwin, E., Winton, P., Brotherson, M., Turnball, A., Hanson, M., \& Brault, L. (2002). Implementing inclusive early childhood education: A call for professional empowerment. Topics in Early Childhood Special Education (22)2, 91-102.

Stake, R.E. (2000). Case studies. In N.K. Denzin \& Y.S. Lincoln (Eds.), Handbook of qualitative research $\left(2^{\text {nd }}\right.$ ed., pp.435-454). Thousand Oaks, CA: Sage.

Sykes, G. (1999). Introduction. In L. Darling-Hammond \& G. Sykes (Eds.) Teaching as the learning profession, (pp. xv-xvii.). San Francisco, CA: Jossey Bass.

Taylor, A., Dunster, L., \& Pollard, J. (1999)...And this helps me how? Family child care providers discuss training. Early Childhood Research Quarterly, 14, 285-312.

The Clearing House. (2005). The effects of mentoring on first-year teachers' perception of support received, (78)3, 110-116.

Todd, C., \& Deery-Schmitt, D. (1996). Factors affecting turnover among family child care providers: A longitudinal study. Early Childhood Research Quarterly, 11, 351-376.

Tomlinson, C. (1995). Understanding mentoring. Philadelphia, PA: The Open University Press.

Torgesen, J.K. (2002). The prevention of reading difficulties. Journal of School Psychology, 40, 7-26. 
Underhill, C.M. (2006). The effectiveness of mentoring in corporate settings: A metaanalytical review of the literature. Journal of Vocational Behavior, 68(2), 292307.

Vinz, R. (1996). Compromising teaching life. Portsmouth, NH: Boynton/Cook Heinemann.

Vygotsky, L. (1978). Mind in society. Cambridge: University Press.

Wagner, J. (1997). The unavoidable intervention of educational research-practitioner cooperation. Educational Researcher, 26, 13-22.

Walker, S.K. (2002). Predictors of family childcare providers' intentions toward professional development. Child and Youth Care Forum, 31(40), 215-231.

Wang, J. (2001). Contexts of mentoring and opportunities for learning to teach: a comparative study of mentoring practice. Teaching and Teacher Education, 17, $51-73$.

Whitebrook, M., \& Phillips, D. (1999). Child care employment: Implications for women's self-sufficiency and for child development. Working paper. New York: Foundation for Child Development.

Whitehurst, G.J., \& Lonigan, C.J. (1998). Child development and emergent literacy. Child Development, 69, 848-872.

Yeh, S.S. (2006). Can rapid assessment moderate the consequences of high-stakes testing? Education and Urban Society, 39(1), 91-112.

Yin, R.K. (1994). Case study research (2 $2^{\text {nd }}$ ed.). Thousand Oaks, CA: Sage. 


\section{APPENDIX}

Focus Group Interview Round 1 Questions

1. What training and/or education have you received in the field of education prior to Literacy Intervention $\mathrm{X}$ ?

2. What college/university did you attend?

3. How many years have you worked in the education of children? Please explain in what capacity (I.E. as a teacher, supervisor etc.).

4. What were your expectations for your role in this project (before it began)?

5. What kinds of issues have you had to deal with, that you did not anticipate?

6. Is there anything positive that you have experienced that you did not expect?

7. What guidelines do you use to measure the progress of the implementation of your literacy program?

8. What system or plan do you follow in order to meet each individual childcare center provider's training needs?

9. How are specific components determined as the focus of a particular mentoring session?

\section{Focus Group Interview Round 2 Questions}

1) What is the distribution of centers among team members?

2) How was it determined?

3) Is the distribution the same as year 1? If not, what caused the revision?

4) How many times per month is each center visited by the coach? By the coordinator?

5) How much average time is spent in a center?

6) What is more important for effective mentoring: the length of time spent in a session, the frequency of visits, or consistency of visits? Why?

7) When a new teacher begins in the middle of the year, how do you train her? Who does the training? Where? For how many days? 
8) If it is the coach, is there a change in her calendar schedule? If so, what happens to the other site visits she was scheduled to visit?

9) What is the biggest challenge you have now towards the end of the study?

10) What is your goal for these last two months of the study?

11) What would have made the job of mentoring easier?

Focus Group Interview Round 3 Questions

Category \#1: Team Dynamics and its effects on mentoring

1) What were the dynamics between the mentor coordinators and the mentors?

2) Did the constitution of the groups themselves significantly change the mentoring process (i.e., change of a mentor)?

3) How important was your coordinator in making this experience?

4) How did the relationship with your developer affect your experience?

5) Was there a relationship between your developer and the childcare providers? Describe it.

Category \#2: Coaches' definition of Mentoring

1) What aspects of the mentoring practice do you believe are essential for the effective implementation of a curriculum?

2) What attributes are most significant in effective mentoring?

3) Describe the mentoring process.

4) Is there a difference in early literacy mentoring and other types of mentoring?

5) What aspects of learning support early literacy mentoring?

6) Is there anything that could have been done differently to better prepare you for the role of mentoring?

7) How did language and cultural issues affect the relationships between mentors and the caregivers? 
Category \#3: The content of the curriculum's impact on the mentoring experience

1) Did their mentors come to believe in their curriculum? If so, why

2) How different would your experience have been if you had been chosen for one of the other curricula?

Category \#4: Post Intervention Project Work - Individual Questions:

1) Tell me about your current position.

2) How is it different from your experience with Literacy Intervention $X$ ?

3) What kinds of things would you like to change in your current position?

4) Are there things from Literacy Intervention $X$ that you would like to see used in your current position?

5) Post-Job satisfaction (control, structure, creativity, and efficiency, etc.) 


\section{VITA}

MAGDALENA CASTAÑEDA

February 8, 1972

1994

1994

1994-1995

1995

1995

1995-1996

1996

1996

1996-1997

1997-2003
Born, Madrid, Spain

B.A., Elementary Education

Florida International University

Miami, Florida

Elementary Education Certification, ESOL

Endorsed

State of Florida

Kindergarten Teacher

Springview Elementary

Miami Springs, Florida

Pre-Kindergarten Inclusion Summer School

Teacher

Springview Elementary

Miami Springs, Florida

Early Childhood Education Certification

State of Florida

First Grade ESOL Self Contained Teacher

Springview Elementary

Miami Springs, Florida

M.S., TESOL

Florida International University

Miami, Florida

TESOL K-12 Certification

State of Florida

Kindergarten Teacher

Kendale Elementary

Miami, Florida

Kindergarten Teacher/Grade Level Chairperson Kendale Elementary

Miami, Florida 
1998

2000-2001

2002

2003-2005

2005

2005-2006

2006-2007
Educational Leadership Certification

State of Florida

Elementary Teacher of the Year Award

Kendale Elementary

Miami, Florida

META Course Instructor, Bilingual Education

Department, Miami-Dade County Public Schools

Miami, Florida

"Add-On Literacy" Literacy Coach

"Literacy Intervention X"

Child Development Services/Miami Dade County

Public Schools

Miami, Florida

Curriculum Support Specialist

Division of Early Childhood, Miami-Dade County

Public Schools

Miami, Florida

Literacy Specialist

Miami-Dade Monroe Early Learning

Coalition/Miami-Dade County Public Schools

Miami, Florida

Miami-Dade TLSI Masters/Specialist Program

Instructor/Ready Schools Mentor

Lastinger Center for Learning

University of Florida

Miami, Florida 